\title{
Restabelecimento de Energia em Sistemas de Distribuição de Energia Elétrica Com Priorização de Chaves Automáticas $^{1}$
}

Dissertação apresentada à Escola de Engenharia de São Carlos, da Universidade de São Paulo, como parte dos requisitos para obtenção do título de Mestre em Ciências, Programa de Engenharia Elétrica.

Área de Concentração: Sistemas Elétricos de Potência.

Orientador: Prof. Dr. João Bosco Augusto London Junior

São Carlos

2014

1 Trata-se da versão corrigida da dissertação. A versão original encontra-se disponível na EESC/USP que aloja o programa de Pós-Graduação em Engenharia elétrica. 
AUTORIZO A REPRODUÇÃO TOTAL OU PARCIAL DESTE TRABALHO, POR QUALQUER MEIO CONVENCIONAL OU ELETRÔNICO, PARA FINS DE ESTUDO E PESQUISA, DESDE QUE CITADA A FONTE.

Amorim Caero Marquez, Remy
A524r Restabelecimento de Energia em Sistemas de Distribuição de Energia Elétrica Com Priorização de Chaves Automáticas / Remy Amorim Caero Marquez; orientador João Bosco Augusto London Júnior. São Carlos, 2014.

Dissertação (Mestrado) - Programa de Pós-Graduação em Engenharia Elétrica e Área de Concentração em Sistemas Elétricos de Potência -- Escola de Engenharia de São Carlos da Universidade de São Paulo, 2014.

1. Sistemas de Distribuição. 2. Reconfiguração de Redes. 3. Restabelecimento de Energia Elétrica. 4. Algoritmos Evolutivos. 5. Representação Nó-Profundidade. I. Título. 


\section{FOLHA DE JULGAMENTO}

Candidato: Engenheiro REMY AMORIM CAERO MARQUEZ.

Título da dissertação: "Restabelecimento de energia em sistemas de distribuição de energia elétrica com priorização de chaves automáticas".

Data da defesa: 28/03/2014

\section{Comissão Julgadora:}

Prof. Associado João Bosco Augusto London Júnior (Orientador)

(Escola de Engenharia de São Carlos/EESC)

Prof. Dr. Cláudio Fabiano Motta Toledo

(Instituto de Matemática e Computação/ICMC)

Prof. Dr. Frederico Gadelha Guimarães

(Universidade Federal de Minas Gerais/UFMG)
Resultado:

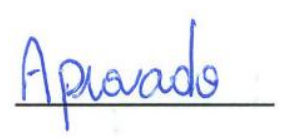

APROVADD

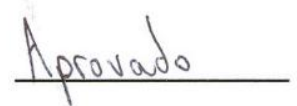

Coordenador do Programa de Pós-Graduação em Engenharia Elétrica e Presidente da Comissão de Pós-Graduação:

Prof. Titular Denis Vinicius Coury 



\section{Agradecimentos}

Dedico meus sinceros agradecimentos:

Á Deus, por conceder-me saúde e inteligência.

Aos meus pais, Shirley e Remy, à minha irmã Carolina e à minha namorada Camila, pelo amor, paciência, apoio e confiança.

Ao meu orientador professor Dr. João Bosco A. London Jr pela confiança e pelo companheirismo nos momentos bons e difíceis no decorrer desta pesquisa. Agradeço também pela orientação e dedicação que resultaram no sucesso deste projeto de pesquisa.

Ao professor Dr. Alexandre Cláudio B. Delbem pelas sugestões e atenção que foram de suma importância para o desenvolvimento deste trabalho.

Aos meus amigos em especial Fabio (Fabão), Camila, Marcelo (Beiço), Leandro (Matupá), Alexandre (Piriquito) e Henrique (Goiás) pelo apoio e pela amizade e pelos bons momentos que vivenciei em São Carlos - SP. Á todos meus familiares, amigos e colegas de laboratório. Á todos colaboradores da Universidade de São Paulo, que de alguma forma participaram deste trabalho.

Á CAPES pelo apoio financeiro. 



\section{Resumo}

MARQUEZ, R. A. C. Restabelecimento de Energia em Sistemas de Distribuição de Energia Elétrica Com Priorização de Chaves Automáticas. 2014. Dissertação de mestrado. Escola de Engenharia de São Carlos, Universidade de São Paulo, São Carlos, 2014.

Esta dissertação trata do problema de restabelecimento de energia em sistemas de distribuição de grande porte (com milhares de linhas, barras de carga e chaves seccionadoras) em situações de contingência. Este problema consiste basicamente na determinação de chaves seccionadoras que devem ser operadas para permitir a transferência de blocos de carga a fim de re-conectar consumidores fora de serviço atendendo às restrições operacionais do sistema.

Diversas metodologias têm sido desenvolvidas para lidar com o problema de restabelecimento de energia. Entretanto, a maioria perde eficiência computacional quando aplicadas em sistemas de distribuição de grande porte e/ou não fazem distinção entre chaves manuais e automáticas (controladas remotamente).

Propõe-se uma metodologia para obtenção, em tempo-real, de planos de restabelecimento de energia em sistemas de distribuição de grande porte, que priorize a utilização de chaves seccionadoras controladas remotamente. Priorizar a utilização de chaves controladas remotamente permite a obtenção de planos de restabelecimento mais rápidos de serem implantados. Para lidar com os múltiplos objetivos e restrições do problema de restabelecimento de energia, a metodologia proposta será baseada em Algoritmos Evolutivos Multi-Objetivo, enquanto que a eficiência computacional para possibilitar o tratamento de sistemas de grande porte será proporcionada através da utilização da codificação de dados denominada Representação Nó-Profundidade. Para validar a metodologia proposta realizarse-ão diversas simulações computacionais no sistema de distribuição real da cidade de São Carlos-SP, e nas suas versões duplicada, quadruplicada e octuplicada, considerando-se a ocorrência tanto de falta única quanto de múltiplas faltas.

Palavras-chaves: Sistema de Distribuição, Reconfiguração de Redes, Restabelecimento de Energia Elétrica, Algoritmos Evolutivos, Representação Nó-Profundidade. 



\section{Abstract}

MARQUEZ, R. A. C. Service Restoration in Distribution Systems With Prioritization of Remote Controlled Switches. 2013. Dissertação (Mestrado: Programa de Pós Graduação em Engenharia Elétrica) - Escola de Engenharia de São Carlos, Universidade de São Paulo, São Carlos, 2013.

This thesis focuses on the service restoration problem in large scale distribution systems (distribution systems with thousands of switches and load buses) in contingency situations. This problem consists basically in determining the sectionalizing switches that must be operated in order to reconnect the out of service loads without violating any operational constraints.

Several methodologies have been developed to deal with the service restoration problem in distribution systems. However, the majority of them demand high running time when used for large scale distribution systems and/or do not consider the existence of switches that can be remotely operated.

It is proposed a methodology for determining, in real time, service restoration plans in large scale distribution systems. In order to determine service plans that can be implemented faster, the methodology will give priority to use remotely controlled switches. To deal with the multiple objectives and constraints of the service restoration problem, the proposed methodology will be based on Multi-objective Evolutionary algorithms. To guarantee computational efficiency to treat large scale distribution systems, the data encoding called Node-Depth Encoding will be used. The real distribution system of the São Carlos-SP city, and its doubled, quadruplicated and octuplicate versions will be used to validate the proposed methodology. It will be simulated cases considering one and multiple faults.

Keywords: Distribution Systems, Network Reconfiguration, Service Restoration, Evolutionary Algorithms, Node-Depth Encoding. 



\section{Lista de Figuras}

Figura 1-1: Exemplo de um SEP (A. J. Monticelli \& A. V. Garcia 2003). .............................................2

Figura 1-2: Representação de um sistema de distribuição radial.....................................................

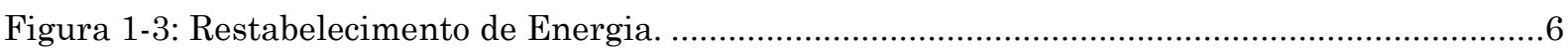

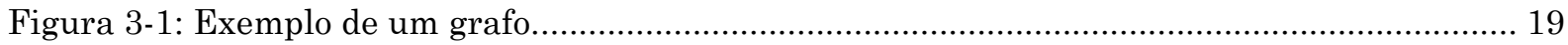

Figura 3-2: Representação através de grafo de um SD com três alimentadores............................. 22

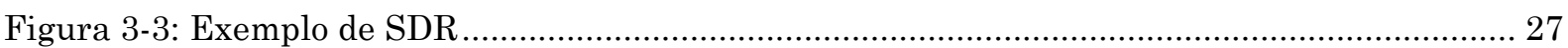

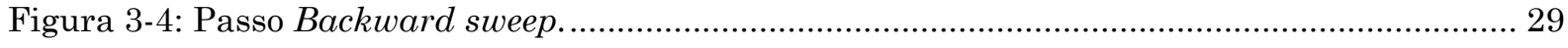

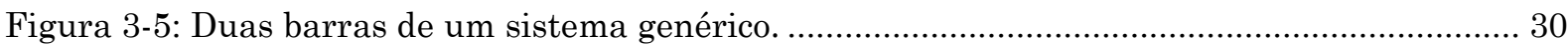

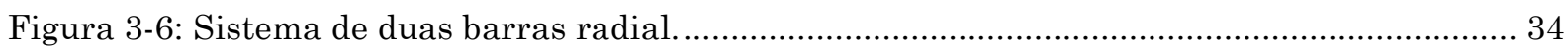

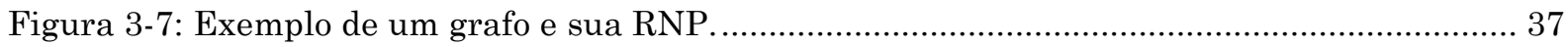

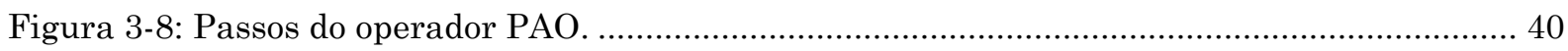

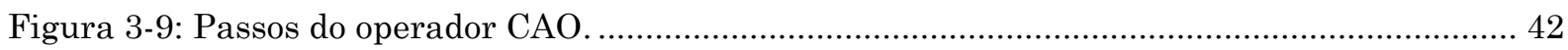

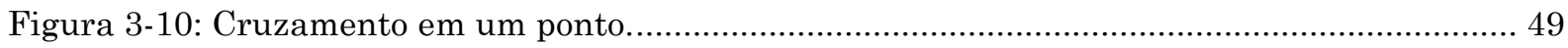

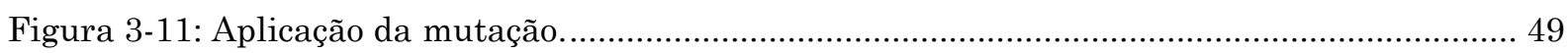

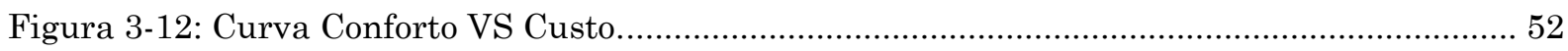

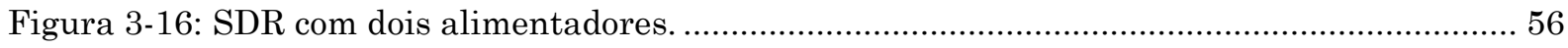

Figura 3-17: Agrupamento das linhas e barras em setores. …...................................................... 57

Figura 3-18: Grafo representando setores do SDR da Figura 4-2 .............................................. 57

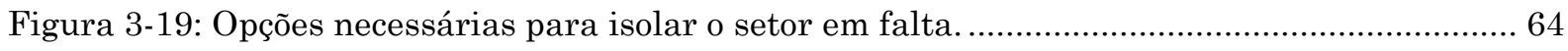

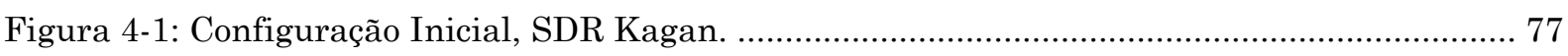

Figura 4-2: Primeira Configuração Factível, SDR Kagan................................................................. 77

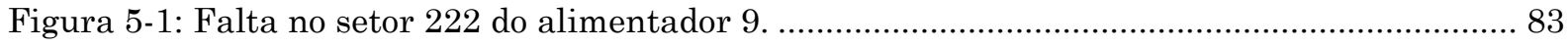

Figura 5-2: Porcentual de vezes que a melhor solução foi encontrada, para os Sistemas 1,2,3 e 4,

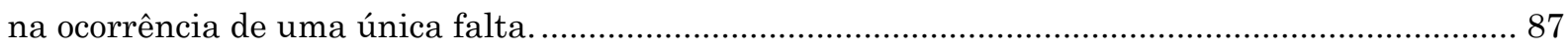

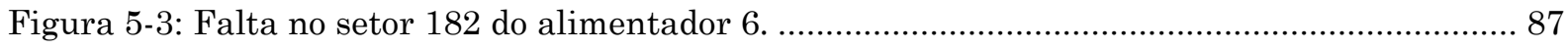

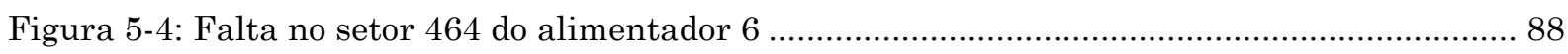


Figura 5-5: Porcentual de vezes que a melhor solução foi encontrada, para os Sistemas 1,2,3 e 4, na ocorrência de múltiplas faltas. 


\section{Lista de Tabelas}

Tabela 3-1: Grau de cada um dos nós do grafo apresentado na Figura 3.1. .................................... 20

Tabela 3-2: Modelos de MOEAs (Ticona \& A. C. B. Delbem 2008)................................................ 54

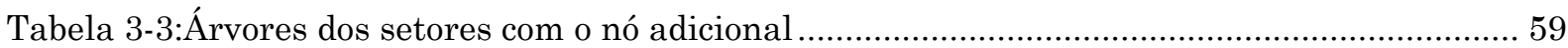

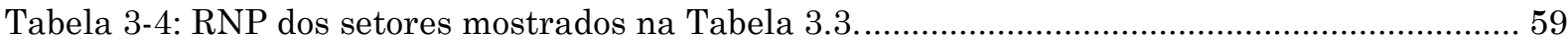

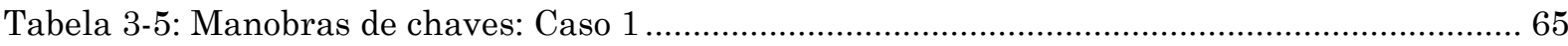

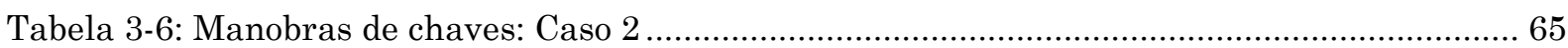

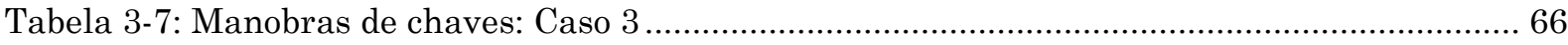

Tabela 4-1 Matriz responsável por armazenas manobras por configuração................................... 76

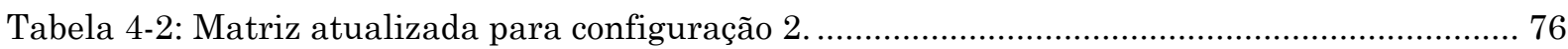

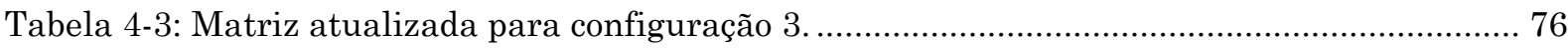

Tabela 4-4: Vetor que armazena os estado e tipos das chaves presentes no sistema...................... 76

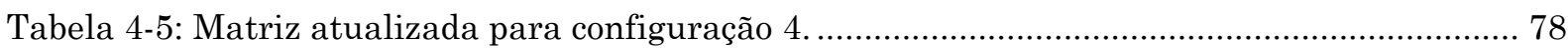

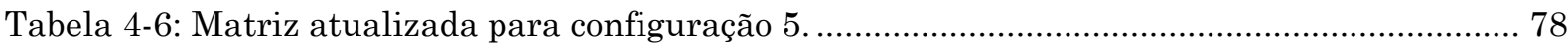

Tabela 5-1: Falta no setor 222 do alimentador 9. Valores das restrições operacionais e perdas para primeira configuração factível obtida. *Desvio Padrão

Tabela 5-2: Falta no setor 222 do alimentador 9. Valores das restrições operacionais e perdas ao final do processo evolutivo. *Desvio Padrão

Tabela 5-3: Número de Manobras de Chaves para a solução final para os Sistemas 1,2,3 e 4, na ocorrência de uma única falta. *Desvio Padrão.

Tabela 5-4: Características dos melhores indivíduos encontrados durante o algoritmo, para os Sistemas 1,2,3 e 4, na ocorrência de uma única falta.

Tabela 5-5: Falta nos setores 182 e 464. Valores das restrições operacionais e perdas para primeira configuração factível obtida. *Desvio Padrão 88

Tabela 5-6: Falta nos setor 182 e 464. Valores das restrições operacionais e perdas ao final do processo evolutivo. *Desvio Padrão 89

Tabela 5-7: Número de Manobras de Chaves para a solução final para os Sistemas 1,2,3 e 4, na ocorrência de múltiplas faltas. *Desvio Padrão 
Tabela 5-8: Características dos melhores indivíduos encontrados durante o algoritmo, para os Sistemas 1,2,3 e 4, na ocorrência de múltiplas faltas. .90

Tabela 5-9 Características dos melhores indivíduos encontrados durante o algoritmo, para os Sistemas 1,2,3 e 4, na ocorrência de uma falta, sem a presença da tabela de perdas. 92

Tabela 5-10: Número de Manobras de Chaves para a solução final para os Sistemas 1,2,3 e 4, na ocorrência de uma falta, sem a presença da tabela de perdas. *Desvio Padrão 93

Tabela 5-11: Característica dos melhores indivíduos encontrados durante o algoritmo na ocorrência de um falta, sem a presença da tabela de perdas. 94 


\section{Sumário}

1 CAPÍTULO

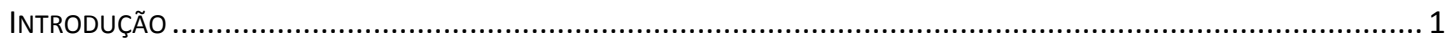

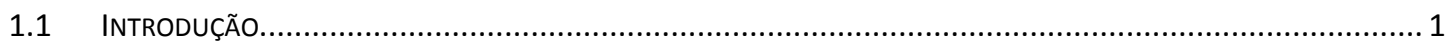

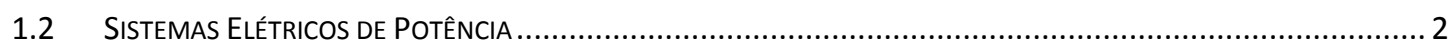

1.2.1 Sistema de Distribuição de Energia Elétrica ................................................................ 2

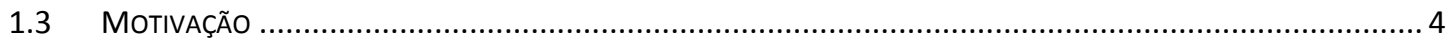

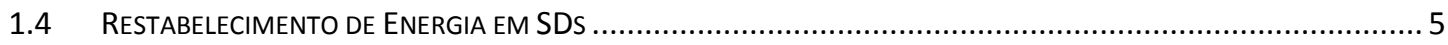

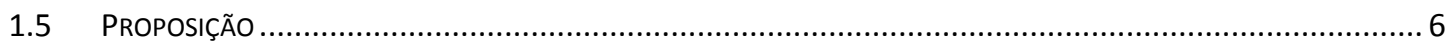

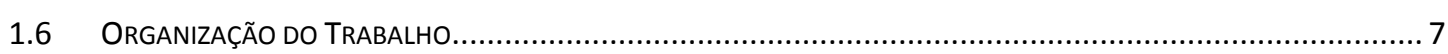

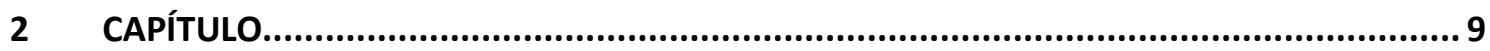

RECONFIGURAÇÃO DE REDES EM SISTEMAS DE DISTRIBUIÇÃO..................................................................

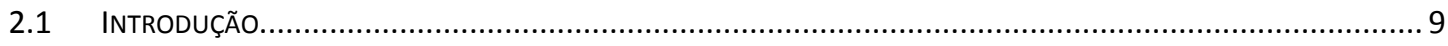

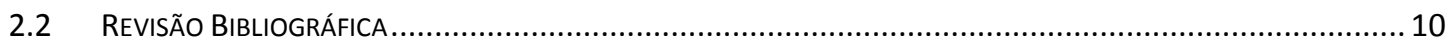

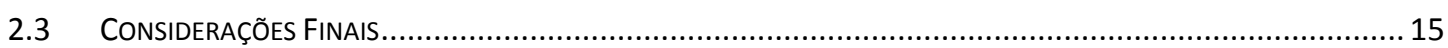

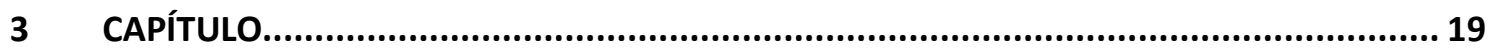

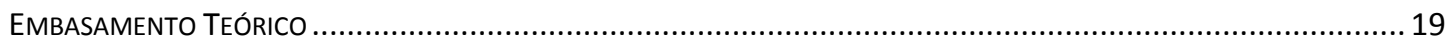

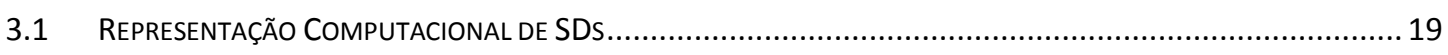

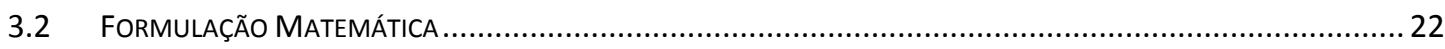

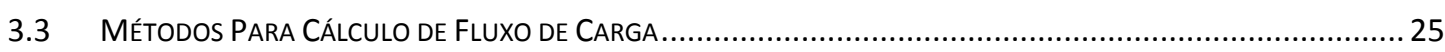

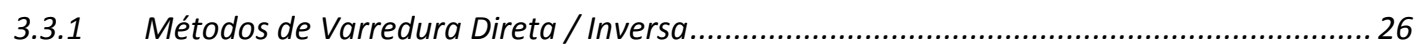

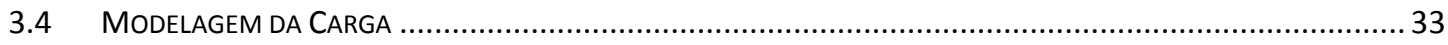

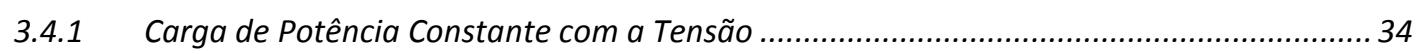

3.4.2 Carga de Impedância Constante com a Tensão ................................................................. 34

3.4.3 Carga de Corrente Constante com a Tensão ...................................................................... 35

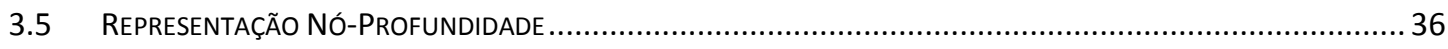

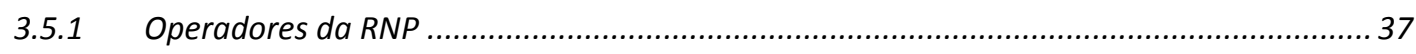

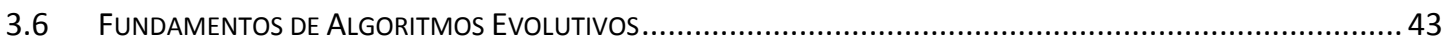

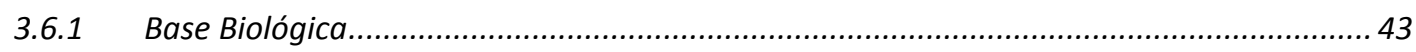

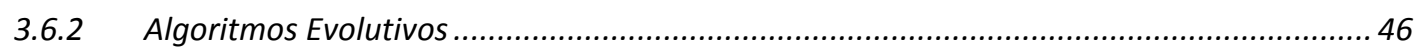

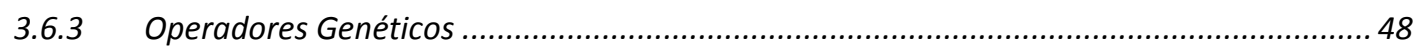

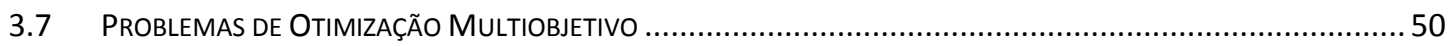




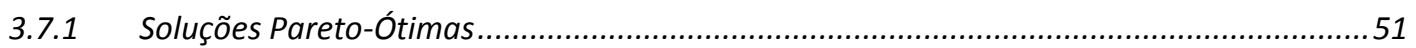

3.7.2 Diferenças entre Otimização Mono-Objetivo e Multiobjetivo ..................................................52

3.8 Algoritmos EVolutivos PARA OtIMIZAÇÃo MultiobJetivo..........................................................5

3.8.1 Algoritmo Evolutivo Multi-Objetivo em Tabelas ........................................................55

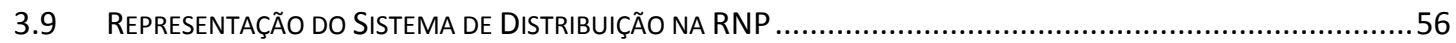

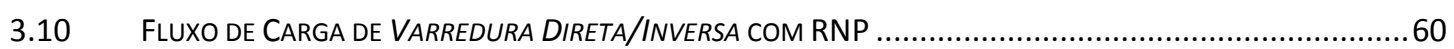

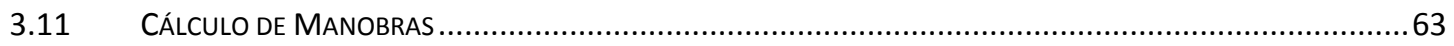

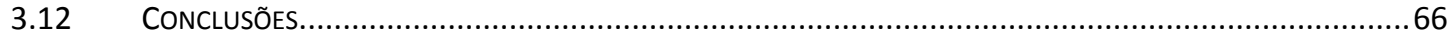

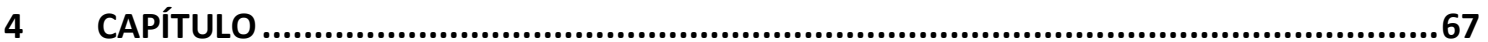

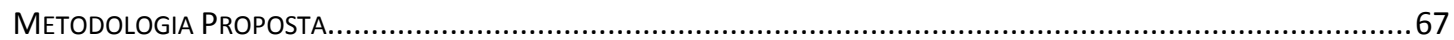

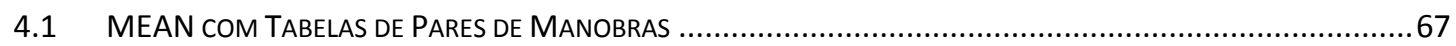

4.2 Metodologia de PriorizaÇÃo de ChaVes Automáticas..............................................................70

4.2.1 Novos Critérios de Armazenamento das Subpopulações em Tabelas............................... 70

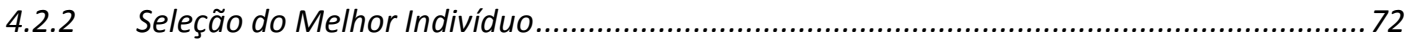

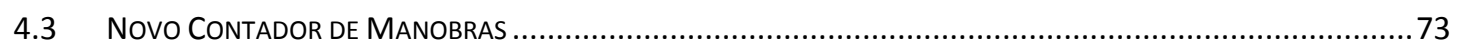

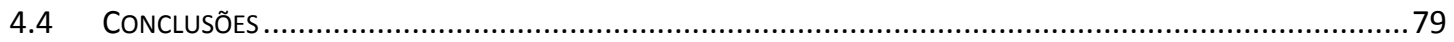

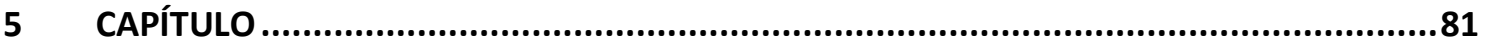

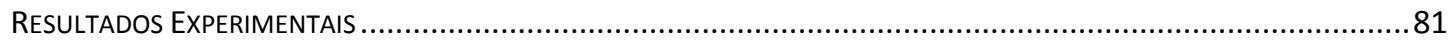

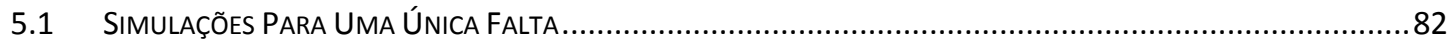

5.1.1 Capacidade de Priorização de Chaves Automáticas .....................................................8 85

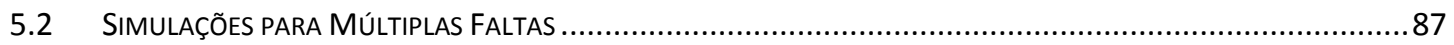

5.2.1 Capacidade de Priorização de Chaves Automáticas .....................................................90

5.2.2 Importância das Tabelas no Processo Evolutivo ....................................................91

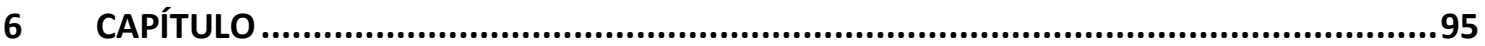

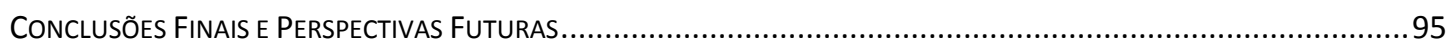

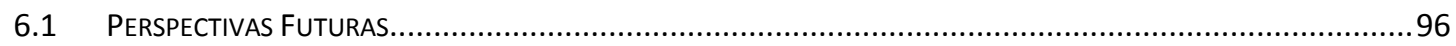

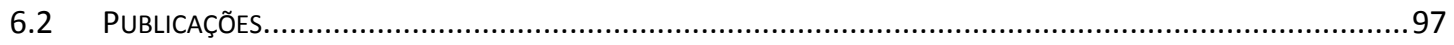

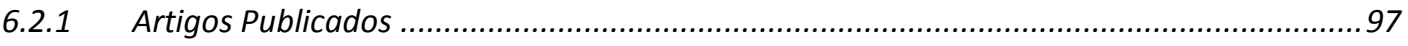

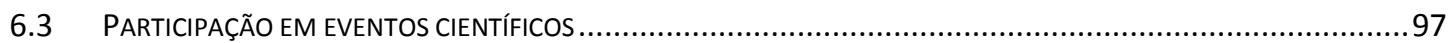




\section{Capítulo}

\section{Introdução}

\subsection{Introdução}

A maior parte da energia elétrica no Brasil produzida nos grandes centros de geração está geralmente localizada a grandes distâncias dos centros de consumo. Dessa forma, através das linhas de transmissão, essa energia é transportada às subestações de subtransmissão. A partir desse ponto, cabe ao sistema de distribuição transportar a energia elétrica ao local onde se encontram os consumidores do sistema. Assim, o sistema de distribuição de energia elétrica deve atender às particularidades dos consumidores, satisfazendo diversos critérios de qualidade que são estabelecidos por órgãos competentes.

Com o passar dos anos, com intuito de melhorar cada vez mais a confiabilidade, continuidade e qualidade do fornecimento de energia, o setor elétrico tem sofrido mudanças significativas na sua regulamentação. Para atender um mercado cada vez mais exigente, as empresas concessionárias de energia elétrica têm continuamente desenvolvido esforços no sentido de melhorar a qualidade de seu produto, ou seja, da energia elétrica fornecida aos seus consumidores. Com isso os engenheiros e operadores que trabalham em concessionárias de energia necessitam, cada vez mais, de ferramentas computacionais para apoio às atividades de planejamento e operação das suas redes elétricas.

No contexto de operação de sistemas de distribuição, um dos problemas que exige a utilização de ferramentas computacionais eficientes, de execução rápida, é o de restabelecimento de energia após a ocorrência de faltas permanentes. Esse é o problema tratado neste trabalho a partir do processo de reconfiguração de redes. Apresentar-se-á, neste capítulo, uma breve descrição da estrutura do sistema elétrico de potência, enfatizando o sistema de distribuição. Em seguida, expõe-se a motivação bem como a proposta deste trabalho e a organização dos demais capítulos deste texto. 


\subsection{Sistemas Elétricos de Potência}

Os sistemas elétricos de potência podem ser divididos em três grandes blocos: geração, transmissão e distribuição. O sistema de geração é responsável pela produção da energia elétrica. Para isso são utilizados geradores, que transformam alguma outra forma de energia em energia elétrica. No Brasil, cerca de 90\% da energia elétrica é gerada por usinas hidrelétricas.

Após a geração, a energia elétrica deve ser transportada dos centros geradores aos centros consumidores, função esta realizada pelo sistema de transmissão. As linhas de transmissão podem possuir centenas de quilômetros. Por razões econômicas (redução de perdas e redução da bitola dos condutores) a transmissão é normalmente efetuada em tensões muito elevadas. Dessa forma, nas subestações elevadoras eleva-se o nível da tensão gerada.

O sistema de distribuição é o responsável por transportar a energia aos consumidores, sendo que nas proximidades das regiões de consumo as tensões são reduzidas para níveis de subtransmissão (tipicamente $65 \mathrm{kV}$ e $130 \mathrm{kV}$ ), ou diretamente para níveis de distribuição (tipicamente $13,8 \mathrm{kV}$ ).

A Figura 1.1 ilustra uma representação clássica da divisão do sistema elétrico de potência (SEP).

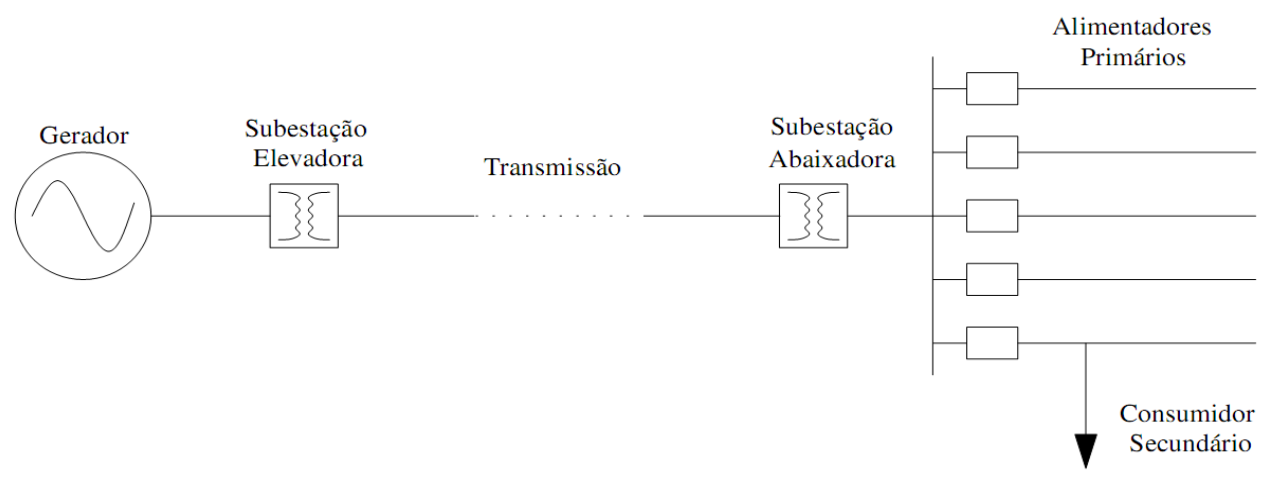

Figura 1-1: Exemplo de um SEP (A. J. Monticelli \& A. V. Garcia 2003).

\subsubsection{Sistema de Distribuição de Energia Elétrica}

O sistema de distribuição (SD) é formado por subestações abaixadoras e circuitos elétricos usados para receber energia do sistema de transmissão e entregá-la aos consumidores. O SD é a parte do SEP localizada entre as subestações de distribuição e os consumidores, sejam eles alimentados em média tensão (MT) ou baixa tensão (BT). Como 
podemos observar na Figura 1.2, o sistema de distribuição de energia elétrica pode ser dividido em:

1. Rede de Distribuição Primária: é o trecho do SD entre as subestações urbanas e os transformadores de distribuição. Essa rede atende aos consumidores primários (indústrias de médio porte, conjuntos comerciais, grandes hospitais, shopping centers, instalações de iluminação pública, etc.) e os transformadores de distribuição secundária, ou de baixa tensão, e opera geralmente em redes radiais aéreas na tensão de $13,8 \mathrm{kV}$. A característica radial simplifica a operação e proteção dessa rede, porém diminui a confiabilidade em relação à continuidade do fornecimento de energia elétrica. Em razão disso, essas redes são projetadas com possibilidade de transferência de blocos de cargas entre circuitos, agrupando vários pontos de carga em blocos (setores), separados por chaves que operam no estado Normalmente Aberto (NA) e Normalmente Fechado (NF). Assim, a partir da reconfiguração da rede, isto é, da operação de chaves, é possível a troca de carga entre alimentadores em caso de interrupção em algum ponto da rede ou para manutenção preventiva e/ou corretiva.

2. Rede de Distribuição Secundária: geralmente opera com tensões de $220 / 127 \mathrm{~V}$ ou 380/220V. Atende aos consumidores de baixa tensão, pequenos comércios e indústrias e, principalmente, os consumidores residenciais. Essa parte do SD, usualmente, não conta com recursos para o atendimento de contingências. 


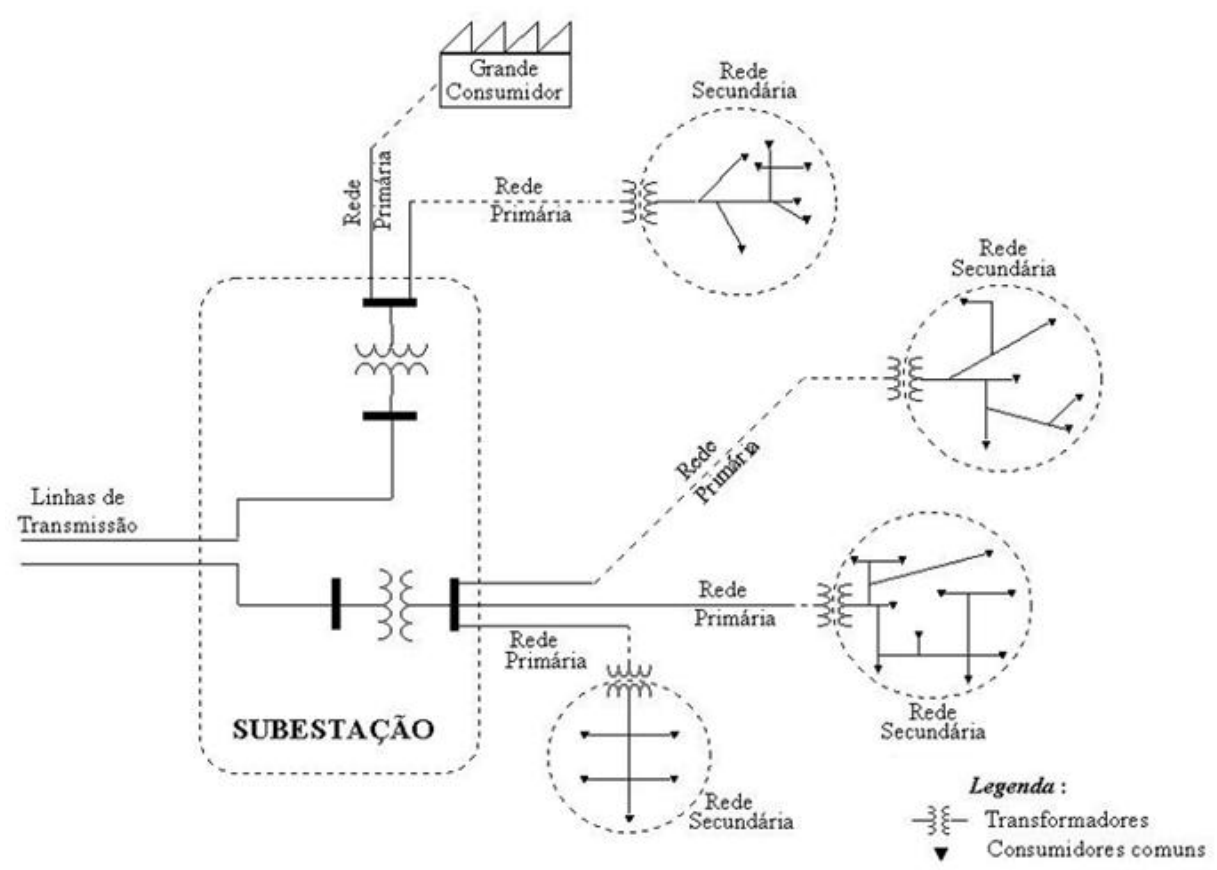

Figura 1-2: Representação de um sistema de distribuição radial.

De uma forma mais específica, este trabalho trata do problema de restabelecimento de energia na rede de distribuição primária.

\subsection{Motivação}

Para aumentar a satisfação dos consumidores e diminuir os gastos com pagamento de compensações por não cumprimento de metas para os indicadores de qualidade e continuidade de serviço, parte dos investimentos das concessionárias focam na trilogia de continuidade, qualidade e economia de serviço.

Nesse sentido as concessionárias vêm investindo na infraestrutura das redes e soluções aplicando o conceito de redes inteligentes (Smart Grids). Por outro lado, a logística/inteligência na alocação e utilização de novos equipamentos é fator crítico. Técnicas de inteligência computacional associadas a procedimentos de reconfiguração de redes têm possibilitado um melhor uso de recursos e economias significativas. Infelizmente, por mais que se invista na redução da quantidade de desligamentos é impossível pensarmos em uma rede completamente segura, principalmente devido às características operacionais e construtivas dos sistemas de distribuição atuais. Desta forma, as concessionárias de energia vêm realizando investimentos com intuito de 
diminuir a quantidade de consumidores que ficam sem energia, após a ocorrência de faltas permanentes e também o tempo de desligamento destes consumidores.

Usualmente o processo de restabelecimento de energia, após a ocorrência de uma ou múltiplas faltas permanentes, é realizado pelos operadores dos Centros de Operação da Distribuição, a partir da reconfiguração da rede. Este processo obedece às normas técnicas da concessionária, a partir da análise de uma série de variáveis, muitas vezes de difícil visualização pelo operador. Devido a essa dificuldade de visualização das variáveis, à grande quantidade de soluções possíveis e ao tempo necessário para um ser humano determinar a solução ótima do problema (configuração ótima do SD), o processo de restabelecimento de energia fica baseado nas características pessoais de cada operador. Vale ressaltar que para um mesmo desligamento, diversas soluções são encontradas, sendo que para alguns casos, nenhuma delas pode ser a melhor.

Face ao exposto, verifica-se a necessidade de desenvolvimento de ferramentas computacionais eficientes, de rápida execução, para obtenção de planos de restabelecimento de energia após a ocorrência de faltas permanentes em SDs.

\subsection{Restabelecimento de Energia em SDs}

Quando da ocorrência de uma falta permanente em um SD, a fim de minimizar o impacto desta, busca-se isolar o defeito e restabelecer rapidamente o fornecimento de energia aos setores não defeituosos. Desta forma, o problema de restabelecimento de energia consiste em determinar uma estratégia de controle, para restabelecer a energia às cargas que não estão no setor atingido pela falta, mas que ficaram sem energia devido ao isolamento daquele setor. Essa estratégia de controle corresponde a uma transição da topologia (ou configuração) do SD, realizada através de manobras de abertura e fechamento de chaves, para alimentar o setor não defeituoso por outro caminho ou fonte.

Para exemplificar o processo de restabelecimento de energia, consideremos o SD com três alimentadores mostrados na Figura 1.3, em que os retângulos representam as subestações, as linhas sólidas as chaves NFs, as linhas pontilhadas as chaves NAs e os círculos os setores de carga. Suponhamos que ocorra uma falta permanente no setor 4, Fig. 1.3a. Este setor deverá ser isolado do SD por meio da abertura das chaves A e B. Contudo, os setores 7 e 8, que não possuem defeitos, ficaram dentro da área sem energia. Esse problema pode ser resolvido, por exemplo, através do fechamento da chave C, conforme Fig. 1.3b. Entretanto, para essa solução ser realmente factível, é necessário 
avaliar o atendimento de algumas restrições operativas, como, por exemplo: (i) manter a estrutura radial da rede; (ii) não violar os limites de corrente em linhas e equipamentos; e (iii) atender os limites de queda de tensão. Além dessas restrições, alguns objetivos geralmente são considerados no problema de restauração de energia, tais como: (i) minimização do número de manobras em chaves; e (ii) minimização dos setores sem defeito fora de serviço.

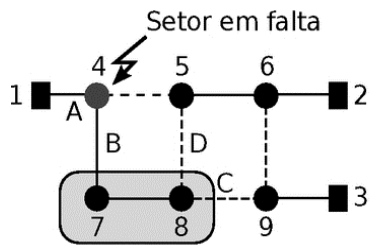

(a) Setor em falta

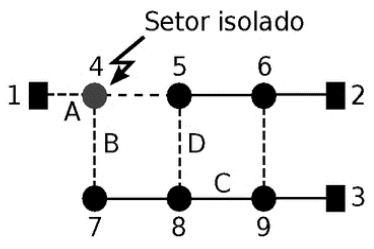

(b) Nova configuração

Figura 1-3: Restabelecimento de Energia.

Face ao exposto, o problema de restabelecimento de energia em SDs possui múltiplos objetivos, sendo que alguns conflitantes. Além disto, devido à grande quantidade de variáveis envolvidas nesse problema, ele está sujeito ainda ao fenômeno de explosão combinatória, tornando inviável a utilização de técnicas de programação matemática (Schmidt et al, 2005; Delbem et al, 2005). Isso ocorre em razão de o espaço de busca de soluções possíveis aumentarem, exponencialmente, com o número de variáveis. Eis a razão de diversas metas-heurísticas estarem sendo propostas como alternativas para resolver o problema de restabelecimento de energia em SDs de grande porte, isto é, SDs com milhares de barras, linhas e chaves. Dentre as metas-heurísticas existentes, os Algoritmos Evolutivos (AEs) têm sido a mais explorada (Zhu, 2002; Carreno et. al., 2008; Santos et al, 2008; Mendoza et al, 2006; Kumar et al, 2008; Mansour et al, 2009; Santos et al, 2010; Fantin et al, 2011).

\subsection{Proposição}

Propõe-se, nesta dissertação de mestrado, o desenvolvimento de uma metodologia de reconfiguração de redes para o tratamento do problema de restabelecimento de energia em SDs de grande porte.

Pretende-se desenvolver uma metodologia que possibilite o tratamento de SDs de grande porte, considerando todas as chaves e barras desses sistemas, que permita a obtenção de planos de restabelecimento de energia em tempo real, sem esgotar a memória do computador. A metodologia proposta permitirá a obtenção de soluções 
(configurações do sistema), minimizando o número de manobras e de consumidores sem energia, priorizando a utilização de chaves automáticas e respeitando as restrições operativas do sistema.

Tendo em vista a característica multiobjetivo do problema de restabelecimento de energia, para desenvolvimento da metodologia proposta utilizar-se-á o Algoritmo Evolutivo Multiobjetivo em Tabelas (AEMT) proposto em (Santos et al, 2010). Importa ressaltar que a eficiência computacional do MEAN deve-se, em especial, pelo fato de o mesmo fazer uso da estrutura de dados chamada Representação Nó-Pronfundidade (RNP), proposta em (Delbem et al, 2004), para representar computacionalmente a topologia elétrica dos SDs. No capítulo 2 serão destacadas as vantagens de se utilizar a RNP para o tratamento de problemas de reconfiguração de redes em SDs.

\subsection{Organização do Trabalho}

Os próximos Capítulos deste texto estão organizados da seguinte forma:

- Capítulo 2 descreve o problema de reconfiguração de redes em SDs de uma forma geral, destacando alguns dos principais trabalhos desenvolvidos para tratamento do problema específico de restabelecimento de energia;

- Capítulo 3 resume todos os estudos realizados até o momento para desenvolvimento deste trabalho, ou seja: conceitos da teoria de grafos; formulação matemática geral do problema de reconfiguração de redes; métodos para cálculo de fluxo de potência em SDs; modelagem de carga; estrutura de dados RNP; otimização multiobjetivo via AEMO; representação de sistemas de distribuição utilizando RNP; fluxo de carga com RNP e por final algoritmo do cálculo de manobras;

- Capítulo 4 apresenta de forma detalhada o desenvolvimento da metodologia tomada como base e as alterações efetuadas para desenvolvimento da metodologia proposta neste trabalho;

- No capítulo 5 encontram-se os resultados experimentais com aplicação da nova metodologia desenvolvida;

- Capítulo 6 apresenta as conclusões gerais e as perspectivas futuras; 


\section{Capítulo}

\section{Reconfiguração de Redes em Sistemas de Distribuição}

Neste capítulo será abordado o problema de reconfiguração de redes em SDs de uma forma geral, destacando alguns dos principais trabalhos desenvolvidos para tratamento do problema específico de restabelecimento de energia.

\subsection{Introdução}

A característica radial das redes de distribuição primárias simplifica a operação e proteção das mesmas (Kagan et al. 2005), porém diminui a confiabilidade desses sistemas em relação à continuidade do fornecimento de energia elétrica. Isto porque a interrupção do fornecimento de energia em um determinado grupo de consumidores, seja em virtude de uma falta ou para execução de obras, pode interromper o fornecimento de energia para os demais grupos de consumidores ligados a jusante do ponto de interrupção (conforme exemplificado na Figura 1.3 do capítulo 1).

As interrupções no fornecimento de energia nos SDs são inevitáveis, isto em virtude da execução de obras de expansão, intervenções de manutenção preventiva em componentes da rede ou pela atuação de um dispositivo de proteção em decorrência de faltas permanentes. Para tentar remediar esse problema, vários pontos de carga são agrupados em blocos separados por chaves NAs e NFs, formando setores. Assim, a partir da reconfiguração da rede, isto é, da operação de chaves, é possível a troca de carga entre alimentadores em caso de interrupção em algum ponto da rede. Nessas situações, tornase necessário um plano de restabelecimento de energia que consiste, basicamente, em determinar um conjunto de manobras de chaves para restringir as interrupções à menor parte possível do sistema, respeitando as restrições operativas da rede. 
A reconfiguração de redes pode ser aplicada também em condições normais de operação, objetivando:

- Reduzir as perdas totais por efeito Joule (Sarfi et al. 1996) e (Gomes et al. 2006)

- Balanceamento de cargas entre os alimentadores (Chen et al. 2000) e (Siti et al. 2007);

- Redução de queda de tensão (Mantovani et al. 2000);

- Sobrecarga em trechos da rede (Prasad et al. 2007).

Face ao exposto, diversos problemas em SDs podem ser resolvidos a partir da reconfiguração de redes, como, por exemplo, o problema de restabelecimento de energia, redução de perdas e alocação de chaves telecomandadas. Em razão disto, tais problemas podem ser chamados, de uma forma geral, de problemas de reconfiguração de redes em SDs.

Um plano genérico adequado de reconfiguração de redes pode envolver as seguintes necessidades práticas:

1. Ser determinado em um curto intervalo de tempo (para aplicações em tempo real, como, por exemplo, para restabelecimento de energia após a ocorrência de faltas permanentes);

2. Minimizar o número de manobras (busca-se reduzir o número de manobras basicamente por dois motivos: a operação frequente das chaves reduz a expectativa de vida das mesmas; quanto mais manobras, maior o tempo para executar o plano, pois a maioria das chaves é operada manualmente);

3. Reduzir o número de consumidores interrompidos;

4. Nenhum componente sobrecarregado;

5. Manter a estrutura radial do sistema;

6. Reduzir o total de perdas de potência;

7. Reduzir quedas de tensão.

Naturalmente, dependendo das necessidades da distribuidora de energia elétrica, outros objetivos, além dos supracitados, podem ser considerados.

\subsection{Revisão Bibliográfica}

Apresentar-se-ão, a seguir, alguns dos principais trabalhos desenvolvidos para tratamento do problema de restabelecimento de energia em SDs. 
Em Aoki et al. 1989 foi desenvolvido um método gradiente dual efetivo para restabelecimento de energia, a partir do processo de reconfiguração de redes, que possui as seguintes etapas: (1) os setores sem falta que ficaram sem energia são transferidos para alimentadores adjacentes (alimentadores de apoio); (2) os alimentadores adjacentes que violaram as restrições operacionais em função da carga extra transferida são definidos como alimentadores de violação; e (3) as cargas que foram para alimentadores de violação são transferidas para outros alimentadores, eliminando as violações de restrições operacionais. As restrições operacionais consideradas são: limite de fluxo nas linhas, limite de queda de tensão, capacidade dos alimentadores e radialidade da rede. A função objetivo tenta restaurar o maior número de cargas fora de serviço. O método demonstra eficiência em evitar operações de chaveamento desnecessárias.

Em Morelato \& A. Monticelli 1989 é proposto um método baseado em busca heurística, que percorre uma árvore de decisão binária, em que o conhecimento específico é utilizado como guia da busca. O método possui como característica a identificação do estado da chave da seguinte maneira: NA (0) e NF (1). Assim, percorrendo a árvore define-se uma variável de decisão. $O$ teste da factibilidade de cada solução é feito através desta busca heurística em profundidade. Se a solução não for factível a busca retorna ao ponto inicial na tentativa de encontrar outra solução. Para validação do método realizaram-se simulações com uma rede com 20 consumidores, 33 chaves e 4 alimentadores, em que o método se mostrou robusto para o problema.

O trabalho de Shirmohammadi (1992) baseia-se em regras heurísticas para redução de manobras de chaves para restabelecimento de energia. O método se inicia com a criação de uma rede malhada, por meio do fechamento de todas as chaves. Em seguida, executa-se um fluxo de carga para essa configuração, classificando cada chave da rede conforme o fluxo de carga que a atravessa. As chaves que apresentam fluxo de carga menor passam para o estado NA. Esse procedimento é repetido até encontrar uma rede radial.

Em Fukuyama \& Hsaio-Dong Chiang (1995) foi utilizado um algoritmo genético paralelo para resolução do problema de restabelecimento de energia. O método define como restrições operacionais: capacidade dos alimentadores, queda de tensão e fluxo na linha; em que são tratados com fatores de penalidade durante o processo de avaliação dos indivíduos. Também foi proposto um operador de reparação para indivíduos que não respeitam o critério de rede radial. Durante as simulações o método se mostrou robusto, com redução no tempo computacional para sistemas de grande porte. 
O método proposto em Augugliaro et al. (2000) baseia-se em Estratégias Evolutivas (EE), com definição fuzzy de múltiplos objetivos conflitantes que compõem um problema de restabelecimento de energia. O método considera a possibilidade de controle remoto das chaves, de bancos de capacitores e conexões de cargas. Sendo assim, na ocorrência de contingência o restabelecimento é executado remotamente. Para formulação do problema duas funções foram consideradas como principais: minimização de perdas resistivas e a maximização da quantidade de cargas a ser restabelecida. A avaliação das soluções geradas é feitas através de um conjunto fuzzy. As restrições foram: manter estrutura da rede radial, carregamento das linhas, carregamento nos transformadores e queda de tensão nas barras. Testes foram realizados em um SD inicialmente malhado contendo 98 setores, 81 barras de carga e 24 bancos de capacitores, onde foi considerada apenas a ocorrência de uma única falta permanente.

Em Toune et al. (2002) realizou-se uma comparação de 4 algoritmos heurísticos para restabelecimento de energia: Busca Tabu (BT), Busca Tabu Reativa (BTR), Simulated Anneling (AS) e AEs. A comparação foi realizada considerando os objetivos de encontrar planos de restabelecimento de energia capazes de minimizar o número de consumidores sem fornecimento de energia. As restrições adotadas foram: queda de tensão, respeitar a topologia radial da rede, carregamento das linhas e carregamento dos transformadores. Apresentaram-se comparações da formulação matemática de cada um dos métodos e foram realizados testes em um SD com 3 alimentadores e 60 barras.

Uma abordagem híbrida, que faz uma combinação de AEs e BTs, foi apresentada em Shin et al. (2004). Nesse trabalho considera-se como "ótima" a configuração que minimiza as perdas e atende as restrições operacionais do sistema, respeitando a topologia radial da rede. A abordagem, denominada de AG-Tabu, procura utilizar as propriedades que os BTs e AEs têm de melhor. As restrições operacionais consideradas foram: carregamento nas linhas, carregamento dos transformadores e estrutura radial do SD. Na formulação do problema foram avaliados custos das perdas resistivas e o custo total, após a interrupção reconexão do sistema devido ocorrência de uma falta. Os testes foram realizados em um sistema com 7 alimentadores e 38 barras, com a ocorrência de uma única falta.

Em A. C. B. Delbem et al. (2005) foi proposta uma nova codificação para SDs baseada em Cadeias de Grafos, com intuito de melhorar o desempenho dos AEs. A partir dessa codificação foram desenvolvidos operadores de reprodução não convencionais que, a partir de uma configuração factível já existente, produzem exclusivamente 
configurações factíveis, isto é, redes radiais capazes de fornecer energia para todo o sistema ${ }^{2}$. Utilizando conceitos de grafos e partindo do princípio que uma árvore de grafo pode ser representada por cadeias conectando a raiz às folhas, o conjunto de todas essas cadeias armazenadas adequadamente representa um alimentador de um SD. Dessa forma, o conjunto de todos os alimentadores representa um SD completo. Para tratar o problema multiobjetivo empregou-se uma $\mathrm{AE}$ que faz uso de subpopulações armazenadas em tabelas, conforme apresentado em (R. Benayoun e Laritchev, 1971). Testes foram realizados em um SD de grande porte com 1471 barras, 249 chaves, 3 subestações e 23 alimentadores. Como restrições foram consideradas: queda de tensão, carregamento nas linhas e carregamento nos transformadores. A estrutura radial do SD é sempre uma condição satisfeita no problema, pois os operadores de reprodução propostos geram apenas configurações factíveis. $\mathrm{O}$ artigo trata de uma falta por vez. Foram consideradas faltas em setores críticos da rede, por exemplo, que acarretam a interrupção de energia para todo um alimentador. Vale destacar que a técnica foi aplicada aos problemas de restabelecimento de energia, redução de perdas resistivas e planejamento de SD.

Em Inagaki et al. (2006) foi proposto uma abordagem multiobjetivo baseada na obtenção de soluções pertencentes ao conjunto de Pareto, que será definido no Capítulo 3. $\mathrm{O}$ método utiliza AEs, que disponibiliza um número maior de boas configurações para o operador decidir qual se adapta melhor ao problema. Realiza-se uma combinação de AEs e AS com o objetivo de melhorar a precisão das soluções. A função objetivo procura minimizar o número de manobras de chaves e reduzir a área fora de serviço. Como restrições foram consideradas: manter a estrutura radial do SD, a energia deve ser restabelecida às áreas a jusante do setor em falta, carregamento nas linhas, carregamento nos transformadores e queda de tensão. Para validar o método o mesmo foi aplicado em um SD com 4 transformadores, 6 alimentadores e 78 barras de cargas, aplicando a ocorrência de uma única falta. Destaca-se que o método prioriza o atendimento de cargas especiais (hospitais, shopping centers, etc).

Kumar et al. (2008) desenvolveram um algoritmo para restabelecimento de energia em SD, baseado no AE de otimização multiobjetivo proposto por (Deb et al. 2002) denominado NSGA-II (do inglês, Elitist Non-Dominanted Sorting Genetic Algorithm). Modificações no NSGA-II foram realizadas com intuito de melhorar o tempo de processamento computacional do mesmo. Os resultados obtidos pelo método proposto, denominado NSGA-II avançado, foram comparados com os resultados obtidos pelo

2 O termo "todo o sistema" significa todas as partes ligadas do sistema, pois, em algumas situações não é possível conectar uma área fora de serviço em razão da falta de chaves 
NSGA-II básico (sem modificações) e por um AE mono-objetivo. O NSGA-II avançado conseguiu obter os mesmos resultados encontrados pelos outros dois métodos, entretanto com um tempo computacional menor. Isso se deve ao fato de o NSGA-II avançado ter sido implementado utilizando a estrutura de dados apresentada em (Jensen 2003). Na formulação do problema foram considerados os seguintes objetivos: minimização do número de manobras de chaves (manual e automática), redução da área fora de serviço e das perdas resistivas. Como restrições foram consideradas: manter a estrutura radial do $\mathrm{SD}$, queda de tensão, carregamento da rede e priorizar o restabelecimento para cargas "especiais" como hospitais e grandes centros industriais. Testes foram realizados em quatro SD, todos de pequeno porte, em que a dimensão varia de 13 barras e 10 chaves até 173 barras e 75 chaves.

O trabalho de Kleinberg et al. (2009) aplica uma heurística em conjunto com um esquema de redução de carga para resolução do problema de restabelecimento. O método faz uso de uma ordenação dos índices de chaves para eliminar soluções infatíveis, onde ao mesmo tempo é identificado conjuntos com soluções "ótimas". Para ilustrar o algoritmo proposto apresenta-se um exemplo numérico.

Santos et al., (2010), foi proposto uma metodologia denominada MEAN que faz uso de AEs juntamente com RNP, para tratar o problema multiobjetivo de forma mais adequada, o método trabalha em paralelo com várias subpopulações armazenadas em tabelas. Dessa forma, os melhores indivíduos (configurações do sistema de distribuição) para cada característica do problema (número de manobras, perdas resistivas, queda de tensão, carregamento da rede e carregamento da subestação) são armazenados em suas respectivas subpopulações. Torna-se possível, então, encontrar de forma eficiente soluções pertencentes ao chamado conjunto de Pareto, que consiste de soluções (configurações do sistema) que não são dominadas por outra solução alguma (DEB, 2001). Assim, um número maior de configurações é disponibilizado para o operador decidir qual se adapta melhor ao problema da empresa. Dessa forma, tal método, nomeado simplesmente de MEAN (do inglês, Multi-objective Evolutionary Algorithm with Node-Depth Encoding), permite o tratamento de SDs de grande porte (com milhares de barras, linhas e chaves), considerando todos os seus alimentadores e subestações.

Para validar o MEAN, foram apresentados vários testes utilizando o SD da cidade de São Carlos, São Paulo, que possuí 3.860 barras, 635 chaves, 3 subestações (sendo duas subestações com dois transformadores com potência de 25MVA cada e outra subestação com um transformador de 25MVA) e 23 alimentadores. Para demonstrar que o MEAN 
pode ser aplicado em SDs maiores que o SD da cidade de São Carlos, não incorrendo no problema de explosão combinatória, foram também apresentados testes utilizando aquele sistema aumentado, ou seja, com tamanho duplicado, quadriplicado e octuplicado.

Sanches et al., (2012), foi desenvolvida com base em RNP uma metodologia denominada de MEAN-NDS, em que a mesma aborda problemas de reconfiguração de redes para restabelecimento de energia em SDs. A metodologia trata da junção das principais características propostas em MEAN (Santos et al., 2010) e NSDE proposta por (Mansour et al., 2009). Devido a essa junção, a metodologia foi denominada de MEANNDS, em que a mesma utiliza tabelas de subpopulações desenvolvidas em MEAN, e foram inseridas novas tabelas de subpopulações, chamadas de tabelas de subpopulações não dominadas, (que utilizam o conceito de dominância de Pareto (DEB, 2001) para comparar duas soluções factíveis de um problema), sendo que essas tabelas são preenchidas de acordo com o grau de não dominância de cada solução. Apesar do MEANNDS ter mostrado grandes avanços nos resultados obtidos, ainda existiam outras questões a serem tratadas para o problema de restabelecimento de energia que esta metodologia não considerou durante o processo de restabelecimento a priorização do uso de chaves automáticas.

\subsection{Considerações Finais}

Conforme apresentado na seção anterior, dentre as metas-heurísticas existentes, os AEs têm sido a mais explorada para o tratamento do problema de restabelecimento de energia em SDs. Alguns trabalhos utilizam AEs mono-objetivos (Zhu, 2002; Carreno et. al., 2008; Santos et al, 2008), que fazem uso de fatores de ponderação que penalizam a violação das restrições operacionais. Outros fazem uso de AEs Multiobjetivos (AEMOs) (Mendoza et al, 2006; Kumar et al, 2008; Moussa et al, 2009; Santos et al, 2010; (Sanches et al., 2012), que permitem o tratamento de diversos objetivos simultaneamente, sem a utilização de fatores de ponderação, através da utilização do conceito de Dominância de Pareto (Deb 2001).

Dentre os fatores críticos para utilização de AEs, em problemas de reconfiguração de redes de uma forma geral, destaca-se a estrutura de dados utilizada para representar a topologia elétrica dos SDs e os operadores genéticos utilizados, que normalmente não são capazes de gerar configurações radiais (Delbem et al, 2005; Mendoza et al, 2006; Carreno et. al., 2008; Kumar et al, 2008; Santos et al, 2010). 
Nas metodologias para reconfiguração de redes desenvolvidas em (Moussa et al, 2009; Santos et al, 2010; Sanches et al, 2011), foi utilizada a estrutura de dados denominada Representação Nó-Profundidade (RNP), e seus correspondentes operadores genéticos (Delbem et al, 2004).

A RNP pode melhorar o desempenho obtido por AEs em problemas de reconfiguração de redes devido as suas seguintes propriedades: (i) A RNP e seus operadores produzem exclusivamente configurações factíveis; (ii) A RNP pode gerar muito mais configurações factíveis em relação as outras estruturas de dados, para um mesmo período de tempo, tendo em vista que a RNP apresenta uma complexidade computacional de ordem $\mathrm{O}(\sqrt{n})$, onde $\mathrm{n}$ é o número de nós do grafo; (iii) Cada configuração gerada pela RNP possui todos os nós ordenados de acordo com uma relação conhecida como Modelo Pai-Filho (MPF), possibilitando, assim, a execução de um Algoritmo de Fluxo de Carga de Varredura direta/inversa de forma mais eficiente. Tipicamente para aplicar esse tipo de fluxo de carga em redes radiais, é necessária a execução de uma rotina para ordenar os nós de acordo com o MPF (Shirmohammadi et al, 1988).

A diferença entre as metodologias desenvolvidas em (Moussa et al, 2009; Santos et al, 2010; Sanches et al, 2011) é o AEMO utilizado. A metodologia proposta em (Santos et. al., 2010), denominado MEAN, faz uso da RNP em conjunto com um AEMO baseado no método de Tabelas. Por outro lado, o método apresentado em (Mansour et. al., 2009), denominado NSDE, baseia-se na combinação da RNP com uma versão modificada do NSGA-II. A metodologia proposta em (Sanches et al, 2011), denominada MEAN-NDS, procura combinar os melhores aspectos das metodologias MEAN e NSDE, para tratamento do problema de restabelecimento de energia e para redução de perdas em SDs. Assim como a metodologia MEAN, a MEAN-NDS trabalha em paralelo com várias subpopulações armazenadas em tabelas, onde as melhores soluções (ou configurações do SD), para cada característica do problema, são armazenadas em suas respectivas tabelas. Entretanto, a MEAN-NDS faz uso de tabelas adicionais de subpopulações não dominadas, que armazenam as soluções não dominadas obtidas durante as gerações (calculadas da mesma forma que no NSDE).

Face ao exposto, para desenvolvimento da metodologia proposta nesta dissertação de mestrado utilizar-se-á, como base, o método desenvolvido por (Santos et al., 2010) com inserção de tabelas de pares de manobras em chaves manuais, o qual será exposto nos próximos capítulos. Vale ressaltar, entretanto, que nenhum dos métodos citados nesta 
seção possibilita a obtenção de planos de restabelecimento de energia priorizando a utilização de chaves automáticas. 


\section{Capítulo}

\section{Embasamento Teórico}

Neste capítulo apresenta-se, de forma sucinta, o embasamento teórico para entendimento deste trabalho, ou seja, conceitos da teoria de grafos, formulação matemática geral do problema de reconfiguração de redes, métodos para cálculo de fluxo de potência em SDs, modelagem de carga, estrutura de dados RNP e otimização multiobjetivo via AEMO;

\subsection{Representação Computacional de SDs}

Para tratar computacionalmente o problema de restabelecimento de energia em SDs, o primeiro passo é definir a maneira de representar computacionalmente os SDs. Para isso utiliza-se, usualmente, grafo. Dessa forma, apresenta-se, na próxima subseção, conceitos e definições da teoria de grafos, conforme apresentado em (Fantin, 2012).

\subsubsection{Conceitos e Definições da Teoria de Grafos}

Um grafo $G(V, A)$ é definido pelo par $V$ e $A$, em que:

- $\quad V$ - conjunto de vértices ou nós do grafo;

- $A$ - conjunto de pares de nós não ordenados: as arestas do grafo.

Se $u$ e $v$ são dois nós de um grafo e se o par $\{u, v\}$ é uma aresta denotada por $y$, diz-se que $y$ conecta $u$ e $v$, como pode ser visto na Figura 3.1. Neste caso, a aresta $\{u, v\}$ é dita ser incidente ao nó $u$ e ao nó $v$.

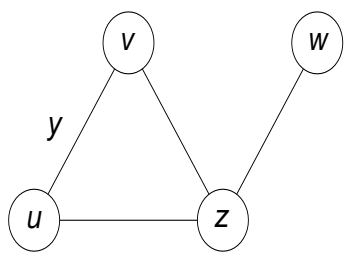

Figura 3-1: Exemplo de um grafo. 
A ordem de um grafo $G$ é dada pelo número de elementos do conjunto de nós, ou seja, pelo número de nós de $G$; a ordem do grafo apresentado na Figura 3.1 é 4. O grau de um nó é dado pelo número de arestas que lhe são incidentes. A Tabela 3.1 informa o grau de cada nó do grafo apresentado na Figura 3.1.

Tabela 3-1: Grau de cada um dos nós do grafo apresentado na Figura 3.1.

\begin{tabular}{ll}
\hline Nó & Grau \\
\hline$w$ & 1 \\
$u$ & 2 \\
$v$ & 2 \\
$z$ & 3 \\
\hline
\end{tabular}

Um caminho é uma seqüência de nós, tal que de cada um dos nós exista uma aresta distinta, para o nó seguinte. Além disso, se nenhum dos nós no caminho se repete, o caminho é chamado de caminho simples ou cadeia. O comprimento do caminho é o número de arestas que o caminho usa. Dois caminhos são independentes se não tiverem nenhum nó em comum, exceto o primeiro e o último.

Se um caminho começa e acaba no mesmo nó, este caminho é chamado de ciclo. Um exemplo de ciclo é a sequência de arestas $\{u, v\},\{v, z\},\{z, u\}$ da Figura 3.1, ou o caminho $\{u, v, z, u\}$ da mesma Figura 3.1.

Um par de nós em um grafo é um par conexo, se existir um caminho entre eles. Um grafo $G(V, A)$ é um grafo conexo, se todo par de nós em $G(V, A)$ for um par conexo.

Diz-se que $H$ é um subgrafo conexo máximo de um grafo $G$, se o único subgrafo conexo contendo $H$ é o próprio $H$. Um subgrafo conexo $H$ máximo também é chamado de componente. Um grafo $G$ é conexo, se o número de seus componentes for igual a um.

Um grafo chama-se acíclico se não contém ciclos. Uma árvore é um grafo conexo acíclico. Seja $G(V, A)$ um grafo de ordem $n>2$; as propriedades seguintes são equivalentes, para caracterizar o grafo $G$ como uma árvore:

- $G$ é conexo e acíclico;

- $G$ é acíclico e tem $n-1$ arestas;

- $G$ é conexo e tem $n-1$ arestas;

- $G$ é acíclico e por adição de uma aresta se cria um ciclo e somente um; 
- $G$ é conexo, mas deixa de sê-lo se uma aresta é eliminada (todas as arestas são pontes $\left.{ }^{3}\right)$.

- Todo par de nós de $G$ é unido por uma e somente uma cadeia simples.

Um grafo formado por um conjunto de árvores é chamado de floresta. Logo, cada componente de uma floresta é uma árvore. No caso de uma floresta com apenas uma árvore, tem-se uma floresta conexa. Assim, uma árvore é uma floresta conexa.

Podemos definir um dos nós da árvore como nó raiz, ou seja, nó tomado com sendo referência e pode ter grau maior ou igual a um. Nós que possuem grau um são chamados nós terminais, exceto se for o nó raiz. Uma árvore geradora (spanning tree) de um grafo $G$ é qualquer subárvore de $G$ que contenha todos os nós $\operatorname{de} G$.

\subsubsection{Representação de SDs através de Grafos}

Para entender como funciona a representação de um SD através de grafo, devemos lembrar inicialmente que um SD pode ser visto como um conjunto de alimentadores, cada um composto por um ou mais setores (lembrando que um setor corresponde a um conjunto de barras e linhas sem a presença de chaves seccionadoras).

Cada alimentador pode ser então representado através de uma árvore de grafo, na qual os nós representam os setores e as arestas (linhas conectando os nós do grafo) as chaves seccionadoras. A Figura 3.2 apresenta uma floresta de grafo que pode ser vista como um SD com três alimentadores (três árvores). As arestas em linhas cheias representam chaves NFs e as arestas em linhas tracejadas as chaves NAs. Os nós 1, 2 e 3 são raízes das árvores 1, 2 e 3, respectivamente, e representam barras em três subestações distintas.

3 Uma aresta é dita ser uma ponte, se sua remoção provoca uma redução na conexidade do grafo. 


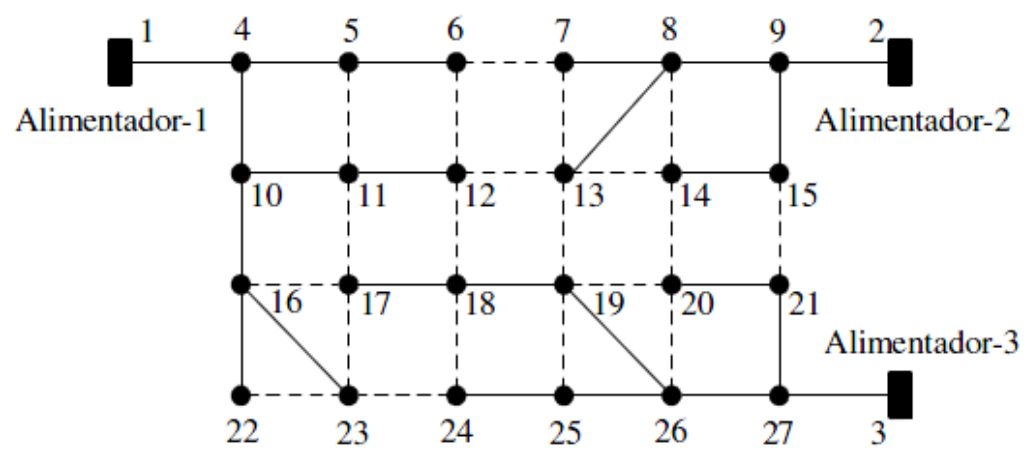

Figura 3-2: Representação através de grafo de um SD com três alimentadores.

\subsection{Formulação Matemática}

Uma formulação genérica para problemas de reconfiguração de redes em SDs pode envolver seguintes objetivos:

1. Minimização da(s) área(s) fora de serviço;

2. Número de chaveamentos;

E as seguintes restrições operacionais:

1. Manter a estrutura radial do sistema;

2. Áreas jusantes do setor em falta (que ficaram fora do serviço) devem ser atendidas quando possível;

3. A carga dos alimentadores não pode ultrapassar a capacidade limite da subestação;

4. A capacidade de condução de corrente elétrica das linhas e chaves deve ser respeitada;

5. A queda de tensão em qualquer barra do SD não deve exceder o limite permissível.

Assim, o problema de reconfiguração de redes de SD pode ser formulado, de uma forma geral, como segue (A. C. B. Delbem et al. 2005):

Min. $E(F)$

$$
\text { s.a. }\left\{\begin{array}{c}
H(F)=0 \\
I(F) \leq 0 \\
\text { F ser uma floresta, }
\end{array}\right.
$$


onde,

- F - grafo corresponde a uma configuração do sistema, onde cada árvore corresponde a um alimentador conectado a uma subestação;

- $\mathrm{E}(\mathrm{F})$ - função objetivo.

A função objetivo contém um ou mais dos seguintes componentes:

- $\phi(\mathrm{F})$ - número de barras de carga fora de serviço para uma topologia de rede radial (uma floresta F);

- $\varphi(\mathrm{F})$ - perdas de potência no sistema para F;

- $\psi\left(\mathrm{F}_{2} \mathrm{~F}_{0}\right)$ - número de manobras de chaves para obter uma dada configuração $\mathrm{F}$ a partir da configuração original $\mathrm{F}_{0}$.

- $\mathrm{H}(\mathrm{F})$ - representa as equações de fluxo de carga (restrições de igualdade);

- $\mathrm{I}(\mathrm{F})$ - representa as restrições operacionais da rede (restrições de desigualdade).

As restrições $\mathrm{H}(\mathrm{F})$ que representam as equações de fluxo de carga podem ser representadas por um sistema linear do tipo $A x=b$, no qual:

- A - matriz incidência de F;

- $\mathrm{x}$ - vetor de corrente de linha;

- b - vetor contendo as correntes de carga nas barras $\left(b_{i} \leq 0\right)$ ou as correntes injetadas nas subestações $\left(b_{i}>0\right)$.

As restrições operacionais $\mathrm{I}(\mathrm{F})$ corresponde à reconfiguração de redes em sistemas de distribuição geralmente incluem:

- Limitante superior de corrente $\bar{x}_{\mathrm{j}}$ para cada corrente de linha $x_{j}$ (carregamento da rede);

- Máxima injeção de corrente $\bar{b}_{i}$ em cada subestação (carregamento da subestação);

- Limitante inferior para a tensão no nó v para cada nó i.

Para resolução desse tipo de problema através de AEs são necessárias algumas modificações na formulação apresentada em (3.1). São inseridos fatores de penalidades, a fim de penalizar configurações da rede que violarem as restrições operacionais I(F) (Goldberg 1989). 
Face ao exposto, o problema pode ser reformulado como segue:

$$
\begin{gathered}
\text { Min. } E(F)+|\Omega I(F)| \\
\text { s.a. }\left\{\begin{array}{c}
H(F)=0 \\
F \text { ser uma floresta, }
\end{array}\right.
\end{gathered}
$$

onde $\Omega$ é a matriz diagonal com os seguintes elementos:

$$
\begin{aligned}
& w_{11}=\left\{\begin{array}{c}
w_{x}, \text { se, } \text { pelo menos para um } j, x_{j}>\bar{x}_{j} \\
0, \text { caso contrário } ;
\end{array}\right. \\
& w_{22}=\left\{\begin{array}{c}
w_{s}, \text { se, } \text { pelo menos para um } i, b_{i}>\bar{b}_{i} \\
0, \text { caso contrário } ;
\end{array}\right. \\
& w_{33}=\left\{\begin{array}{c}
w_{v}, \text { se, } \text { pelo menos para um } i, v_{i}>\underline{v} \\
0, \text { caso contrário } ;
\end{array}\right.
\end{aligned}
$$

os pesos $w_{\mathrm{X}}, \mathrm{w}_{\mathrm{S}}$ e $\mathrm{w}_{\mathrm{v}}$ são valores positivos e, |.| é a norma usual (Gradshteyn \& Ryzhik 2000), isto é a norma $L_{1}$ de um vetor $z$ de tamanho $n$ é dada por $\sum_{r=1}^{n}\left|Z_{r}\right|$.

Para verificar se uma dada configuração atende às restrições operacionais do problema $(I(F))$, é necessária a execução de um fluxo de carga, que deve ser eficiente computacionalmente em virtude da grande quantidade de configurações que devem ser analisadas na busca pela configuração "ótima”. Para isso, torna-se necessária a utilização de estruturas de dados eficientes computacionalmente, para representação da topologia elétrica dos SDs, bem como de eficientes algoritmos para cálculo de fluxo de carga. Nesse contexto importa destacar que para facilitar o cálculo de fluxo de potência, em problemas de reconfiguração de redes as cargas podem ser modeladas como corrente constante e empregam-se métodos para cálculo de fluxo de potência monofásicos de varredura inversa/direta.

Dentre os métodos de varredura inversa/direta existentes na literatura, para o problema em questão, destaca-se o soma de correntes. Para aplicar esse método, as barras da rede devem estar ordenadas segundo um modelo conhecido como Pai-Filho (MPF). Dessa forma, pode-se calcular o fluxo de corrente partindo dos nós terminais (nós folhas) em direção à subestação (nó raiz); enquanto as tensões podem ser obtidas de forma encadeada partindo da subestação até as barras terminais. 
Para tornar ainda mais simples a formulação de problemas de reconfiguração de redes em SDs através de AEs, conforme apresentado no capítulo 2 em (Moussa et al, 2009; Santos et al, 2010; Sanches et al 2011) foi proposta a utilização da RNP e de seus operadores. Haja vista a RNP e seus operadores gerarem exclusivamente configurações factíveis, através da utilização dos mesmos o problema descrito na Equação (3.2) pode ser reescrito como segue:

$$
\begin{gathered}
\text { Min. } E(F)+|\Omega I(F)| \\
\text { s.a. }\left\{\begin{array}{c}
H(F)=0 \\
\text { F ser dado pelos operadores da RNP. }
\end{array}\right.
\end{gathered}
$$

Com o uso da RNP evita-se a utilização de um algoritmo de busca (Cormen 2002) para obter o MPF, pois a RNP garante a ordenação, tornando o fluxo de carga mais eficiente que os fluxos de carga convencionais. Além disso, o uso do MPF garante que as restrições de igualdade $\mathrm{H}(\mathrm{F})$ em (3.3) sejam atendidas. Assim, fazendo uso da propriedade da RNP de permitir o armazenamento dos nós de acordo com o MPF, pode-se escrever o problema em pauta da seguinte forma:

$$
\begin{gathered}
\text { Min. } E(F)+|\Omega I(F)| \\
\text { s.a. }\left\{\begin{array}{c}
\text { Utilizar MPF com RNP } \\
\text { F ser dado pelos operadores da RNP }
\end{array}\right.
\end{gathered}
$$

A utilização da RNP e seus operadores juntamente com o fluxo de carga pelo MPF com RNP tornam a modelagem matemática do problema mais simples, o que pode ser constatado comparando-se as equações (3.4) e (3.1). Além disso, tendo em vista que a RNP e seus operadores produzem exclusivamente configurações factíveis, somente às restrições de queda de tensão, carregamento na rede e carregamento nas subestações serão consideradas na formulação matemática do problema.

\subsection{Métodos Para Cálculo de Fluxo de Carga}

Para avaliar as soluções geradas faz-se necessário o cálculo do fluxo de carga para essa configuração, que consiste na obtenção das condições de operações 
(tensões complexas nas barras, fluxos de potência nas linhas e transformadores) em função da topologia do sistema e dos níveis de demanda e geração de potência.

Aproveitando a característica radial dos SDs, desenvolveram-se métodos específicos para cálculo de fluxo de potência em SDs, que foram chamados de métodos de varredura direta / inversa. A principal vantagem desses métodos, em relação aos métodos tradicionais (Newton-Raphson, Desacoplado Rápido e versões modificadas dos mesmos), é a não exigência de processos de fatoração de matrizes que se tornam mal condicionadas em função das características particulares dos SDs, como, por exemplo, baixa relação X/R (reatância/resitência) dos parâmetros dos alimentadores, trechos com impedâncias relativamente baixas associados com trechos com impedâncias altas e grande número de cargas distribuídas.

\subsubsection{Métodos de Varredura Direta / Inversa}

Os métodos de varredura Direta / Inversa são bastante empregados em SDs radiais (ou fracamente malhados), nos quais podemos representar a rede como uma árvore, cujo nó raiz corresponde à subestação, como ilustrado na figura 3.3.

Os métodos de varredura direta / inversa recebem esse nome devido ao fato de apresentarem um processo iterativo que faz o percurso das barras extremas em direção à subestação e vice-versa. Inicialmente se realiza a varredura inversa (Backward) que consiste em, partindo-se dos nós extremos (nós folhas) e usando uma estimativa inicial das tensões nodais, calculam-se as correntes ou fluxos de potência nas linhas até a subestação (nó raiz). A partir do resultado da injeção de corrente ou potência do nó raiz, e do valor conhecido da tensão nessa barra, procede-se a etapa de varredura direta (Forward), que consiste em recalcular os valores de tensão das barras da rede até os nós extremos. Esse processo é repetido até que algum critério de convergência seja atendido. 


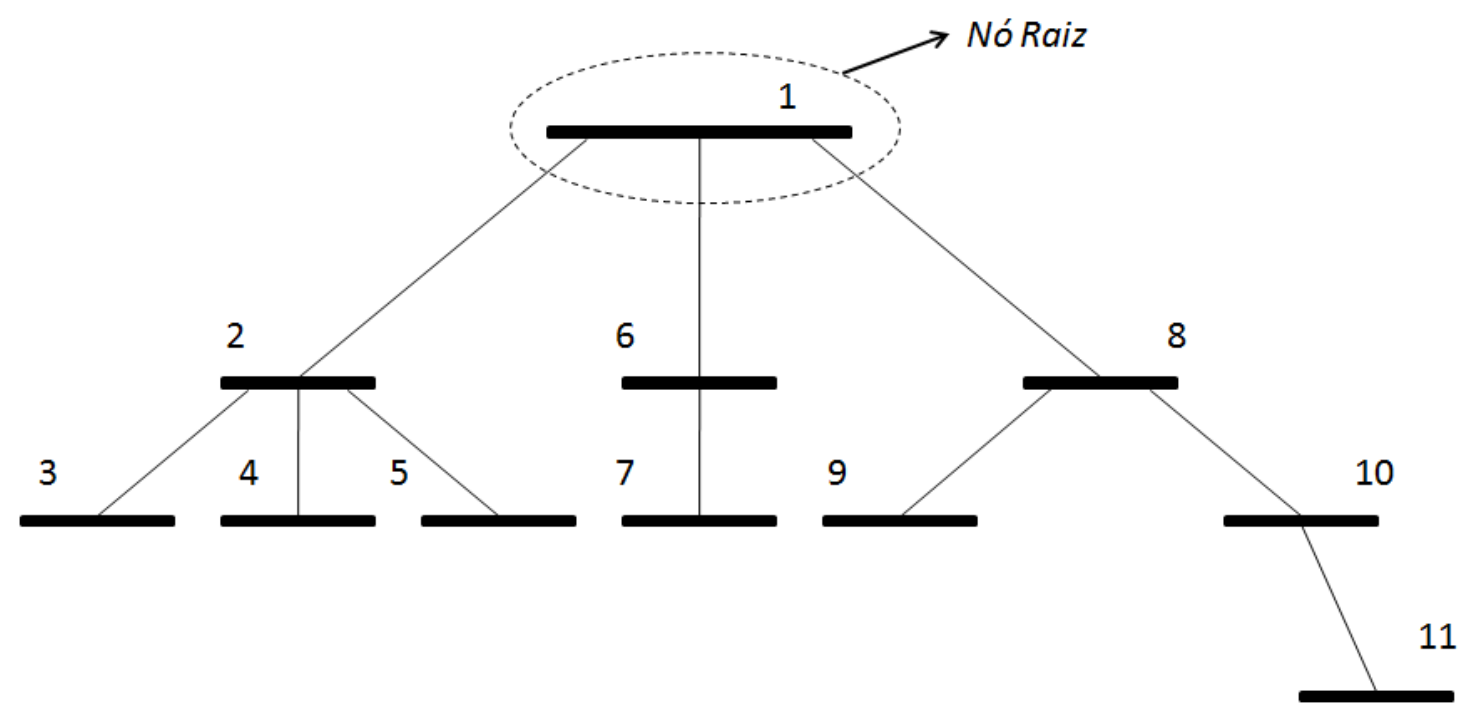

Figura 3-3: Exemplo de SDR

Existem duas versões de métodos de varredura Direta / Inversa (Srinivas, 2000):

- Soma de Correntes (Shirmohammadi et al. 1988);

- Soma de Potência (Baran \& Wu 1989); (Cespedes 1990) e (Haque 1996).

\subsubsection{Método de Soma de Correntes}

O método de Soma de Correntes (Shirmohammadi et al. 1988) foi desenvolvido para SDs radiais. Entretanto, o mesmo pode ser aplicado para SDs fracamente malhados. Esse método é conceitualmente simples e apresenta um bom desempenho.

Considerando um sistema de distribuição radial com $n$ nós e $l$ ramos $(l=n-$ 1), dada a tensão no nó raiz e assumindo a tensão com magnitude igual a 1(um) p.u. com ângulo igual a 0 (zero) graus para todas as demais barras do sistema, o método de resolução consiste em três passos:

1. Cálculo da corrente nodal: na iteração $k$, as injeções de correntes nodais são calculadas através da seguinte expressão:

$$
I_{i}^{(k)}=\left(\frac{S_{i}}{V_{i}^{(k-1)}}\right)^{*}-Y_{i}^{s h} V_{i}^{(k-1)}, i=1,2, \ldots, n,
$$


em que $V_{i}^{(k-1)}$ é a tensão na barra i, calculada durante a iteração $(k-1), S_{i}$ é a injeção de potência complexa especificada na barra i, $\mathrm{Y}_{\mathrm{i}}^{\text {sh }}$ é a soma de todos os elementos shunt da barra i; e n é o número total da representação radial do SDs.

2. Etapa Backward (varredura Inversa): esta etapa se inicia a partir das linhas conectadas às barras mais extremas do sistema (barras com maiores profundidades) e movendo-se até as linhas conectadas à subestação, ou seja, ao nó raiz (com profundidade zero), calcula-se as correntes $\left(C_{L}\right)$ na linha $L$, que liga uma barra $N_{2}$ à sua antecessora $N_{1}$, conforme ilustrado na Figura 3.4, da seguinte forma:

$$
C_{L}^{(k)}=-I_{N 2}^{(k)}+\sum(\text { Correntes nas linhas que saem do nó N2) }
$$

onde $\mathrm{L}=\mathrm{p}, \mathrm{p}-1, \ldots, 1, \mathrm{I}_{\mathrm{N} 2}^{(\mathrm{k})}$ é a injeção no nó $\mathrm{N}_{2}$ e $\mathrm{p}$ é o número de linhas que possui o sistema;

3. Etapa Forward (varredura Direta): nesta etapa atualizam-se as tensões complexas nas barras, iniciando pelas barras que estão conectadas ao nó raiz (subestação) e seguindo até as barras extremas. Por exemplo, para atualização da tensão na barra $\mathrm{N}_{2}$, utilizando a tensão na iteração $\mathrm{k}$ de $\mathrm{N}_{1}$ e o fluxo de corrente na linha calculado no passo 2, temos:

$$
V_{N 2}^{(k)}=V_{N 1}^{(k)}-Z_{L} C_{L}^{(k)}, L=1,2, \ldots, p,
$$

onde $\mathrm{Z}_{\mathrm{L}}$ é a impedância sério da linha $\mathrm{L}$;

4. Etapa de teste de convergência: os passos 2, 3 e 4 são repetidos até que seja alcançado o critério de convergência. Usualmente o critério adotado é o maior erro de potência ativa e reativa nas barras do sistema, tal que esse erro seja menor que uma tolerância $\varepsilon$ previamente estabelecida. Assim, a potência complexa injetada na barra $i$, na iteração $k$, é calculada da seguinte forma:

$$
S_{i}^{(k)}=V_{i}^{(k)} I_{i}^{(k)^{*}}-Y_{i}\left|V_{i}^{(k)}\right|^{2}, i=1,2, \ldots, n,
$$


Portanto o erro de potência ativa e reativa na barra i é calculado utilizando a expressão 3.9 .

$$
\begin{aligned}
\Delta P_{i}^{(k)} & =\operatorname{Re}\left[S_{i}^{(k)}-S_{i}\right] \\
\Delta Q_{i}^{(k)} & =\operatorname{Im}\left[S_{i}^{(k)}-S_{i}\right] \quad i=1,2, \ldots, n,
\end{aligned}
$$

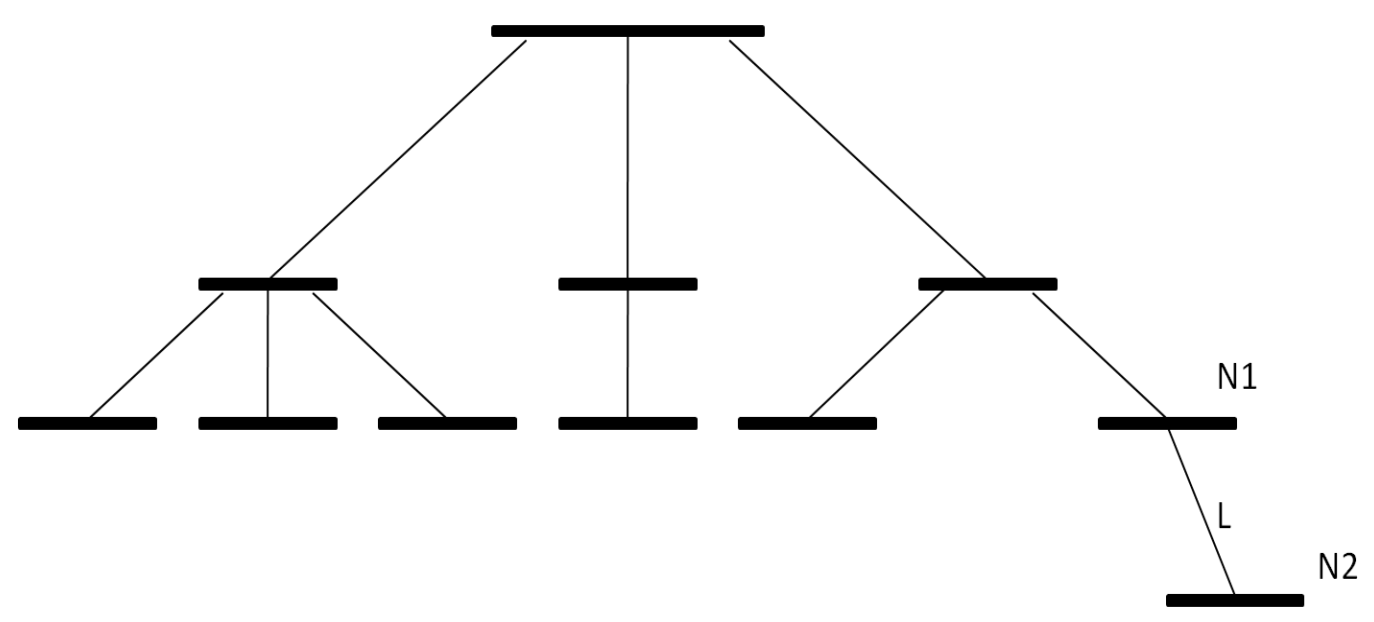

Figura 3-4: Passo Backward sweep.

\subsubsection{Método de Soma de Potência}

O método de soma de potência (Baran \& Wu 1989); (Cespedes 1990) e (Haque 1996) é o método mais difundido na literatura. Tal método é relativamente simples, do ponto de vista conceitual, e apresenta um desempenho eficiente na resolução de problemas de fluxo de carga em SDs radiais (Brandini 2000).

Para o cálculo dos fluxos de potência nos ramos da rede, adotam-se as equações para o cálculo de fluxos em rede radial desenvolvida e adaptado por (Haque 1996). A Figura 3.5 ilustra duas barras ( $k$ e $m$ ), de um alimentador, ligadas por um ramo $i$ que possui uma impedância $Z_{i}$. Então as equações de fluxo de carga utilizadas na etapa Backward (varredura Inversa) são: 


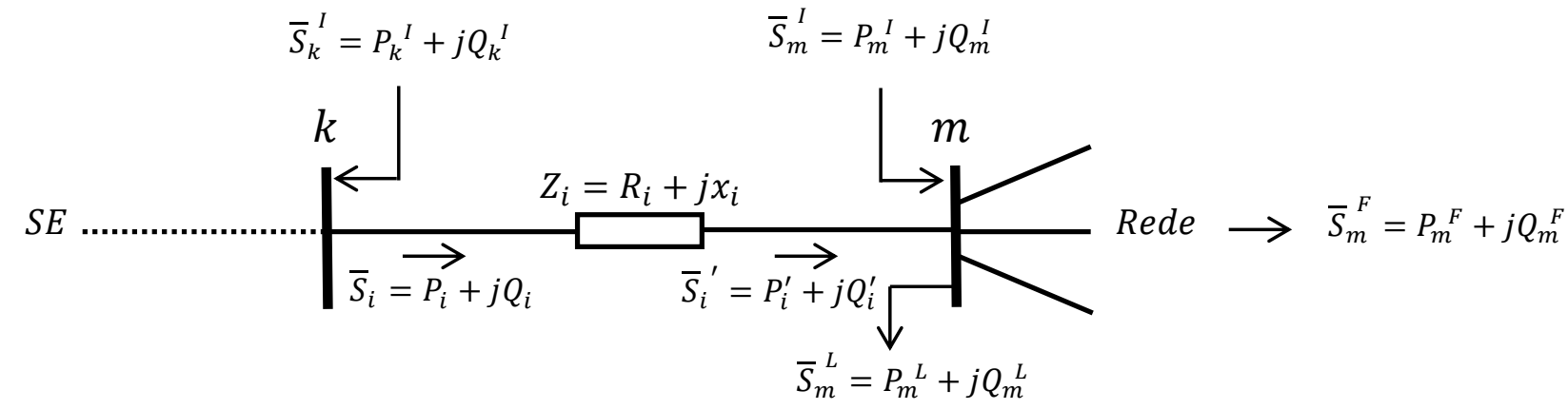

Figura 3-5: Duas barras de um sistema genérico.

- Fluxo de potência na impedância do ramo $i$ chegando na barra $m$ :

$$
\bar{S}_{i}^{\prime}=\bar{S}_{m}^{L}+\bar{S}_{m}^{F}-\bar{S}_{m}^{I},
$$

onde $L$ significa carga; $F$ fluxo e $I$ injeção.

Escrevendo em termos de potência ativa e reativa:

$$
\left\{\begin{array}{l}
P_{i}^{\prime}=P_{m}{ }^{L}+P_{m}{ }^{F}-P_{m}{ }^{I} \\
Q_{i}^{\prime}=Q_{m}{ }^{L}+Q_{m}^{F}-Q_{m}{ }^{I}
\end{array}\right.
$$

- Fluxo de potência no ramo $i$ saindo da barra $k$ :

$$
S_{i}=S_{i}{ }^{\prime}+Z_{i} \cdot\left|I_{i}\right|^{2}
$$

onde:

$$
I_{i}=\frac{\left|S_{i}{ }^{\prime}\right|}{V_{m}}
$$

desse modo:

$$
\begin{aligned}
& S_{i}=P_{i}^{\prime}+j Q_{i}^{\prime}+\left[\left(R_{i}+j x_{i}\right) \cdot \frac{{P_{i}^{\prime}}^{2}+{Q_{i}^{\prime}}^{2}}{V_{m}}\right]
\end{aligned}
$$

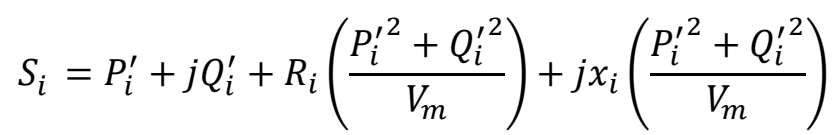

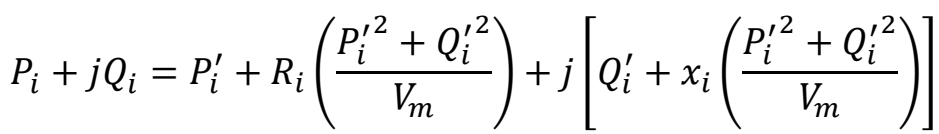


Assim:

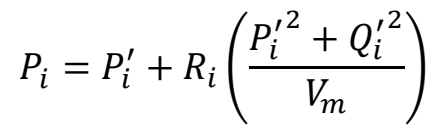

$$
\begin{aligned}
& Q_{i}=Q_{i}^{\prime}+x_{i}\left(\frac{{P_{i}^{\prime}}^{2}+Q_{i}^{\prime 2}}{V_{m}}\right) \text {, onde: }
\end{aligned}
$$

- $\quad P_{i}$ é o fluxo de potência ativa que sai da barra $k$ no ramo $i$;

- $Q_{i}$ é o fluxo de potência reativa que sai da barra $k$ no ramo $i$;

- $P_{i}^{\prime}$ é o fluxo de potência ativa que chega na barra $m$ no ramo $i$;

- $Q_{i}^{\prime}$ é o fluxo de potência ativa que chega na barra $m$ no ramo $i$;

- $V_{m}$ tensão na barra $m$;

- $R_{i}$ resistência no ramo $i$;

- $\quad x_{i}$ reatância no ramo $i$;

A seguir apresentam-se as equações utilizadas na etapa Forward (varredura Direta):

Considerando $\theta_{k}=0$ ( $V_{k}$ será apenas módulo):

$$
\begin{gathered}
V_{m}=V_{k}-I_{i} \cdot Z_{i}=V_{k}-\frac{S_{i}{ }^{*}}{V_{k}{ }^{*}}\left(R_{i}+j x_{i}\right) \\
V_{m}=V_{k}-\left[\frac{P_{i}^{\prime}-j Q_{i}^{\prime}}{V_{k}}\left(R_{i}+j x_{i}\right)\right] \\
V_{m}=V_{k}-\left[\frac{P_{i}^{\prime} \cdot R_{i}+j P_{i}^{\prime} \cdot x_{i}-j Q_{i}^{\prime} \cdot R_{i}+Q_{i}^{\prime} \cdot x_{i}}{V_{k}}\right] \\
V_{m}=\left(V_{k}-\frac{P_{i}^{\prime} \cdot R_{i}}{V_{k}}-\frac{Q_{i}^{\prime} \cdot x_{i}}{V_{k}}\right)-j\left(\frac{P_{i}^{\prime} \cdot x_{i}-Q_{i}^{\prime} \cdot R_{i}}{V_{k}}\right)
\end{gathered}
$$


A partir da equação acima, temos a equação para atualização das magnitude das tensões nas barras:

$$
V_{m}=\sqrt{V_{k}{ }^{2}-2\left(P_{i}^{\prime} \cdot R_{i}+Q_{i}^{\prime} \cdot x_{i}\right)+\frac{\left(P_{i}^{\prime 2} \cdot R_{i}^{2}+{Q_{i}^{\prime}}^{2} \cdot x_{i}^{2}\right)}{V_{k}{ }^{2}}}, \text { onde: }
$$

- $V_{m}$ tensão na barra $m$;

- $\quad V_{k}$ tensão na barra $k$;

- $R_{i}$ resistência no ramo $i$;

- $x_{i}$ reatância no ramo $i$.

Da equação 3.12 encontra-se a equação de atualização do ângulo da tensão nas barras:

$$
\theta_{m}=-\tan ^{-1}\left(\frac{K_{1}}{K_{2}}\right)
$$

$$
\text { Se } \theta_{k} \neq 0 \longrightarrow \theta_{m}=\theta_{k}-\tan ^{-1}\left(\frac{K_{1}}{K_{2}}\right) \text {, onde }:
$$

- $K_{1}=\left(\frac{P_{i}^{\prime} \cdot x_{i}-Q_{i}^{\prime} \cdot R_{i}}{V_{k}}\right)$;

- $K_{2}=V_{k}-\frac{\left(P_{i}^{\prime} \cdot R_{i}+Q_{i}^{\prime} \cdot x_{i}\right)}{V_{k}}$.

O algoritmo deste método para o cálculo do fluxo de carga é composto pelos seguintes passos:

1. Assumir que as tensões iniciais em todas as barras são iguais à tensão da subestação (nó raiz);

2. Etapa Backward (varredura Inversa): iniciando pelas barras extremas do sistema, calculam-se os fluxos de potência ativa e reativa para cada ramo utilizando as equações 3.10 e 3.11;

3. Etapa Forward (varredura Inversa): partindo do nó raiz (subestação) calculam-se as atualizações da magnitude e do ângulo das tensões nas barras utilizando as equações 3.13 e 3.14;

4. Etapa de teste de convergência: verificar a variação da magnitude e da fase das tensões nodais obtidas na iteração atual na anterior. Se as diferenças forem maiores ou iguais a uma tolerância próxima de zero, o processo é repetido a partir do passo 2; caso contrário, encerram-se os cálculos. 


\subsection{Modelagem da Carga}

A forma construtiva e o princípio físico de funcionamento de cada equipamento elétrico definem seu comportamento em regime permanente senoidal perante variações do nível de tensão de fornecimento, ou seja, a potência elétrica absorvida por uma carga depende da sua natureza e pode variar em função da tensão a ela aplicada (Kagan et al. 2005). Assim, as cargas oferecem dificuldade para sua modelagem, onde cada conjunto de consumidores possui diferentes características e nem sempre são previsíveis. Portanto, deve-se encarar a carga como uma representação esquemática na qual se faz referência ao fato de serem variáveis e apresentarem duas componentes, potência ativa e reativa (M. R. Carvalho 2006)

No estudo de fluxo de potência, a modelagem da carga assume um papel importante nos resultados obtidos, possuindo influência decisiva na qualidade dos resultados, podendo conduzir a valores imprecisos com prejuízo significativo para o sistema elétrico, à medida que a representação das cargas não conduz a realidade do estado de regime permanente (Souza 1995).

Qualquer carga é dependente da tensão aplicada e da frequência da tensão de suprimento. Entretanto, no contexto deste trabalho a modelagem da carga será realizada considerando apenas a sua dependência da tensão aplicada.

Existem vários modelos para representação do comportamento da carga em função da tensão aplicada, dentre os quais se destacam (Kagan et al. 2005)

- cargas de potência constante com a tensão;

- cargas de impedância constante com a tensão;

- cargas de corrente constante com a tensão.

Apresenta-se, a seguir, uma descrição sucinta de cada um desses modelos, sendo que, para melhor entendimento, considerar-se-á o sistema de duas barras apresentado na Figura 3.6. 


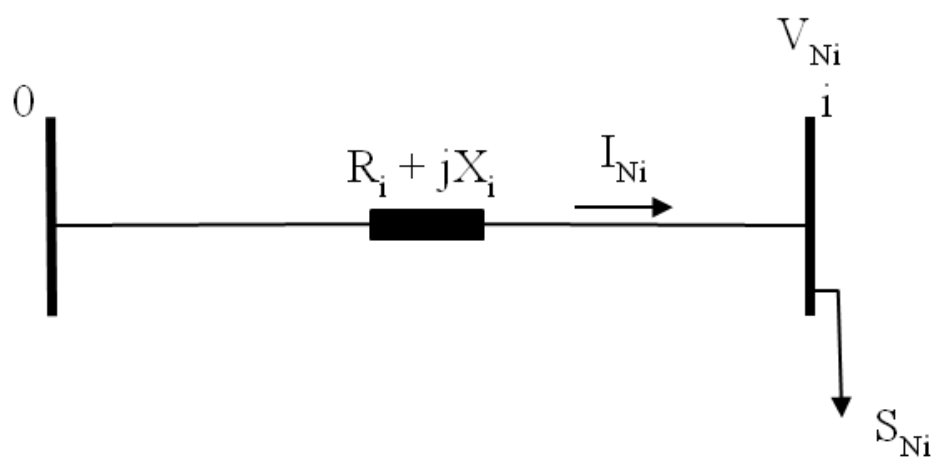

Figura 3-6: Sistema de duas barras radial.

\subsubsection{Carga de Potência Constante com a Tensão}

De acordo com este modelo, as potências ativas e reativas da carga não variam com a tensão de suprimento, ou seja, independentemente do valor da tensão de suprimento, os valores de potência são iguais aos valores nominais. Portanto, baseado no sistema da Figura 3.6, a potência absorvida por uma carga monofásica, com tensão nominal $\dot{\mathrm{V}}_{\mathrm{Ni}}=\mathrm{V}_{\mathrm{Ni}} \angle \theta_{\mathrm{i}}$, dada pela expressão:

$$
\dot{S}_{N i}=S_{N i} \angle \alpha_{i}=P_{i}+j Q_{i}
$$

é constante para qualquer valor de tensão.

Por exemplo, aplicando uma tensão qualquer $\dot{\mathrm{V}}_{\mathrm{i} 2}=\mathrm{V}_{\mathrm{i} 2} \angle \theta_{\mathrm{i} 2}$ na carga $\mathrm{i}$, o valor da corrente será:

$$
\dot{I}_{i 2}=\frac{\dot{S}_{N i}^{*}}{\dot{V}_{i 2}^{*}}=\frac{S_{N i} \angle-\alpha_{i}}{V_{i 2} \angle-\theta_{i 2}}=\frac{S_{N i}}{V_{i 2}} \angle \theta_{i 2}-\alpha_{i}
$$

Observa-se que a potência absorvida $\dot{S}_{\mathrm{Ni}}$ se mantém constante, e que a corrente absorvida é inversamente proporcional à tensão aplicada.

Para cargas trifásicas equilibradas o equacionamento é idêntico, desde que se considerem as grandezas envolvidas em por unidade.

\subsubsection{Carga de Impedância Constante com a Tensão}

O modelo da carga de impedância constante com a tensão possui característica de ter sua impedância invariante independentemente do valor da 
tensão aplicada, e é obtida a partir da potência ativa e reativa absorvida pela carga quando alimentada com tensão nominal ou de referência, potência absorvida pela carga $\mathrm{i}$ quando suprida por tensão nominal $\dot{\mathrm{V}}_{\mathrm{Ni}}=\mathrm{V}_{\mathrm{Ni}} \angle \theta_{\mathrm{i}}$ (Equação 3.15), obtém para impedância:

$$
\dot{Z}_{\text {cons }}=\frac{V_{N i}^{2}}{\dot{S}_{N i}^{*}}=\frac{V_{N i}^{2}}{S_{N i}} \angle \alpha_{i}=R+J X
$$

Face ao exposto, aplicando uma tensão qualquer $\dot{\mathrm{V}}_{\mathrm{i} 2}=\mathrm{V}_{\mathrm{i} 2} \angle \theta_{\mathrm{i} 2}$ sobre carga $\mathrm{i}$, o valor da potência absorvida será:

$$
\dot{S}_{i 2}=\dot{\mathrm{V}}_{\mathrm{i} 2} \dot{\mathrm{I}}^{*}=\dot{\mathrm{V}}_{\mathrm{i} 2} \frac{\dot{V}_{i 2}^{*}}{\dot{Z}_{\text {cons }}^{*}}=\frac{V_{i 2}{ }^{2}}{\frac{V_{N i}^{2}}{\dot{S}_{N i}}}=\left(\frac{\mathrm{V}_{\mathrm{i} 2}}{\mathrm{~V}_{\mathrm{Ni}}}\right)^{2} \dot{S}_{N i}
$$

Observa-se que a impedância $\dot{Z}_{\text {cons }}$ se mantém constante, e que a potência absorvida pela carga varia quadraticamente com a tensão aplicada.

\subsubsection{Carga de Corrente Constante com a Tensão}

Este modelo engloba cargas que têm a característica de manter os valores da intensidade de corrente e do ângulo de defasagem invariantes, independentemente do valor da tensão aplicado. Observe que para este modelo, os valores da intensidade de corrente e do ângulo de defasagem são aqueles obtidos com a carga suprida por a tensão nominal. Assim, quando aplicado uma tensão nominal $\dot{V}_{N i}=V_{N i} \angle \theta_{i}$ sobre a carga $i$ da Figura 3.6 temos potência absorvida (Equação 3.15):

Portanto, a corrente absorvida pela carga quando aplicado a tensão nominal é:

$$
\dot{I}_{N i}=\frac{\dot{S}_{N i}^{*}}{\dot{V}_{N i}^{*}}=\frac{S_{N i} \angle-\alpha_{i}}{V_{N i} \angle-\theta_{i}}=\frac{S_{N i}}{V_{N i}} \angle \theta_{i}-\alpha_{i}=I_{N i} \angle \theta_{i}-\alpha_{i}
$$

Agora, quando se aplica uma tensão $\dot{V}_{i 2}=V_{i 2} \angle \theta_{i 2}$ qualquer sobre carga $i$, o valor da corrente será:

$$
\dot{I}_{i 2}=I_{N i} \angle \theta_{i 2}-\alpha_{i}
$$

ou seja, o módulo da corrente $I_{N i}$ e o ângulo de defasagem $\alpha_{i}$ permanecem constantes, e a potência absorvida será dada por:

$$
\begin{gathered}
\dot{S}_{i 2}=\dot{V}_{i 2} \dot{I}_{i 2}^{*}=V_{i 2} \angle \theta_{i 2} I_{N i} \angle-\left(\theta_{i 2}-\alpha_{i}\right) \\
\dot{S}_{i 2}=V_{i 2} I_{N i} \angle \alpha_{i}
\end{gathered}
$$




$$
\dot{S}_{i 2}=\frac{V_{i 2}}{V_{N i}} \dot{S}_{N i}
$$

ou seja, a potência absorvida pela carga varia linearmente com a tensão aplicada.

Quando o estudo de fluxo de carga é realizado assumindo-se carga modelada por corrente constante com a tensão, o processo de solução torna-se direto, isto é, sem iteração. Isto ocorre quando se despreza a rotação de fase da tensão, que permite o cálculo da queda de tensão, nos trechos dos alimentadores, através de números reais. O fluxo de carga assumindo-se carga modelada por corrente constante com a tensão será iterativo quando se considera a rotação de fase da tensão. Nessa situação, realiza-se o cálculo da queda de tensão, nos trechos dos alimentadores, através de números complexos (representação complexa da rede).

Importa destacar que estudos demonstram que os resultados obtidos através da solução direta, que se baseia em aproximações, estão muito próximos aos valores exatos.

\subsection{Representação Nó-Profundidade}

A representação Nó-Profundidade (RNP), proposta por (A. Delbem et al. 2004), baseia-se nos conceitos de caminhos e de profundidade do nó em um grafo acíclico e conexo (árvore). Basicamente a RNP é composta por uma lista linear contendo os nós da árvore e suas respectivas profundidades, formando pares do tipo $\left(n_{x}, p_{x}\right)$, onde $n_{x}$ é o nó e $p_{x}$ é a profundidade. Vale lembrar que profundidade de um nó (ou vértice) num grafo é igual à distância deste nó até o nó raiz do grafo, distância esta correspondente ao número de nós existentes no caminho percorrido desse nó até o nó raiz. A ordem em que os pares são dispostos na lista é importante.

Computacionalmente, esta lista é formada por uma matriz de dimensão $2 \times n$, sendo $n$ o número de nós. Os pares $n_{x}$ e $p_{x}$ são armazenados na primeira e segunda linha, respectivamente, conforme ilustrado na Figura 3.7b. Para armazenar um nó e a respectiva profundidade na RNP, utiliza-se um algoritmo de busca em profundidade (Cormen 2002). Portanto, o processo se inicia a partir do nó raiz da árvore, produzindo uma lista contendo os respectivos nós e sua profundidade em uma sequência apropriada, enquanto um nó $n_{x}$ é visitado.

Nó exemplo da árvore da Figura 3.7a, o nó 1 é inicialmente armazenado como nó raiz, ou seja, profundidade igual a 0 . Assim se realiza uma busca de 
profundidade na árvore, através dos ramos conectados ao nó raiz, para armazenar os demais nós juntamente com suas respectivas profundidades, as quais são sempre calculadas em relação ao nó raiz.

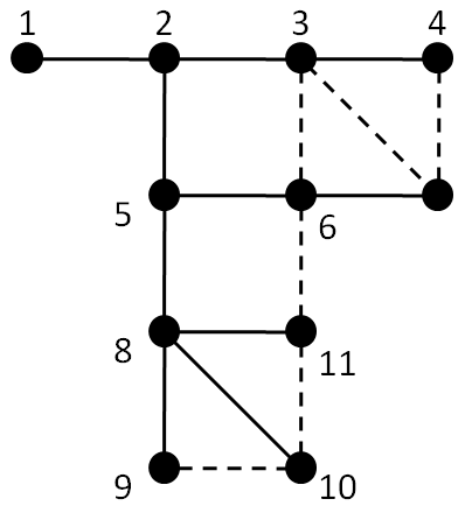

$\left[\begin{array}{c}\text { Profundidade } \\ \text { Nó }\end{array}\right]=\left[\begin{array}{lllllllllcc}0 & 1 & 2 & 3 & 2 & 3 & 4 & 3 & 4 & 4 & 4 \\ 1 & 2 & 3 & 4 & 5 & 6 & 7 & 8 & 9 & 10 & 11\end{array}\right]$

(a) Grafo

(b) Representação Nó-Profundidade

Figura 3-7: Exemplo de um grafo e sua RNP.

Uma alternativa interessante para implantação computacional da RNP é a utilização de listas encadeadas. Esta alternativa facilita tanto na construção de representações (tendo em vista a quantidade desconhecida de elementos que serão gerados), quanto na operação de corte ("poda") e inclusão ("plantio") de elementos nas árvores de grafo armazenadas nas RNPs. Para representar uma floresta possuindo $\left(N_{a}\right)$ árvores, teremos um conjunto de $\left(N_{a}\right)$ RNPs. A codificação de uma floresta é composta pela união da codificação de todas as árvores da mesma, sendo que a estrutura de dados da floresta pode ser facilmente implementada utilizando ponteiros e matrizes, onde cada ponteiro indica os pares $\left(n_{x}, p_{x}\right)$, ou seja, nó e sua profundidade na árvore da floresta.

\subsubsection{Operadores da RNP}

A fim de gerar novas florestas, a partir de uma floresta inicial representada computacionalmente através de RNPs, em (A. Delbem et al. 2004) e (Santos 2009) foram propostos dois operadores, chamados de PAO (do inglês, Preserve Ancestor Operator) e CAO (do inglês, Change Ancestor Operator), com características de operação distintas, porém produzindo resultados similares. 
Estes operadores produzem novas árvores $A^{\prime}$, quando aplicados a outras árvores $A$ de uma mesma floresta. Na prática, ao se aplicar o Operador PAO (ou CAO) em uma determinada árvore de uma floresta (composta por duas ou mais árvores), realiza-se a transferência de uma subárvore (parte podada) de uma árvore $A_{d e}$ (árvore origem) para outra árvore $A_{\text {para }}$ (árvore destino). Ao aplicar o operador PAO, a raiz da subárvore podada $A_{d e}$ será também a raiz dessa sub-árvore em $A_{\text {para }}$. Por outro lado, ao aplicar operador CAO, a subárvore podada terá um novo nó raiz, que poderá ser qualquer nó da subárvore podada diferente da raiz original. Sendo essa a diferença básica entre os operadores PAO e CAO (Lima 2009).

A RNP e seus operadores, quando aplicados à reconfiguração de redes, são utilizados com intuito de gerar novas configurações. Inicialmente, seleciona-se um indivíduo (uma floresta que representa toda a topologia elétrica de um SD). Em seguida aplicasse um dos operadores de mutação da RNP (PAO ou CAO) no mesmo, criando modificações nesse indivíduo (floresta) gerando um novo indivíduo (ou uma nova floresta).

\subsubsection{Operador PAO}

Para descrição do operador PAO, considera-se que os nós $p$ e a sejam previamente escolhidos. A RNP é implementada utilizando-se as matrizes, sendo conhecidos os índices de $p\left(i_{p}\right)$ e $a\left(i_{a}\right)$ Figura 3.8 a nas matrizes $A_{d e}$ e $A_{\text {para }}$, respectivamente.

O algoritmo do operador PAO segue os seguintes passos (Figura 3.8):

1. Determinam-se as posições $\left(i_{p}, i_{l}\right)$ dos índices na árvore $A_{d e}$, correspondente à subárvore enraizada no nó $p$. Conhecido $i_{p}$, é necessário encontrar apenas $i_{l}$, que corresponde ao índice do último nó na subárvore que tem o nó $p$ como raiz. O conjunto $\left(i_{p}, i_{l}\right)$ correspondente ao nó $p$, em $i_{p}$, consecutivos nós $x$ na segunda linha da matriz $A_{d e}$, tal que $i_{x}>i_{p}$ e $p_{x}>p_{p}$ (entre as linhas tracejadas na Figura $3.8 \mathrm{a}, p_{x}$ é a profundidade do nó $x$;

2. Copiam-se os dados do conjunto $\left(\mathrm{i}_{\mathrm{p}}, \mathrm{i}_{1}\right)$, da árvore $A_{\mathrm{de}}$, em uma matriz temporária $A_{\text {tmp }}$ (contendo os dados da sub-árvore que está sendo transferida); ver Figura 3.8b. A profundidade do nó x, do conjunto $\left(\mathrm{i}_{\mathrm{p}}, \mathrm{i}_{\mathrm{l}}\right)$, é atualizada utilizando a seguinte equação: $\mathrm{p}_{\mathrm{x}}=\mathrm{p}_{\mathrm{x}}-\mathrm{p}_{\mathrm{p}}+\mathrm{p}_{\mathrm{a}}+$ 
1, onde $\mathrm{p}_{\mathrm{x}}, \mathrm{p}_{\mathrm{p}} \mathrm{e} \mathrm{p}_{\mathrm{a}}$ são profundidades dos nós $\mathrm{x}, \mathrm{p}$ e a, respectivamente;

3. Cria-se matriz $A_{\text {para }}$, contendo os nós de $A_{\text {para }}$ e inserindo depois a matriz $A_{\text {tmp }}$ na posição $i_{a}+1$ de $A_{\text {para }}$, isto é, gera-se uma nova árvore que conecta a subárvore $A_{\text {tmp }}$ na árvore $A_{\text {para }}$ (Figura 3.8c);

4. Constrói-se uma matriz $A_{d e}$, que possua os nós de $A_{d e}$, sem os nós de $\mathrm{A}_{\mathrm{tmp}}$

5. Atualiza-se a floresta, fazendo com que a estrutura de dados que antes apontava para $A_{d e}$, e $A_{\text {para }}$, aponte agora para $A_{d e}, e A_{\text {para }}$.

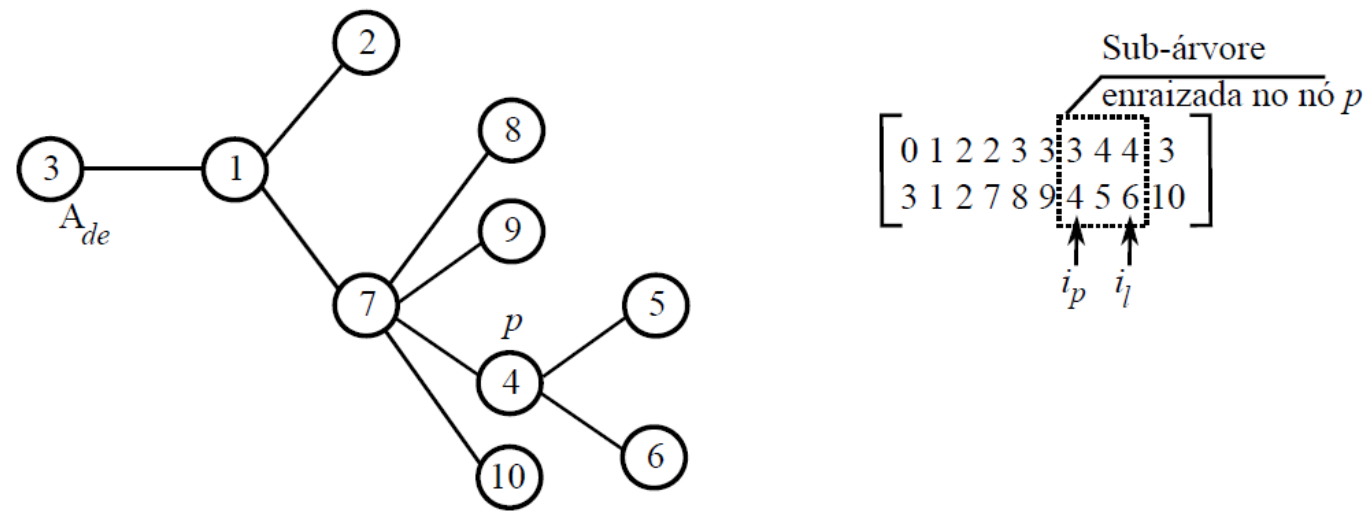

$\overbrace{\mathrm{A}_{\text {para }}}^{a}$

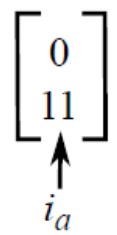

(a) $A_{d e}, A_{\text {para }}$ e suas respectivas RNPs.
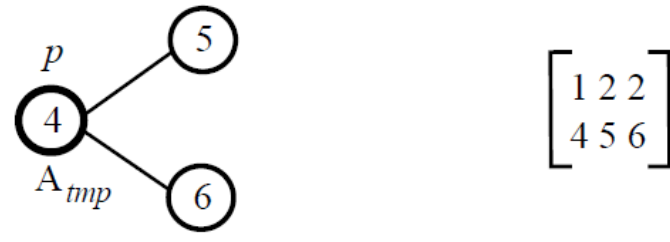

(b) $A_{\text {tmp }}$, e suas respectivas RNP. 


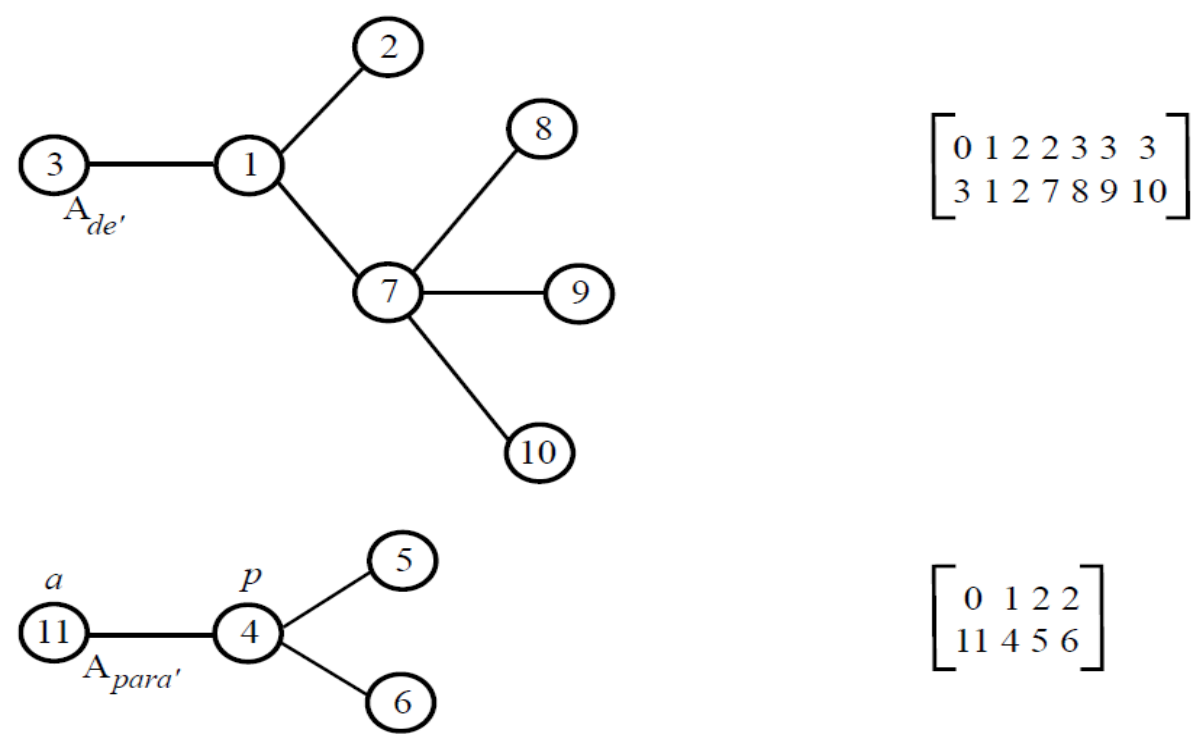

(c) $A_{\text {de }}, A_{\text {para }}$ e suas respectivas RNPs.

Figura 3-8: Passos do operador PAO.

\subsubsection{Operador CAO}

Para descrição do operador $\mathrm{CAO}$, considera-se que um conjunto de nós seja previamente determinado: o nó de poda $p$, o novo nó raiz $r$ e o nó adjacente $a$. Os nós $p$ e $r$ pertencem à árvore $A_{d e}$, e o nó $a$ à $A_{\text {para }}$;

Operador CAO difere do PAO na formação da subárvore cortada e como a mesma é armazenada em um vetor temporário tmp são diferentes, ou seja, as diferenças estão nos passos 2 e 3 apresentados na seção anterior. Portanto os passos 2 e 3 para o operador CAO são descritos na sequência. As Figuras 3.9a, 3.9b, $3.9 \mathrm{c}$ e $3.9 \mathrm{~d}$ ilustram um exemplo destes passos para as mesmas árvores $A_{d e} \mathrm{e}$ $A_{\text {para }}($ Figura 3.8) utilizadas para análise do operador PAO.

Então podemos dividir o procedimento de cópia da subárvore para operador CAO em dois passos:

1. Este passo é similar ao passo 2 do PAO, com diferença de que, no operador CAO, troca-se o índice $i_{p}$ por $i_{r}$;

2. Consideram-se os nós de $r$ até $p$ de $A_{d e}$, isto é $r_{0}, r_{1}, r_{2}, \ldots \ldots, r_{n}$, onde $r_{0}=r$ e $r_{n}=p$, como raízes de subárvores (ver os nós destacados na Figura 3.9a). O algoritmo para o segundo passo deve copiar a subárvore enraizada em $r_{i}(i=1,2, \ldots \ldots, n)$, sem a sub-árvore enraizada em $r_{i-1}$ (Figura 3.9b), e armazene o resultado das subárvores na 
matriz temporária $A_{t m p 1}$ (Figura $3.9 \mathrm{c}$ ). Em seguida, operador CAO cria a matriz $A_{\text {para }}$, contendo os nós de $A_{\text {para }}$ e inserindo depois a matriz $A_{t m p 1}$ na posição $i_{a}+1$ de $A_{\text {para }}$. Ou seja, cria-se uma nova árvore que conecta a subárvore $A_{t m p 1}$ na árvore $A_{\text {para }}$ (Figura $3.9 \mathrm{~d}$ ).

O terceiro passo do operador PAO cria-se $A_{\text {para }}$ a partir de $A_{\text {para }}$ e $A_{t m p}$. Já no operador CAO, cria-se a matriz $A_{\text {para }}$ a partir de $A_{\text {para }}$ e $A_{t m p 1}$.
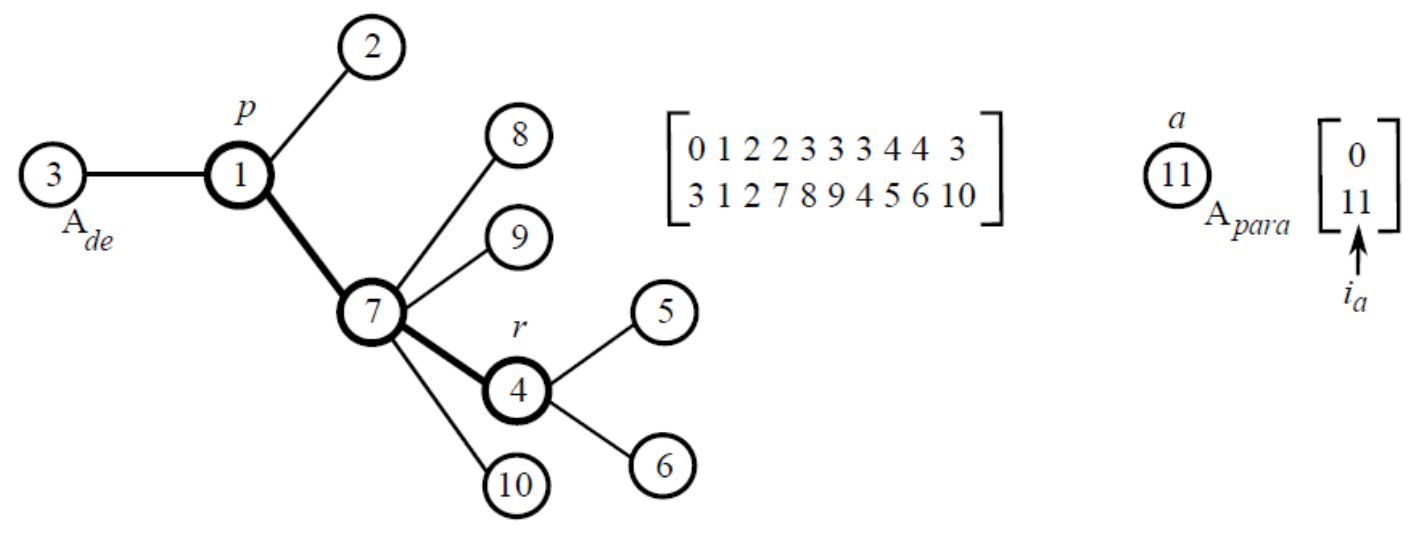

(a) RNP de $A_{\text {de }}$ e escolha do vértice $a$.
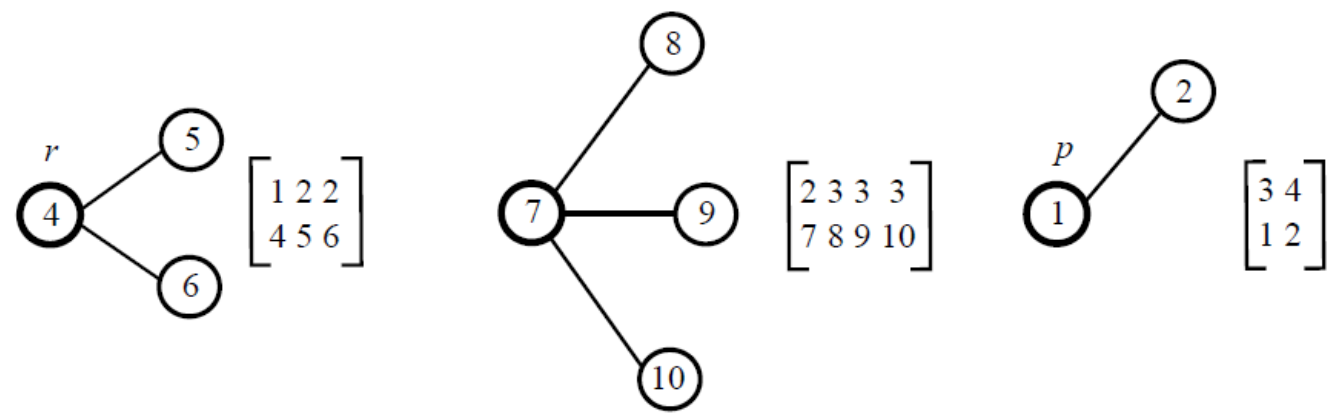

(b) Subárvores enraizadas nos nós de caminho $r$ a $p$. 


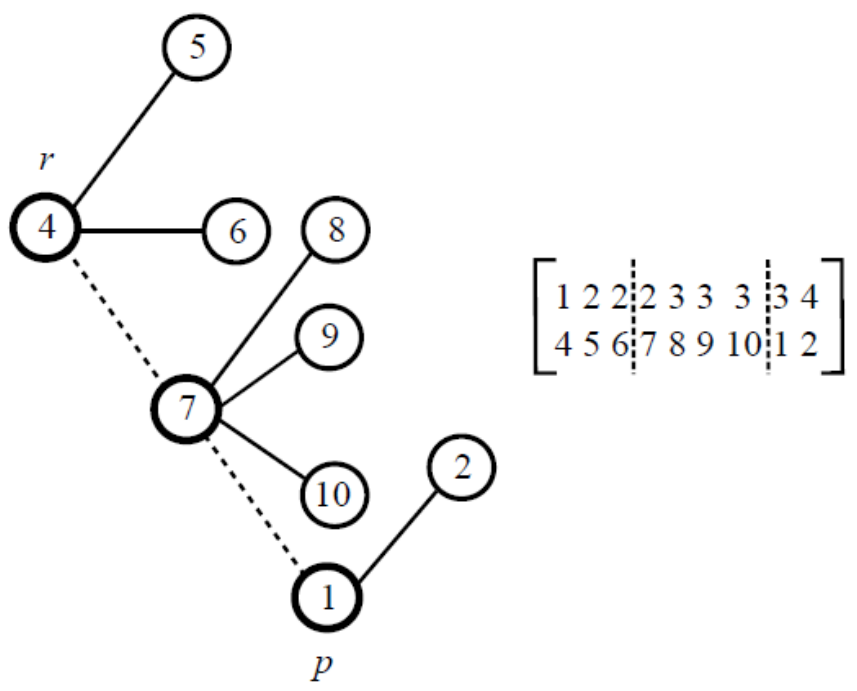

(c) RNP da subárvore podada.

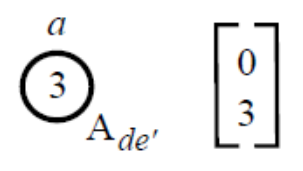

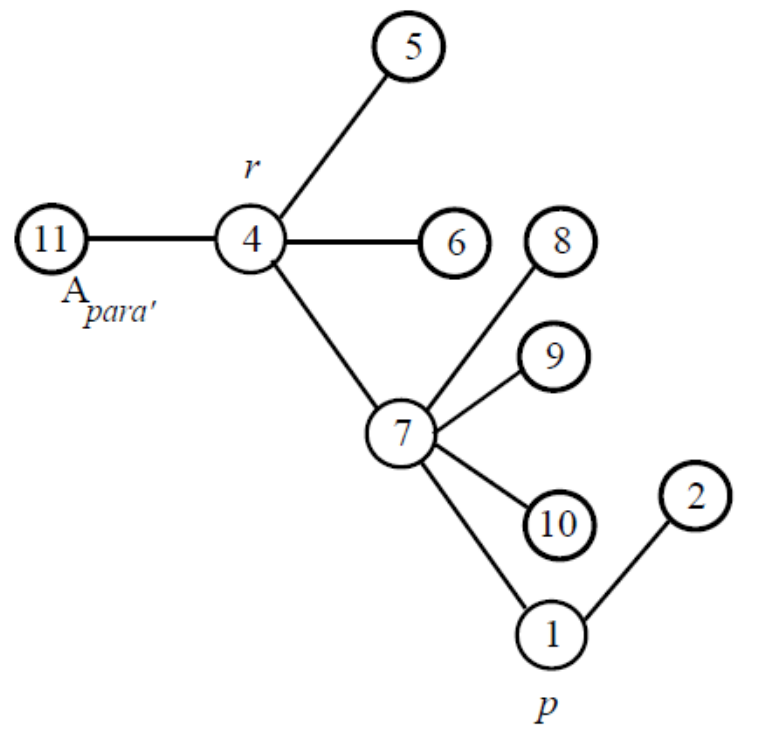

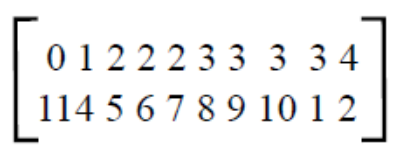

(d) Árvore $A_{\text {para }}$ e sua RNP.

Figura 3-9: Passos do operador CAO. 


\subsection{Fundamentos de Algoritmos Evolutivos}

Os Algoritmos Evolutivos (AEs) são métodos de otimização e busca inspirada nos princípios da Teoria de Darwin, isto é, são baseados em princípios que são encontrados na evolução dos sistemas biológicos. Este capítulo introduz os principais conceitos sobre AEs os quais receberam maior atenção dos pesquisadores após a proposta dos Algoritmos Genéticos (AGs) por John Holland (Hayes-Roth, 1975) e a popularização dos mesmos por meio dos trabalhos de David Goldberg (Goldberg, 1989). Na seção 3.6.1 é apresentada a base biológica dos AEs. Na seção 3.6.2 são descritos os AEs, bem como as subáreas que vêm se destacado da computação evolutiva. Na seção 3.6.3 são descritos os operadores genéticos. Para escrever este Capítulo utilizou-se (Gabriel e Delbem,2008) como referência principal.

\subsubsection{Base Biológica}

OS AEs podem ser vistos como técnicas de Computação Bioinspirada (Teuscher et al., 2003) ou Computação Natural (Ballard, 1999). Tais áreas de pesquisa abordam uma série de técnicas computacionais fundamentadas em conceitos Biológicos. As técnicas evolutivas apresentam conceitos cuja origem está em diversos campos da Biologia, em especial em idéias evolucionistas e na Genética. Esta Seção foca nesses conceitos e resume a terminologia empregada na definição de AEs.

\subsubsection{O Processo Evolutivo}

Conforme dito anteriormente, os AEs baseiam-se nos processos evolutivos que ocorrem na natureza. Como principais componentes dos sistemas evolutivos têm-se (Arciszewski e Jong, 2001):

- Populações de indivíduos: uma ou mais populações concorrem por recursos limitados;

- Fitness: reflete a habilidade de um indivíduo para sobreviver ou reproduzir-se;

- A noção de mudanças dinâmicas nas populações devido ao nascimento e morte dos indivíduos; 
- Os conceitos de variabilidade e hereditariedade, ou seja, os novos indivíduos possuem muitas das características de seus pais, embora não sejam idênticos.

Tais conceitos foram inspirados no neodarwinismo (Ridley, 1996), que admite que os principais fatores evolutivos são a mutação, a recombinação e a seleção natural, os quais são resumidos a seguir:

\section{- Mutação Genética}

A origem da variabilidade é a mutação, processo pelo qual o gene (é um segmento de DNA que contém uma informação codificada para determinada característica ou processo que a célula tem ou executa (Amabis e Martho, 1985)) sofre alterações em sua estrutura. Tais alterações são modificações na sequência de bases do DNA. Essa molécula, quando duplicada, produz cópias idênticas de si, ou seja, diferentes da original (sem mutação), transmitindo hereditariamente a mudança. Isso pode acarretar a alteração da sequência de aminoácidos da proteína, alterando o metabolismo celular, podendo favorecer o organismo ou mesmo ser letal.

\section{- Recombinação Genética}

O processo evolutivo seria relativamente lento se não fosse possível colocar juntas, em um mesmo indivíduo, mutações ocorridas em indivíduos da geração anterior. $\mathrm{O}$ fenômeno que possibilita esse evento é a reprodução sexuada. É importante considerar que a seleção natural não atua aceitando ou rejeitando mudanças individuais, mas sim escolhendo as melhores combinações gênicas entre todas as variações presentes na população.

- Seleção Natural

A seleção natural é consequência de dois fatores:

1. Os membros de uma espécie diferem entre si;

2. A espécie produz descendência em maior número de indivíduos que de fato podem sobreviver.

Os indivíduos mais aptos a sobreviver são aqueles que, graças à variabilidade genética, herdaram a combinação gênica mais adaptada para determinadas condições naturais. 


\subsubsection{Terminologia Básica}

Apresenta-se, a seguir, a terminologia necessária para o estudo de AEs (Sait e Youssef, 1999).

\section{Cromossomoss, Genes e Alelos}

A estrutura que determina como os organismos são construídos é chamada cromossomo. Os cromossomos associam-se de modo a formar um organismo e seu número varia de uma espécie para outra (Amabis e Martho, 1985). O conjunto completo de cromossomos de um ser vivo é chamado genótipo e as características do organismo gerado com base no genótipo constituem o fenótipo. De forma similar, a representação de soluções de um problema pode ser determinada em uma estrutura de dados chamada cromossomo. Os cromossomos são agrupados em um conjunto de símbolos chamados genes. Os diferentes valores de um gene são chamados alelos. A posição do gene em um cromossomo é denominada locus (Lamont e Veldhuizen, 2002).

A representação das soluções candidatas (ou seja, os indivíduos) é o primeiro estágio da elaboração de um AE e é crucial para o desempenho do algoritmo. Essa etapa consiste em definir o genótipo e a forma como este é mapeado no fenótipo. A codificação mais simples é a representação binária: o genótipo é descrito como um arranjo de 0s e 1s. É necessário determinar o tamanho do arranjo, bem como o mapeamento genótipo-fenótipo. Entretanto, em muitas aplicações do mundo real, a representação binária pode apresentar fraco poder de expressão (Deb, 2001), não sendo eficiente na representação das possíveis soluções. Uma alternativa empregada é a representação em ponto flutuante ou representação oral, segundo a qual as soluções são arranjos de números reais. Essa representação é usualmente empregada quando os genes são distribuídos em um intervalo contínuo, em vez de um conjunto de valores discretos (Andrew, 2004).

\section{Fitness}

O valor de fitness de um indivíduo (seja um genótipo ou um cromossomo) é um número positivo que mede o quanto adequado é o indivíduo, que representa uma solução. Em problemas de otimização, ele pode ser o custo da solução. Se o problema for de minimização, as soluções de maior fitness são as de menor custo. 


\section{Pais, Operadores de Reprodução e Descendentes}

Os AEs trabalham sobre um ou mais cromossomos a fim de gerar novas soluções, chamadas descendentes. Os operadores que trabalham sobre cromossomos, chamados operadores de reprodução, são a recombinação (também conhecido como crossover) e a mutação. Esses operadores fazem analogia aos principais mecanismos da evolução natural, ou seja, a recombinação e a mutação gênica. A recombinação é aplicada, em geral, a um par de cromossomos. Os indivíduos selecionados para o processo de recombinação são chamados pais. A mutação é aplicada a um simples cromossomo, modificando-o aleatoriamente.

\section{Geração e Seleção}

A geração é uma iteração do $\mathrm{AE}$, na qual os indivíduos da população atual são selecionados e recombinados e/ou mutados, gerando descendentes. Devido à criação de novos descendentes, o tamanho da população cresce; deste modo um mecanismo de seleção controla esse tamanho. A ideia básica da seleção é a seguinte: seja uma população de tamanho $M$ e seja $N_{d}$ o número de descendentes, então, para a próxima geração, são selecionados $M$ novos indivíduos ( $N_{d}$ pode ser maior que $M$ ). Cada $\mathrm{AE}$ desenvolve, com base nesse princípio, uma estratégia de seleção.

\subsubsection{Algoritmos Evolutivos}

Os AEs funcionam basicamente da seguinte forma:

1. Primeiramente é criada uma população inicial com soluções aleatórias;

2. A partir da população atual, é gerada uma nova população. Os novos indivíduos desta nova população são criados através do uso dos operadores genéticos. Esta tarefa é realizada aplicando-se o operador de cruzamento nos indivíduos com o melhor fitness, que são escolhidos através de um processo chamado de seleção;

3. Retornar para o item 2 até atender à condição de parada;

O Algoritmo 1 mostra os principais passos de um AE.

Os AEs são utilizados para problemas de otimização em decorrência de ser o método preferencialmente utilizado pela natureza, que é considerada por muitos 
como o sistema mais perfeito. Além disso, resolvem problemas com modelos matemáticos complexos de modo simples, sendo de fácil acoplamento com outras técnicas (hibridação) (Santos, 2004).

Existem várias subáreas na Computação Evolutiva, das quais destacam-se:

\section{Algoritmos Genéticos (AG)}

Tais algoritmos foram propostos por Holland na década de 1970 e trabalham com populações de indivíduos (cromossomos), que durante o processo de evolução são submetidos aos procedimentos de seleção e reprodução. Deste modo o algoritmo consegue aproveitar das melhores soluções e ao mesmo tempo explorar o espaço de busca.

Algoritmo 1: Algoritmo Evolutivo.

1: // Inicia o contador de tempo

2: $g \leftarrow 1$

3: Inicia População $\left(P_{g}\right)$

4: // Avalia o fitness dos indivíduos $P_{g}$

5: Avalia $\left(P_{g}\right)$

6: // Verifica o critério de parada

7: while critério de parada não é atingido do

8: $\quad$ // Incrementa a geração

9: $\quad g \leftarrow g+1$

10: // Seleciona os indivíduos para a geração dos descendentes

11: $\quad P_{g} \leftarrow$ Seleciona $\left(P_{g-1}\right)$

12: // Realiza o cruzamento dos pais selecionados

13: $\quad$ Cruzamento $\left(P_{g}\right)$

14: / Realiza a mutação sobre a nova população

15: $\quad$ Muta $\left(P_{g}\right)$

16: // Avalia o fitness dos indivíduos $P_{g}$

17: $\quad$ Avalia $\left(P_{g}\right)$

18:end while 


\subsubsection{Operadores Genéticos}

Nesta Seção são abordados os principais aspectos dos operadores genéticos utilizados nos AEs.

\subsubsection{Seleção}

O objetivo deste operador é escolher um ou mais indivíduos para gerar um ou mais descendentes para a próxima população do processo evolutivo. Os indivíduos com o melhor grau de fitness têm uma maior probabilidade de serem escolhidos nesta etapa. Existe, na literatura, uma grande variedade de estratégias de seleção. Porém, as mais utilizadas são a seleção por torneio, roda da roleta e ranking.

Na seleção por torneio, são realizadas várias competições entre duas ou mais soluções, e a melhor solução é a escolhida. $\mathrm{Na}$ roda da roleta, geralmente, os pais são selecionados com probabilidade proporcional aos seus fitness. Para tal seleção usa-se a expressão 3.21 (Michalewicz, 1992).

$$
P_{i}=\frac{F_{i}}{\sum_{i=1}^{N}\left(F_{i}\right)}
$$

onde, $F_{i}$ é o fitness da solução $i$ e $N$ é o tamanho da população. Logo, é gerado um valor aleatório $k$, no intervalo de 0 a PTOTAL (Soma de todos os valores de fitness). Finalmente, o indivíduo selecionado é o primeiro que possui uma probabilidade de seleção maior que $k$. Na seleção por ranking, são ordenadas as soluções de acordo com o seu valor de fitness (sendo o ranking 1 pertencente a pior solução e o ranking $N$ pertencente a melhor solução, $N$ sendo o número de soluções). Com isso, determina-se a probabilidade de seleção para cada solução. Logo, a escolha das soluções progenitoras é referente ao valor do ranking.

\subsubsection{Cruzamento}

O operador de cruzamento gera as soluções descendentes das soluções progenitoras. Basicamente, para cada duas das soluções progenitoras selecionadas corta-se o seu vetor de símbolos em uma posição aleatória, produzindo duas cabeças e duas caudas. Em seguida as caudas são trocadas, gerando dois novos indivíduos (Figura 3.10). 


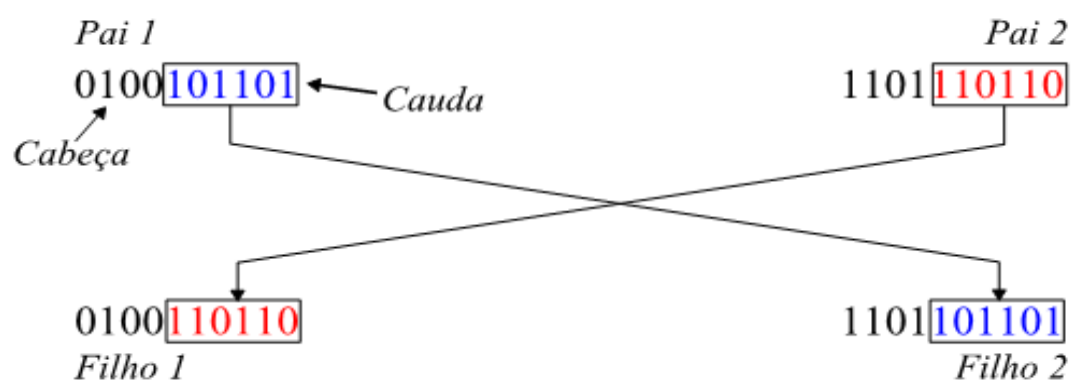

Figura 3-10: Cruzamento em um ponto.

Existem diversas variações desse operador, vários deles são específicos para determinado problema (Goldberg, 1989).

\subsubsection{Mutação}

Este operador gera uma determinada taxa de "perturbação" em um determinado número de soluções, isto é, gera pequenas alterações em um determinado número de soluções, com o objetivo de explorar o espaço de busca (Figura 3.11) e manter a diversidade das soluções. Desta forma, o AE tende a não ter uma convergência rápida, evitando a sua estabilização em regiões chamadas de mínimos locais, nos quais os AEs sempre estão sujeitos a cair.

\section{Antes da Mutação}

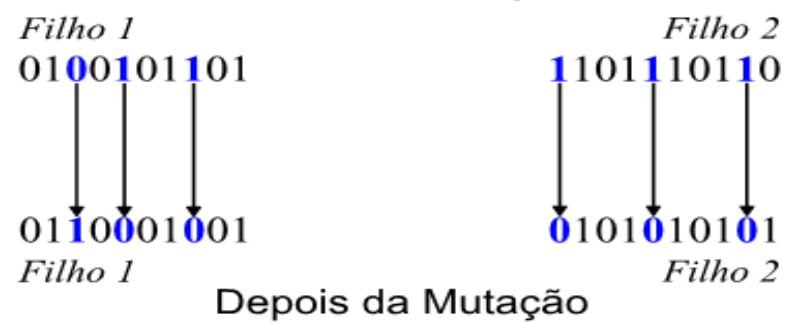

Figura 3-11: Aplicação da mutação.

\subsubsection{Eletismo}

Existe um grande risco de perder os melhores indivíduos na transição de uma geração para outra, isto devido à aplicação dos operadores de mutação e cruzamento. Desse modo, o objetivo do operador de elitismo é preservar os melhores indivíduos para as próximas gerações que possam surgir, sem que esses sofram alguma alteração. Assim, as melhores soluções não se deterioram. 


\subsection{Problemas de Otimização Multiobjetivo}

Problemas que envolvem a otimização de vários objetivos simultaneamente, que, em geral, são conflitantes, são chamados de problemas de otimização multiobjetivo (MOOP do inglês Multi-Objective Optimization Problem). Um MOOP (do inglês Multi-Objective Optimization Problem) e formado pelos seguintes conjuntos (Deb 2001): conjunto de funções objetivo a serem otimizadas (maximizar/minimizar) e conjunto de restrições, e pode ser formulado da seguinte forma:

$$
\begin{array}{ccc}
\text { Máx ou Min } & f_{m}(x), & m=1,2, \ldots, N_{\text {obj }} \\
\text { sujeito a: } & g_{j}(x) \leq 0, & j=1,2, \ldots, N R_{\text {des; }} \\
h_{k}(x)=0, & k=1,2, \ldots, N R_{\text {igu; }} \\
& x_{i}^{(\text {inf })} \leq x_{i} \leq x_{i}^{(\text {sup })}, & i=1,2, \ldots, N_{\text {var }}
\end{array}
$$

onde:

- $x$ é um vetor de $N_{\text {var }}$ variáveis de decisão, $x=\left(x_{1}, x_{2}, \ldots \ldots, x_{N_{v a r}}\right)^{T}$, também denominado de solução.

- $x_{i}^{(i n f)}$ e $x_{i}^{(\sup )}$, representam limites inferior e superior para a variável $x_{i}$, que definem o espaço de variáveis de decisão ou espaço de decisão $S_{d e c}$.

- As $N R_{\text {des }}$ desigualdades $\left(g_{j}\right)$ e as $N R_{i g u}$ igualdades $\left(h_{k}\right)$ são chamadas de funções de restrição.

Uma solução x factível satisfaz as $N R_{\text {igu }}+N R_{\text {des }}$ funções de restrição e os $2 \mathrm{~N}_{\text {var }}$ limites. $\mathrm{O}$ conjunto de todas as soluções factíveis forma a região factível ou espaço de busca $S_{\text {fact }}$.

Cada função $\mathrm{f}_{\mathrm{m}}(\mathrm{x})$ pode ser maximizada ou minimizada. Porém, para trabalhar com os algoritmos de otimização, é necessário converter todas as funções para serem apenas de maximização ou minimização. $O$ vetor de funções objetivo $\mathrm{f}(\mathrm{x})=\left[\mathrm{f} 1(\mathrm{x}), \mathrm{f} 2(\mathrm{x}), \ldots . . \mathrm{f}_{\text {Nobj }}(\mathrm{x})\right]$ compõe um espaço multidimensional chamado espaço de objetivos $S_{\text {obj }}$. Para cada solução x, no espaço de decisão, existe um f(x) em $\mathrm{S}_{\text {obj. }}$. Esta é uma diferença fundamental em relação à otimização de objetivos simples, cujo espaço de objetivos é unidimensional. O mapeamento ocorre então 
entre um vetor x (de dimensão $N_{\text {var }}$ ) e um vetor $\mathrm{f}\left(\mathrm{x}\right.$ ) (de dimensão $N_{o b j}$ ). Por exemplo, se cada elemento de $\mathrm{x}$ e $\mathrm{f}(\mathrm{x})$ são números reais, então $\mathrm{f}(\mathrm{x})$ estaria mapeada como $f(x): \Re^{N_{v e r}} \rightarrow \Re^{N_{\text {obj }}}$ (Ticona \& A. C. B. Delbem 2008).

\subsubsection{Soluções Pareto-Ótimas}

As funções objetivo empregadas nos MOOPs são em geral conflitantes entre si, ou seja, quando não é possível melhorar o valor de $f_{1}$ sem piorar o valor da função $f_{2}$. Em (Deb 2001) encontramos um exemplo prático de objetivos conflitantes que é a tomada de decisão a partir de dois critérios (custo e conforto) para compra de um automóvel. Qanto mais confortável o automóvel, maior será o custo. Na Figura 3.12 são ilustradas algumas alternativas de escolha.

Portanto temos como objetivo uma minimização do custo e uma maximização do conforto. Pela Figura 3.12 tem-se 6 opções de compra, e por intuição a opção 5 é descartada, pois possui o mesmo conforto que opção 3 com maior custo. Ao analisar as opções 2 e 6, observa-se que a solução 6 também deve ser descartada, pois possui menor conforto e maior custo em ralação à solução 3. Então após eliminarmos as soluções ruins, tem-se então 4 opções (1,2,3 e 4) como boas alternativas para compra. Dentre essas soluções, não se pode afirmar qual é a melhor, pois quando uma tem maior conforto, também tem maior custo, e vice versa. Assim, podemos dizer que uma solução domina outra solução, quando é melhor que a outra em pelo menos 1 objetivo e não pior em todos os demais objetivos. Da Figura 3.12 tem-se que a solução 3 domina a solução 5 e a solução 2 domina a solução 6 . Portanto as soluções 5 e 6 são dominadas e as soluções 1,2,3 e 4 são não dominadas por nenhuma outra. Temos então o conjunto das soluções não dominadas (1,2,3 e 4) e o conjunto das soluções dominadas (5 e 6). 


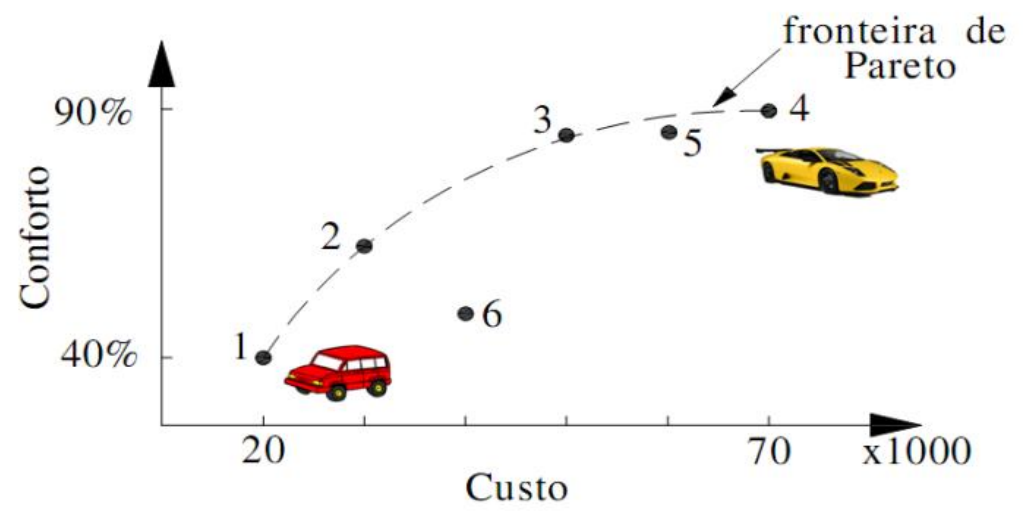

Figura 3-12: Curva Conforto VS Custo.

Em um MOOP, emprega-se o conceito de Dominância de Pareto para comparar duas soluções factíveis de um problema. Dadas duas soluções $x$ e $y$, diz-se que $x$ domina $y$, denotado como $x \preccurlyeq y$, se as seguintes condições forem satisfeitas:

1. A solução $x$ é pelo menos igual a $y$ em todas as funções objetivo;

2. A solução $x$ é superior a $y$ em pelo menos uma função objetivo.

Observe que existe um conjunto de alternativas ótimas que são não dominadas entre si nos objetivos de custo e desempenho. Em um MOOP, o conjunto de soluções não dominadas é chamado de conjunto Pareto-ótimo, que representa as soluções ótimas do problema. A fronteira de Pareto é o conjunto dos valores das funções objetivo das soluções do conjunto Pareto-ótimo.

\subsubsection{Diferenças entre Otimização Mono-Objetivo e Multiobjetivo}

Em (Deb 2001) são identificados três importantes aspectos, diferenciando a otimização multiobjetivo da mono-objetivo:

1. Em problemas de otimização mono-objetivo, a meta é encontrar uma solução ótima global. Se a função objetivo desses problemas for multimodal, poderia existir mais de um ótimo global. Neste caso, todos os ótimos são equivalentes. Por outro lado, em MOOP, determinar um conjunto de soluções da fronteira de Pareto é tão importante quanto preservar a diversidade neste conjunto. Um 
algoritmo eficiente para otimização deve considerar ambos os aspectos;

2. Nos problemas de otimização multiobjectivo, trabalha-se com os espaços das variáveis e dos objetivos, enquanto os problemas com um objetivo trabalham unicamente no espaço das variáveis, já que se procura apenas uma solução no espaço dos objetivos. Desta forma, manter a diversidade nos espaços das variáveis e dos objetivos torna a solução dos problemas multiobjetivo mais complicada, pois a proximidade de duas soluções no espaço das variáveis não implica proximidade no espaço dos objetivos;

3. Os métodos tradicionais de otimização multiobjetivo reduzem o conjunto de funções objetivo a uma função simples que pondera cada objetivo. Estes métodos podem também tratar cada objetivo separadamente, utilizando os demais objetivos como restrições. Portanto, um MOOP pode ser convertido, por meio de algumas técnicas, em um problema de otimização simples.

\subsection{Algoritmos Evolutivos para Otimização Multiobjetivo}

AEs são alternativas interessantes para tratamento de MOOP, em razão de apresentarem as seguintes características:

1. Trabalham com mais de uma função simultaneamente;

2. Não são necessárias informações adicionais;

3. São robustos para escapar de ótimos locais.

A Tabela 3.2 (Ticona \& A. C. B. Delbem 2008) relaciona os principais trabalhos desenvolvendo AEs para MOOP, onde a mesma classifica os modelos de MOEA da seguinte maneira:

- Eletistas: modelos que utilizam alguma forma de eletismo;

- Não Eletistas: modelos que não empregam forma alguma de eletismo em suas gerações. 
Tabela 3-2: Modelos de MOEAs (Ticona \& A. C. B. Delbem 2008).

\begin{tabular}{|c|c|c|}
\hline 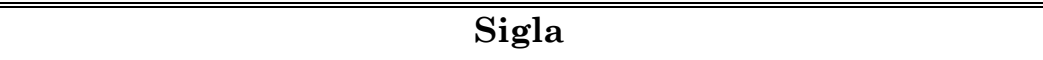 & Autoria & 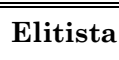 \\
\hline VEGA[50](Vector Evaluated Genetic Algorithm) & (Schaffer, 1985) & Não \\
\hline WBGA [51] (Weight Based Genetic Algorithm) & (Hajela e Lin, 1992) & Não \\
\hline MOGA[52] (Multiple Objective Genetic Algorithm) & (Fonseca e Fleming, 1993) & Não \\
\hline NSGA[53] (Non-Dominated Sorting Genetic Algorithm) & (Srinivas e Deb, 1994) & Não \\
\hline NPGA [54] (Niched-Pareto Genetic Algorithm) & (Horn et al., 1994) & Não \\
\hline PPES [55] (Predator-Prey Evolutionary Strategy) & (Laumanns etal.,1998) & Não \\
\hline $\begin{array}{l}\text { REMOEA [56] (Rudolph's Elitist Multi-Objective Evolutionary } \\
\text { Algorithm) }\end{array}$ & (Rudolph, 2001) & Sim \\
\hline $\begin{array}{l}\text { NSGA-II }[57,23] \text { (Elistist Non-Dominated Sorting } \\
\text { Genetic Algorithm) }\end{array}$ & $\begin{array}{l}\text { (Deb et al., 2000; Deb } \\
\text { e Sundar, 2006) }\end{array}$ & Sim \\
\hline SPEA, SPEA2 [58, 59] (Strenght Pareto Evolutionary Algorithm) 1 e 2 & $\begin{array}{l}\text { (Zitzler e Thiele, 1998; } \\
\text { Zitzler et al., 2001) }\end{array}$ & Sim \\
\hline TGA [60] (Thermodynamical Genetic Algorithm) & (Kita et al., 1996) & Sim \\
\hline PAES [61] (Pareto-Archived Evolutionary Strategy) & (Knowles e Corne, 1999) & Sim \\
\hline $\begin{array}{l}\text { MOMGA-I, MOMGA-II[62](Multi-Objective Messy Genetic Algorithm) I } \\
\text { e II }\end{array}$ & (Van Veldhuizen, 1999) & Sim \\
\hline Micro-GA [63] (Multi-Objective Micro-Genetic Algorithm) & (Coello et al., 2002) & Sim \\
\hline PESA-I, PESA-II [64, 65] (Pareto Envelope-Base Selection Algorithm) & $\begin{array}{l}\text { (Corne et al., 2000; } \\
\text { Corne et al., 2001) }\end{array}$ & Sim \\
\hline G-MOEA [66] (G-dominance Multi-Objective Evolutionary Algorithm) & (Deb et al., 2005) & Sim \\
\hline
\end{tabular}

Na próxima seção será apresentado o AEMT proposto em (Santos et al 2010), empregado com sucesso para o tratamento de problemas de reconfiguração de redes em SDs. Lembrando que o AEMT será utilizado como base para o desenvolvimento da metodologia proposta. 


\subsubsection{Algoritmo Evolutivo Multi-Objetivo em Tabelas}

O AE Multiobjetivo em Tabelas, denominado MEAN, segundo (Santos et al. 2010 E Benayoun et al. 1971), trabalha com várias subpopulações em paralelo armazenadas em tabelas, em que os melhores indivíduos para cada característica do problema são armazenados em sua respectiva subpopulação (cada subpopulação é representada por uma tabela). Uma importante característica do MEAN é o uso de uma subpopulação para armazenar indivíduos avaliados por uma função agregação, também chamada como soma ponderada (Deb, 2001; Coelho, 1998). O indivíduo selecionado para reprodução pode ser proveniente de qualquer subpopulação (ou tabela). Essa estratégia de seleção aumenta a diversidade entre os indivíduos que se reproduzem, pois, as características de um indivíduo de uma subpopulação podem migrar para as demais subpopulações. Em consequência, aumenta-se a possibilidade de o algoritmo escapar de ótimos locais, aproximandose de soluções com avaliações próximas de um ótimo global na fronteira de Paretoótima, além disso, dar-se-à possibilidade de implementar paralelismo fator importante quando aplicado ao processo de restabelecimento de energia elétrica.

Conforme (Santos et al 2010), alguns parâmetros são importantes para o MEAN:

1. O tamanho de cada subpopulação $S_{P i}$, que indica o número máximo de indivíduos que podem permanecer na subpopulação $P i$ de uma geração para outra;

2. O número máximo de gerações $\left(g_{\max }\right)$.

Soluções (ou indivíduos) geradas pelo MEAN podem ser armazenadas ou descartadas, dependendo do grau de adaptação do indivíduo a cada objetivo do problema (características do problema em uma subpopulação $P_{i}$ ).

Durante o processo de seleção de sobreviventes, um novo indivíduo é acrescentado a uma subpopulação $P i$ se sua adequação ao objetivo de $P i$ for melhor que pelo menos um indivíduo da mesma. Importante destacar que o mesmo indivíduo pode ser incluído em mais de uma tabela de acordo com esse critério de seleção. Como a população é estacionária, os novos indivíduos substituem os piores. 


\subsection{Representação do Sistema de Distribuição na RNP}

Conforme mencionado anteriormente, nos SDs existem trechos entre barras que não são separados por chaves. Esses trechos são chamados de setores. Usualmente, nos trabalhos desenvolvidos para tratamento de problemas de reconfiguração de redes, as barras de carga de um setor são modeladas como se estivessem concentradas em um único ponto. Esse procedimento reduz o grau de confiabilidade dos resultados obtidos.

Para reproduzir com maior fidelidade os SDs, em (Santos 2009) utiliza-se a RNP de dois níveis diferentes: a RNP do alimentador e a RNP do setor. Considere os 2 alimentadores mostrados na Figura 3.16. As barras em vermelho pertencem ao alimentador 1, enquanto as barras em preto são do alimentador 2. Na Figura 3.16 e na Figura 3.17, retângulos representam barras em uma subestação, círculos são barras do SDR (barras de carga, extremidades de chaves, ponto de conexão de duas ou mais linhas), linhas cheias representam as linhas do SDR, linhas tracejadas são chaves seccionadoras NF e a linha interrompida representa uma chave seccionadora NA.

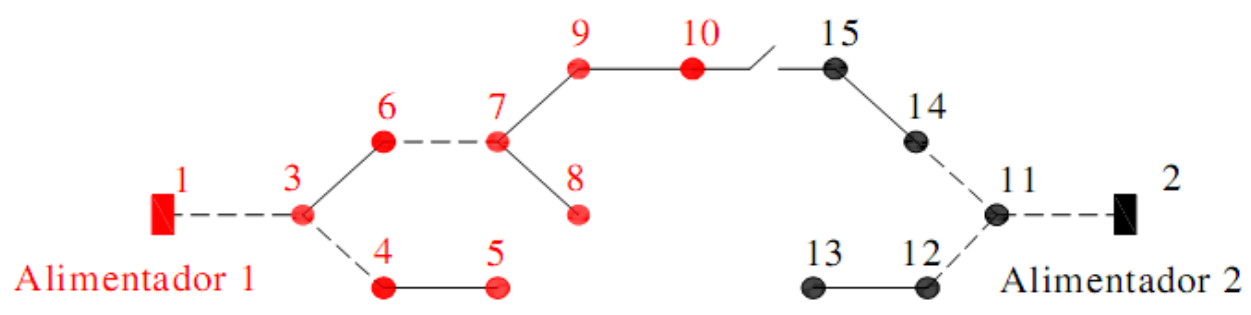

Figura 3-13: SDR com dois alimentadores.

Ao agrupar as barras e linhas não separadas por chaves da Figura 3.16 (ver Figura 3.17), tem-se um grafo em que todas as arestas são chaves seccionadoras. Veja a Figura 3.18. 


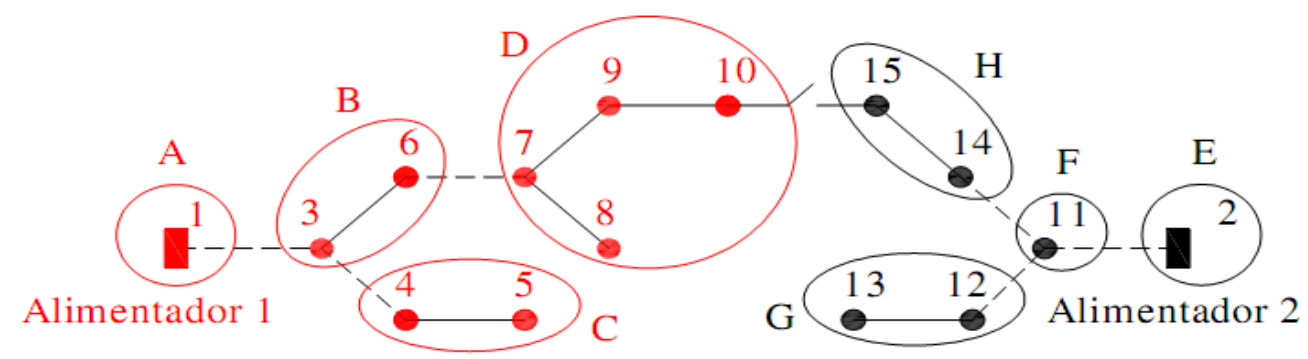

Figura 3-14: Agrupamento das linhas e barras em setores.

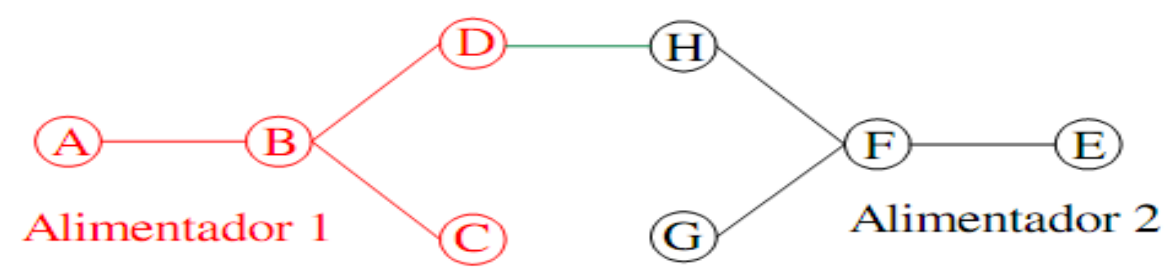

Figura 3-15: Grafo representando setores do SDR da Figura 4-2.

Portando a Figura 3.18 possui 2 RNPs, uma para o alimentador 1 (em vermelho) e outra para o alimentador 2 (em preto), denominadas RNP do alimentador. As arestas em vermelho e preto são chaves seccionadoras NF e a aresta em verde é uma chave aberta. Assim, temos uma estrutura T1 que armazena o endereço de memória da RNP do alimentador 1 e a estrutura T2 armazena o endereço de memória da RNP do alimentador 2:

$$
\begin{aligned}
& T_{1}=\left[\begin{array}{c}
\text { Profundidade } \\
\text { Nó }
\end{array}\right]=\left[\begin{array}{llll}
0 & 1 & 2 & 2 \\
\mathrm{~A} & \mathrm{~B} & \mathrm{C} & \mathrm{D}
\end{array}\right] \\
& T_{2}=\left[\begin{array}{c}
\text { Profundidade } \\
\text { Nó }
\end{array}\right]=\left[\begin{array}{llll}
0 & 1 & 2 & 2 \\
\mathrm{E} & \mathrm{F} & \mathrm{G} & \mathrm{H}
\end{array}\right]
\end{aligned}
$$

A partir da Figura 3.17, é possível também associar RNPs aos setores. Em outras palavras, cada trecho de linhas e barras não separadas por chaves podem ser analisados como uma árvore de grafo. Cada setor pode ter mais de um nó raiz, dependendo do sentido em que está sendo alimentado. Assim, pode haver mais de uma árvore representando cada setor. Para a finalidade de fluxo de carga, acrescenta-se a cada uma dessas árvores, o nó adjacente ao seu nó raiz. Para o acréscimo do nó adequado, pode-se utilizar a seguinte regra: todo nó $i$ adjacente a um nó $x$, tal que $i$ pertença a um setor diferente do setor de $x$, sendo $x$ raiz, é acrescentado à árvore correspondente ao setor de $x$. Exceções ocorrem para os nós 
em uma subestação, que possuem somente um setor vizinho. A Tabela 3.3 mostra as árvores geradas a partir da Figura 3.17, acrescentando os nós adjacentes.

A RNP do setor pode ser representada computacionalmente de forma semelhante a RNP do alimentador, onde as árvores foram armazenadas em estruturas denotadas por $T_{i}$. Para RNP do setor, denotar-se-á por $B_{s r}$, onde $s$ representa o setor em análise e $r$ refere-se ao setor pelo qual a energia chega ao setor $s$, setor pai. Para um mesmo setor $s$ podem existir mais de uma RNP conforme mostra a Tabela 3.4.

Como exemplo, considere o setor D da Figura 3.18. Fluxo de corrente pode chegar ao setor $\mathrm{D}$ por dois caminhos diferentes, através do setor $\mathrm{B}$ ou do setor $\mathrm{H}$. Logo, pelo setor $\mathrm{B}$, tem-se $B_{s r}=B_{D B}$ e para o setor $\mathrm{H}$, tem-se $B_{s r}=B_{D H}$. As estruturas que armazenam as RNPs possíveis para o setor D são mostradas a seguir:

$$
\begin{aligned}
B_{D, B} & =\left[\begin{array}{lllll}
0 & 1 & 2 & 2 & 3 \\
6 & 7 & 8 & 9 & 10
\end{array}\right] \\
B_{D, H} & =\left[\begin{array}{ccccc}
0 & 1 & 2 & 3 & 4 \\
15 & 10 & 9 & 7 & 8
\end{array}\right]
\end{aligned}
$$

A análise da RNP do alimentador nos informa qual das configurações acima utilizar. Através da RNP do alimentador 1, notamos que o setor D está conectado ao setor B. Portanto, no exemplo acima o $r$ correto é o setor B, conforme RNP abaixo.

$$
T_{1}=\left[\begin{array}{c}
\text { Profundidade } \\
\text { Nó }
\end{array}\right]=\left[\begin{array}{llll}
0 & \mathbf{1} & 2 & \mathbf{2} \\
\mathrm{A} & \mathbf{B} & \mathrm{C} & \mathbf{D}
\end{array}\right]
$$


Tabela 3-3:Árvores dos setores com o nó adicional

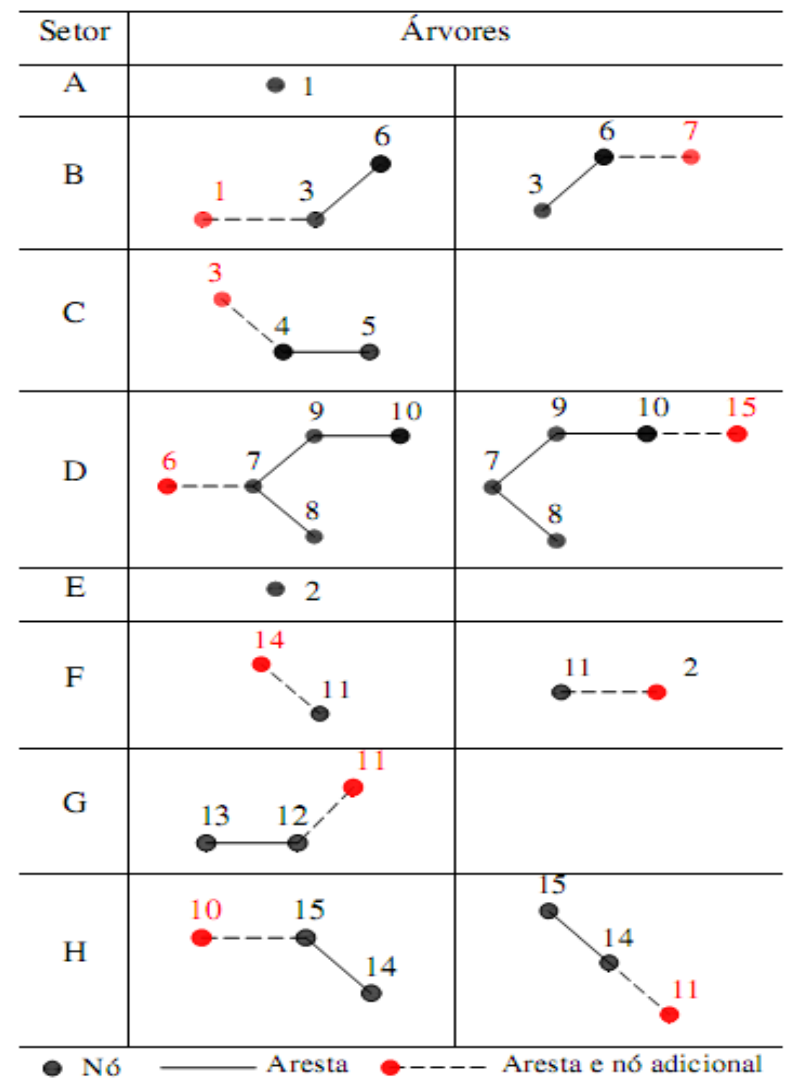

Tabela 3-4: RNP dos setores mostrados na Tabela 3.3. 


\begin{tabular}{|c|c|c|}
\hline Setor & \multicolumn{2}{|c|}{ RNPs do Setor } \\
\hline A & $\begin{array}{l}0 \\
1\end{array}$ & \\
\hline B & $\begin{array}{lll}0 & 1 & 2 \\
1 & 3 & 6\end{array}$ & $\begin{array}{lll}0 & 1 & 2 \\
7 & 6 & 3\end{array}$ \\
\hline $\mathrm{C}$ & $\begin{array}{lll}0 & 1 & 2 \\
3 & 4 & 5\end{array}$ & \\
\hline D & $\begin{array}{ccccc}0 & 1 & 2 & 2 & 3 \\
6 & 7 & 8 & 9 & 10\end{array}$ & $\begin{array}{lllll}0 & 1 & 2 & 3 & 4 \\
15 & 10 & 9 & 7 & 8\end{array}$ \\
\hline $\mathrm{E}$ & $\begin{array}{l}0 \\
2\end{array}$ & \\
\hline $\mathrm{F}$ & $\begin{array}{ll}0 & 1 \\
14 & 11\end{array}$ & $\begin{array}{lc}0 & 1 \\
2 & 11\end{array}$ \\
\hline G & $\begin{array}{lll}0 & 1 & 2 \\
11 & 12 & 13\end{array}$ & \\
\hline $\mathrm{H}$ & $\begin{array}{lll}0 & 1 & 2 \\
10 & 15 & 14\end{array}$ & $\begin{array}{lll}0 & 1 & 2 \\
11 & 14 & 15\end{array}$ \\
\hline
\end{tabular}

Deve-se observar que a determinação de todas as RNPs de cada setor pode ser executada por um procedimento off-line, deixando todos os cálculos prontos para serem utilizados pelo fluxo de carga on-line.

\subsection{Fluxo de Carga de Varredura Direta/Inversa com RNP}

Conforme mencionado nas seções anteriores, para analisar a factibilidade das soluções (ou configurações) geradas pelo AEMO que será empregado, utilizar-se-á o método de fluxo de potência de Varredura Direta / Inversa soma de correntes, considerando as cargas modeladas como corrente constante. Isso tudo buscando minimizar o tempo de processamento necessário para analisar a factibilidade das soluções geradas.

Vale lembrar que a utilização da RNP facilita ainda mais a aplicação de um método de varredura Direta / Inversa tendo em vista que na RNP as barras já estão armazenadas segundo o MPF, necessário para execução de um método de varredura. As linhas da rede serão representadas por uma impedância constante $Z_{m n}$ para cada linha entre as barras $m$ e $n$. 
O algoritmo de fluxo de carga de soma de correntes finaliza seu ciclo após a execução de 2 sub-rotinas: uma obtém as correntes, a jusante, por meio da varredura inversa (CORRENTES, ver Algoritmo 5), para todas as barras de um alimentador, e a outra utiliza as correntes a jusante para obter as tensões nas barras do mesmo alimentador, utilizando a varredura direta (TENSÕES, ver Algoritmo 6). Com o modelo de corrente constante, a convergência é atingida em um único ciclo, diferindo de vários modelos usuais de varredura direta/inversa (Srinivas 2000), (Shirmohammadi et al. 1988) e (D. Das et al. 1994).

A sub-rotina “CORRENTES” utiliza a varredura inversa, ou seja, parte dos nós terminais em direção do nó raiz (ver Algoritmo 5), ordem que está prédeterminada nas RNPs do alimentador e do setor. A carga de uma barra $m$ é denominada $I_{m}$ e a corrente à jusante dessa barra $m$ é denominada $J_{m}$.

Algoritmo 5: Subrotina CORRENTES.

1: for $k \leftarrow|T|,|T|-1, \ldots \ldots, 1$ do

2: $\quad u \leftarrow T \cdot \operatorname{prof}(k)-1$

3: $\quad s \leftarrow T . n o(k)$

4: $\quad r \leftarrow T . n o(u)$

5: $\quad / / A$ corrente jusante em todas as barras em $T$ recebem zero

6: $\quad J(T) \leftarrow 0$

7: $\quad$ while $q \leftarrow\left|B_{s r}\right|,\left|B_{s r}\right|-1, \ldots . .1$ do

8: $\quad p \leftarrow B_{s r} \cdot \operatorname{prof}(q)-1$

9: $\quad m \leftarrow B_{s r} . n o(p)$

10: $\quad n \leftarrow B_{s r} . n o(q)$

11: $\quad J(m) \leftarrow J(m)+J(n)+I(n)$

12: $\quad$ ende while

13: end for

Algoritmo 6: Subrotina TENSÕES.

1: for $k \leftarrow 1,2, \ldots \ldots,|T|$ do 


$$
\begin{aligned}
& \text { 2: } \quad u \leftarrow T \cdot \operatorname{prof}(k)-1 \\
& \text { 3: } \quad s \leftarrow \text { T.no }(k) \\
& \text { 4: } \quad r \leftarrow T . n o(u) \\
& \text { 5: } \quad \text { //A tensão nas barras da subestação geralmente é } 13.8 \mathrm{kV} \\
& \text { 6: } \quad B_{s r} \leftarrow V_{\text {sub }} \\
& \text { 7: } \quad \text { while } q \leftarrow 1,2, \ldots,\left|B_{s r}\right| \text { do } \\
& \text { 8: } \quad p \leftarrow B_{s r} \cdot \operatorname{prof}(q)-1 \\
& \text { 9: } \quad m \leftarrow B_{s r} . n o(p) \\
& \text { 10: } \quad n \leftarrow B_{s r} . n o(q) \\
& \text { 11: } \quad / / C a l c u l a r \text { queda de tensão na rede entre as barras } m \text { e } n \\
& \text { 12: } \quad \Delta V \leftarrow Z_{m n} *(J(n)+I(n)) \\
& \text { 13: } \quad V(n) \leftarrow V(m)-\Delta V / / \text { tensão na barra } n \\
& \text { 14: } \quad \text { ende while }
\end{aligned}
$$

A sub-rotina TENSÕES (ver Algoritmo 6) utiliza varredura direta, ou seja, do nó raiz em direção os nós terminais. Novamente, a ordem em que os nós serão visitados está pré-determinada nas RNPs do alimentador e do setor. O algoritmo TENSÕES depende das correntes a jusante de cada barra, que são obtidas pela sub-rotina CORRENTES. Com isso para obtenção das tensões em cada barra é necessário a corrente na barra $I_{n}$, a tensão a montante da bara $n, V_{m}$, e a impedância $Z_{m n}$ entre as barras $m$ e $n$.

O Algoritmo 7 apresenta a rotina principal do fluxo de carga utilizando a RNP. Como os Operadores PAO e CAO modificam pares de árvores de uma floresta, para cada nova floresta, apenas 2 alimentadores são alterados. Assim, as sub-rotinas CORRENTES e TENSOES são aplicadas somente a esses alimentadores, pois o fluxo de carga para os outros alimentadores não se alteram.

\section{Algoritmo 7: Algoritmo Principal de Fluxo de Carga}

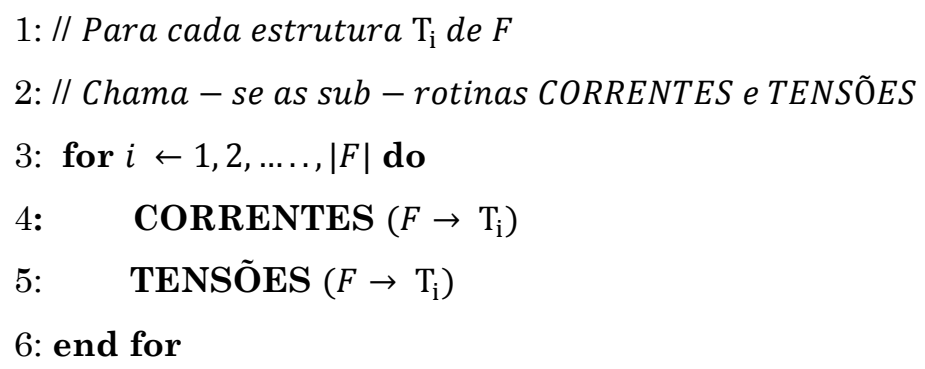




\subsection{Cálculo de Manobras}

Conforme exposto, para o problema de restabelecimento de energia o número de manobras de chaves necessário para implantação de uma nova configuração do sistema é uma informação de suma importância para avaliar as configurações geradas, ou seja, a avaliação da qualidade (aptidão) de uma determinada configuração é feita por dois procedimentos: execução do fluxo de carga e pelo cálculo do número de manobras.

O número de manobras é determinado, em geral, a partir de comparações entre vetores binários que guardam o estado das chaves (1 - aberta e 0 - fechada) de cada configuração (atual e proposta). Ou seja, para encontrar o número de manobras necessárias para gerar a nova configuração do sistema, compara-se o vetor com os estados de todas as chaves dessa nova configuração com o vetor com os estado das chaves da configuração inicial. Porém, tal processo envolve um custo computacional relativamente alto, pois para cada nova configuração gerada é necessário criar um vetor com o estado atual das chaves e realizar a comparação com o vetor da configuração inicial. Como esses vetores têm o comprimento igual ao número de chaves $(m)$ no sistema, o tempo para percorrê-lo uma vez é bem maior que o tempo de realizar uma modificação no sistema pelos operadores PAO ou CAO, que requerem tempo de computação da ordem do tamanho dos alimentadores envolvidos, em geral, bem menor que $m$ (Santos 2009).

Em (Santos et al, 2010) desenvolveu-se um algoritmo que determina o número de manobras de forma mais eficiente, exigindo menor esforço computacional. A proposta é utilizar dois vetores: um com o estado das chaves na configuração inicial e outro, de tamanho $G_{\max }$ (número máximo de gerações), que armazena alterações nas chaves em relação à configuração inicial.

Após a ocorrência de uma falta, o procedimento de isolar o setor em falta e de conectar os setores a jusante do mesmo ao SD exige manobras de chaves que nem sempre ocorrem aos pares. Para tornar mais claro esse procedimento, consideremos o SD apresentado na Figura 3.19, onde o setor 19 sofreu uma falta. O primeiro passo é isolar o setor que esta em falta abrindo as chaves A e B, realizando assim duas manobras que resultam na desconexão dos setores 17 e 18 (ficaram sem energia). Para conectá-los ao SD novamente, é necessário fechar uma chave (dentre 
as chaves $\mathrm{C}, \mathrm{D}, \mathrm{E}, \mathrm{F}$ ou G) que os conectam a algum alimentador, implicando em mais 1 manobra de chaves. Resumindo, para isolar o setor em falta e reenergizar os setores que ficaram sem energia foram necessárias 3 manobras de chaves.

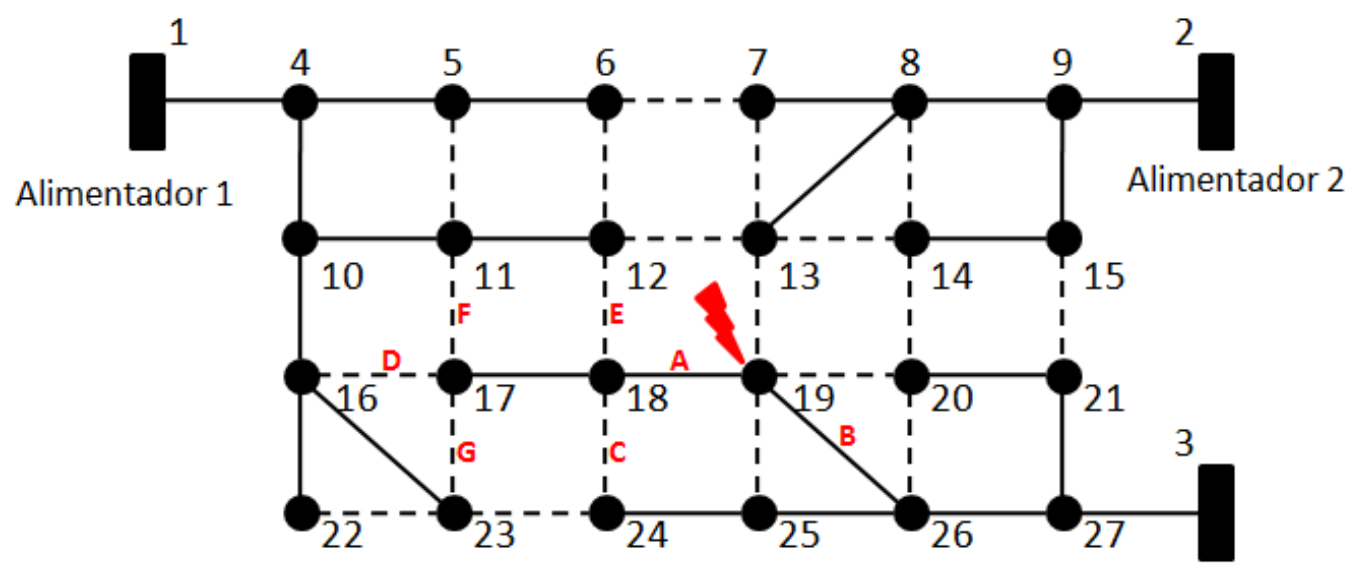

Alimentador 3

Figura 3-16: Op̧̧ões necessárias para isolar o setor em falta.

Note que nesta primeira etapa (que pode ser chamada de isolação do problema e restabelecimento imediato da energia nas áreas sãs), as manobras não ocorreram em pares.

Após o procedimento descrito anteriormente, as chaves alteradas sempre ocorrerão aos pares, ou seja, quando uma chave é aberta outra é fechada. Para determinar o número de manobras para originar uma dada configuração, considere o estado das chaves em 3 configurações específicas: configuração inicial (o) (nesta configuração o setor em falta se encontra isolado e a energia restabelecida aos setores a jusante), configuração alterada ( $x$ ) e configuração final $(y)$. Dessa forma, considerando que uma configuração $y$ originou-se de alterações em uma configuração $x$, temos 3 possibilidades para computar o número de chaves alteradas da configuração $y$ (Santos 2009):

1. Os estados das duas chaves alteradas em $y$, em relação $x$, são diferentes dos estados dessas chaves em $o$. Deste modo, o número de chaves alteradas de $y$ será o número de chaves alteradas de $x$ mais 2. Considere que as chaves 1 e 4 da Tabela 3.5 foram alteradas em $x$ para $y$. Como $y_{1} \neq o_{1}$ e $y_{4} \neq o_{4}$, duas manobras de chaves a mais que as manobras para implantar $x$ são necessárias. Como de $o$ para $x, 2$ alterações foram realizadas, de $o$ para $y$ são necessárias 4 manobras; 
Tabela 3-5: Manobras de chaves: Caso 1

\begin{tabular}{|c|c|c|c|c|c|}
\hline & \multicolumn{3}{|c|}{ Configurações } \\
\hline & & & o & $\mathbf{x}$ & $\mathbf{y}$ \\
\hline \multirow{5}{*}{$\begin{array}{l}\bar{y} \\
D_{0}^{2} \\
\stackrel{\sigma}{0} \\
\overrightarrow{0}\end{array}$} & \multirow{5}{*}{ 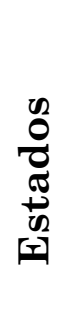 } & 1 & 1 & 1 & 0 \\
\hline & & 2 & 1 & 0 & 0 \\
\hline & & 3 & 0 & 1 & 1 \\
\hline & & 4 & 0 & 0 & 1 \\
\hline & & 5 & 1 & 1 & 1 \\
\hline
\end{tabular}

2. Os estados das duas chaves alteradas em $y$, em relação a $x$, são iguais aos estados dessas chaves em $o$. Portanto, o número de chaves alteradas de $y$ será o número de chaves alteradas de $x$ menos 2 . Considere alterações realizadas nas chaves 2 e 3 da Tabela 3.6. Como $y_{2}=o_{2}$ e $y_{3}=o_{3}$, os estados dessas duas chaves em $y$ retornaram aos seus estados em $o$. Portanto, para implantar $y$ serão necessárias 2 manobras a menos que o número de manobras para implantar $x$;

Tabela 3-6: Manobras de chaves: Caso 2

\begin{tabular}{|c|c|c|c|c|c|}
\hline & \multicolumn{3}{|c|}{ Configurações } \\
\hline & & & $\mathbf{O}$ & $\mathbf{x}$ & $\mathbf{Y}$ \\
\hline \multirow{5}{*}{\multicolumn{2}{|c|}{ 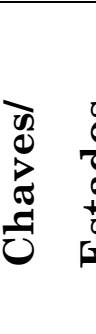 }} & 1 & 1 & 1 & 1 \\
\hline & & 2 & 1 & 0 & 1 \\
\hline & & 3 & 0 & 1 & 0 \\
\hline & & 4 & 0 & 0 & 0 \\
\hline & & 5 & 1 & 1 & 1 \\
\hline
\end{tabular}

3. O estado de uma das chaves alteradas em $y$, em relação a $x$, é igual ao estado dessa chave em $o$ e, o estado da outra chave alterada é diferente. Deste modo, o número de chaves alteradas de $y$ será igual ao número de chaves alteradas de $x$. 
Tabela 3-7: Manobras de chaves: Caso 3

\begin{tabular}{|c|c|c|c|c|c|}
\hline & \multicolumn{3}{|c|}{ Configurações } \\
\hline & & & $\mathbf{0}$ & $\mathbf{x}$ & $\mathbf{Y}$ \\
\hline \multirow{5}{*}{$\begin{array}{l}\bar{y} \\
D_{0}^{0} \\
\stackrel{\sigma}{0}\end{array}$} & \multirow{5}{*}{ 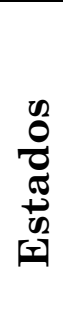 } & 1 & 1 & 1 & 1 \\
\hline & & 2 & 1 & 0 & 1 \\
\hline & & 3 & 0 & 1 & 1 \\
\hline & & 4 & 0 & 0 & 0 \\
\hline & & 5 & 1 & 1 & 0 \\
\hline
\end{tabular}

Em todos os casos acima, 2 mudanças de chaves em $x$ para originar $y$ são necessárias, porém não garante que essas duas mudanças sejam efetivas, ou seja, em relação à configuração inicial $o$. Por esse motivo, não se pode simplesmente dizer que o número de manobras necessárias para implantar y é o número de manobras para implantar $x$ mais 2 .

\subsection{Conclusões}

O objetivo desta dissertação de mestrado é desenvolver e implementar uma metodologia, para tratamento do problema de restabelecimento de energia em SDs de grade porte, que possibilite a obtenção de planos de restabelecimento priorizando a utilização de chaves automáticas. Conforme apresentado neste capítulo, dentre as metas-heurísticas aplicadas para o tratamento do problema de otimização multiobjetivo de restabelecimento de energia em SDs, destacam-se os AEMOs. Porém, para aumentar a eficiência computacional desses algoritmos, torna-se necessário empregar estruturas de dados adequadas para representar a topologia elétrica dos SDs. Dentre as estruturas já utilizadas para isso, destaca-se a RNP, pelas razões apresentadas na seção 3.5. 


\section{Capítulo}

\section{Metodologia Proposta}

A metodologia proposta tem como objetivo sanar as dificuldades encontradas por algumas metodologias já desenvolvidas para restabelecimento de energia em tempo real de sistema de distribuição de grande porte. O diferencial da pesquisa está na etapa de elaboração do plano de restabelecimento sendo que o mesmo durante este processo priorize a utilização de chaves automáticas. Neste capitulo será apresentado, inicialmente, a metodologia tomada como base (MEAN + Pares de Manobras), logo após apresentar-se-ão as alterações efetuadas no MEAN + Pares de Manobras para desenvolvimento da metodologia proposta e, em seguida, exemplificar-se-á a aplicação da metodologia proposta para o problema de restabelecimento de energia priorizando utilização de chaves automáticas.

\subsection{MEAN com Tabelas de Pares de Manobras}

A metodologia MEAN com Tabelas de Pares de Manobras apresentados em (Santos et al, 2010) será utilizada como base para desenvolvimento da metodologia neste trabalho. Para tratar o problema de restabelecimento o MEAN com Tabelas de Pares de Manobras considera como indivíduo uma floresta de grafo modelada em RNP que representa a configuração do SD na qual o setor em falta encontra-se isolado e a(s) área(s) sã(s) fora de serviço re-conectada(s) a algum setor da rede com fornecimento de energia elétrica (Santos, 2009).

O MEAN com Tabelas de Pares de Manobras trabalha com várias subpopulações em paralelo, armazenadas em tabelas, sendo que as mesmas armazenam os melhores indivíduos de: carregamento da rede, carregamento da subestação, queda de tensão, perdas resistivas, função agregação e número de operações de manobra em chaves. 
Conforme podemos observar, o algoritmo 7 mostra, de forma simplificada, o funcionamento do MEAN com Tabelas de Pares de Manobras desenvolvido em (Santos et al, 2010).

Algoritmo 7: Algoritmo MEAN com Tabelas de Pares de Manobras.
1: Inicie o contador de gerações $(g \leftarrow 1)$
2: Obtenha a primeira configuração factível
3: Geração das subpopulações iniciais a partir da primeira factível
4: Avaliação dos indivíduos das subpopulações iniciais
5: Teste critério de parada $\left(g_{\max }\right)$
6: while Critério não for atingido faça
7: $\quad$ Seleção aleatoriamente uma subpopulação $\left(P_{*}\right)$
8: $\quad$ Seleção aleatoriamente uma indivíduo $\left(G^{*}\right)$ de $\left(P_{*}\right)$
9: $\quad$ Decisão do operador PAO ou CAO
10: $\quad$ Aplicar operador escolhido para geração do novo indivíduo $\left(G^{\text {new }}\right)$ apartir de $\left(G^{*}\right)$
11: Avaliar o novo indivíduo
12: $\quad$ Selecionar os sobreviventes
13: $\quad$ Incrementar o contador de geração $(g \leftarrow g+1)$

Como ilustrado no Algoritmo 7, o funcionamento do MEAN com Tabelas de Pares Manobras começa pela obtenção da primeira configuração factível a partir da configuração inicial. Sendo que para a solução ser uma configuração factível, esta tem que garantir radialidade do sistema e isolação do setor sob a falta. Esta configuração factível é gerada a partir da isolação do setor sob falta e da conexão de forma aleatória dos setores sem fornecimento de energia à setores adjacentes que não tiveram seu fornecimento de energia interrompido. Logo após a definição da configuração do individuo, o mesmo é tomado como sendo o indivíduo inicial e será responsável pela geração da população inicial e para o processo evolutivo das subpopulações armazenadas em tabelas.

Aplicasse exclusivamente o operador PAO no indivíduo inicial, a fim de gerar a população inicial e logo após a criação do novo indivíduo sua avaliação é feita por meio da aplicação do algoritmo de fluxo de potência de Varredura Direta/Inversa pelo método de Soma de Correntes (Shirmohammadi et al. 1988) com RNP ( Seção 3.10) . E logo após tabelas são preenchidas de acordo com o grau de aptidão do 
indivíduo, ou seja, tem a possibilidade de algumas tabelas iniciarem o processo iterativo sem nenhum indivíduo armazenado.

O MEAN com Tabelas de Pares de Manobras possui dez tabelas de subpopulações (tabelas $P_{j}, j=1, \ldots 10$ ):

- $\quad P_{1}-$ soluções com os menores valores de função agregação;

$$
f(x)=\delta 1 x 1+\delta 2 x 2+\delta 3 \times 3+\delta 4 x 4+\delta 5 x 5
$$

onde $x_{1}, x_{2}, x_{3}, x_{4}$ e $x_{5}$ correspondem, respectivamente, somatória das perdas de potência em $\mathrm{kW}$, ao número de chaveamentos, ao máximo carregamento da rede em p.u, ao máximo carregamento da subestação em p.u, à máxima queda de tensão em p.u, e $\delta i$ é o peso de cada objetivo $x i$.

- $\quad P_{2}-$ soluções com os menores valores de perdas resistivas;

- $\quad P_{3}$ - soluções com os menores valores de carregamento da rede;

- $\quad P_{4}$ - soluções com os menores valores de carregamento da subestação;

- $P_{5}$ - soluções com os menores valores de queda de tensão;

- $P_{5+i}$ - soluções com os menores valores de perdas e com $i$ pares de manobras após a isolação da falta e reconexão das cargas sem fornecimento, sendo que $i=1, \ldots, 5$.

Depois da criação da população inicial, o MEAN com Tabelas de Pares de Manobras iniciará então o processo iterativo onde há evolução das populações devido ao processo de competição entre as soluções geradas. A seleção do novo indivíduo para reprodução inicia-se pela escolha randômica de uma tabela de subpopulação $P_{*}$

Em seguida, a seleção de um indivíduo $G^{*}$, pertencente à tabela da subpopulação $P_{*}$, é feita também de forma randômica. Com isso uma nova solução $G^{\text {new }}$ é gerada por meio da aplicação dos operadores PAO e CAO em $G^{*}$. Em seguida avalia-se o grau de aptidão desse indivíduo $G^{\text {new }}$ e este é comparado com os piores indivíduos de todas as tabelas de subpopulações e será inserido em uma tabela $P_{q}$ qualquer, se $G^{\text {new }}$ for melhor que a pior solução presente em $P_{q}$.

O critério de parada adotado para o MEAN com Tabelas de Pares de Manobras será o número máximo de gerações $g_{\max }$ parametrizado no início do algoritmo. 


\subsection{Metodologia de Priorização de Chaves Automáticas}

Com intuído de priorizar a utilização de chaves automáticas optou-se como critério de avaliação da solução minimizar a utilização de chaves manuais, por exemplo, dois indivíduos com o mesmo número total de manobras de chaves e diferente número de manobras de chaves manuais, o melhor indivíduo será o que apresentar menor número de operação de chaves manuais. Assim esse indivíduo exigirá maior utilização de chaves automáticas para um mesmo número de manobras totais.

Para funcionamento dessa metodologia para priorização de chaves automáticas algumas alterações e inserções serão necessárias na metodologia tomada com base (MEAN com Tabelas de pares de manobras (Santos et al, 2010)), tais como: alterações dos critérios de inserção e objetivos dos indivíduos nas tabelas $P_{6}, P_{7}, P_{8}, P_{9}$ e $P_{10}$; criação de um vetor para armazenar o tipo das chaves (manuais e automáticas) e por fim modificação do algoritmo de cálculo de manobras.

\subsubsection{Novos Critérios de Armazenamento das Subpopulações em Tabelas}

Propõem-se alterações nos critérios que definem as soluções que serão armazenadas nas tabelas $P_{6}, P_{7}, P_{8}, P_{9}$ e $P_{10}$ e a criação de uma nova tabela de subpopulação $\left(P_{11}\right)$. Conforme dito anteriormente, a metodologia tomada como base tem com critério de armazenamentos das subpopulações $P_{6}, P_{7}, P_{8}, P_{9}$ e $P_{10}$ soluções que possuem menor valor de perdas resistivas e que possuem respectivamente, 1, 2, 3, 4, e 5 pares de manobras totais. Os critérios de armazenamento da metodologia tomada como base de um indivíduo $G^{\text {new }}$ em uma tabela $P_{5+i}(1 \leq i \leq 5)$ são: se $P_{5+i}$ não estiver cheia, então $G^{\text {new }}$ será inserido na mesma sem nenhuma avaliação; caso contrário, se $P_{5+i}$ estiver completa, $G^{\text {new }}$ será inserido em uma tabela $P_{5+i}$ somente se tiver $i$ pares de manobras e possuir perdas menores que o pior indivíduo existente em $P_{5+i}$.

Portanto para atender ao objetivo deste trabalho de priorizar a utilização de chaves automáticas, foram propostos novos critérios de armazenamento nas tabelas de manobras. A saber: 
- $\quad P_{6}$ - zero manobra de chaves manuais, ou seja, apenas manobras em automáticas;

- $\quad P_{7}-1$ à 4 manobras de chaves manuais;

- $P_{8}-5$ à 8 manobras de chaves manuais;

- $P_{9}-9$ à 12 manobras de chaves manuais;

- $P_{10}-13$ à 16 manobras de chaves manuais.

Propõe-se, também, uma alteração na avaliação de todos os indivíduos durante o processo de inserção nas tabelas, mesmo quando a tabela estiver incompleta. Ou seja, aplica-se um filtro no processo de geração da população inicial onde apenas soluções factíveis serão incrementadas nas tabelas de subpopulações. Verificou-se que sem essa avaliação, durante o processo de evolução das subpopulações armazenadas nas tabelas poderia haver indivíduos inadequados ao critério estabelecido e que se manterão até o final do algoritmo, por exemplo: em $P_{9}$ indivíduos com manobras de chaves manuais menor que 9.

Devido a esse controle do preenchimento das tabelas, as mesmas ficarão completas em instantes diferentes, em que o processo de evolução das subpopulações armazenadas nestas tabelas começará em gerações diferentes.

Tendo em vista a possibilidade de dois ou mais indivíduos empatarem no critério específico de cada uma das Tabelas de manobras em chaves manuais, foram criados alguns critérios de desempate na tentativa de prestigiar os melhores indivíduos. Dessa forma, nas Tabelas $P_{i}$, com $1 \leq i \leq 5$, são minimizados simultaneamente os seguintes parâmetros, cuja prioridade de otimização é a mesma na qual estes são apresentados a seguir: número de manobras em chaves manuais; número de manobras em chaves automáticas; menor queda de tensão; e menor carregamento da rede.

Outra alteração proposta nesse trabalho é a inserção de uma tabela $P_{11}$, na metodologia, com intuito de criar uma tabela capaz de minimizar ao mesmo tempo o número de manobras ponderadas, ou seja, o número ponderado de manobras em chaves manuais e automáticas para obtenção de uma configuração $G^{y}$ a partir de uma configuração $G^{i}$ definido por:

$$
\text { FIT } 2\left(G^{y}, G^{i}\right)=\text { Manobras Manuais_ } G^{y}+\frac{1}{10} * \text { Manobras Auto_ } G^{y}
$$


onde, o primeiro termo da equação 4.2 representam o número Manobras Manuais_G $G^{y}$ e o segundo o número Manobras Auto_G $G^{y}$ alteradas em relação $G^{i}$, e o custo de uma manobra de uma chave manual é 10 vezes maior que o custo de uma manobra de chave automática.

Os critérios adotados nas outras tabelas $P_{6}, P_{7}, P_{8}, P_{9}$ e $P_{10}$ não foram considerados, sendo assim, logo depois de preenchida a tabela, os indivíduos que entrarão na tabela $P_{11}$, serão aqueles que possuírem menor valor ponderado de manobras em relação ao pior indivíduo da tabela $P_{11}$.

Vale ressaltar à importância das tabelas $P_{1}$ à $P_{5}$, onde as mesmas foram mantidas durante o processo evolutivo com intuito de abranger uma maior quantidade do espaço de busca, tornando o algoritmo mais robusto para sair de ótimos locais (conforme atestam os resultados apresentados na seção 5.2.2).

\subsubsection{Seleção do Melhor Indivíduo}

Ao término do processo evolutivo, a metodologia MEAN com Tabelas de pares de manobras, utilizada como base para desenvolvimento da metodologia proposta, fornece um conjunto de soluções factíveis. Para auxiliar os operadores na tarefa de determinar um único plano de restabelecimento de energia em situação de contingência, a metodologia proposta analisa as soluções factíveis armazenadas nas Tabelas de pares de manobras manuais. Para isso, busca-se inicialmente a melhor solução armazenada na Tabela $P_{6}$ (melhor em relação à quantidade de manobras em manuais e aos critérios de desempate apresentados anteriormente). Se essa tabela estiver vazia, o melhor indivíduo da Tabela $P_{7}$ será escolhido e assim por diante, até a obtenção de uma solução final.

Se solução alguma for armazenada nas tabelas de pares de manobras manuais $P_{6}, P_{7}, P_{8}, P_{9}$ e $P_{10}$, o indivíduo selecionado será o que estiver presente na primeira linha da tabela $P_{1}$, ou seja, indivíduo que tem o menor valor de função agregação. 


\subsection{Novo Contador de Manobras}

O novo algoritmo para cálculo do número de manobras consiste em tratar o tipo da chave que esta sendo alterada e a cada nova configuração geradas efetuar separadamente o cálculo do número de manobras de chaves automáticas e chaves manuais. Com base no algoritmo apresentado na seção 3.11 (Santos et al, 2010), o novo algoritmo também considera que após a isolação da falta e a re-conexão dos setores sãos fora de serviço, as manobras deverão ocorrer sempre em pares, para cada chave aberta uma tem que ser fechada; também considera as três configurações: inicial, alterada e final.

Com intuito de auxiliar o novo contador, para armazenar separadamente o número de manobras de chaves automáticas e manuais, foi necessária à criação de dois vetores auxiliares e uma matriz. O primeiro vetor auxiliar, com dimensão de $N_{\text {chaves }}$ (número de chaves presentes no sistema), é responsável por armazenar os estados das chaves na configuração de pré-falta; o segundo vetor auxiliar, também com dimensões $N_{\text {chaves }}$ (número de chaves presentes no sistema), é responsável por armazenar o tipo de chave (automática ou manual); e a matriz auxiliar tem dimensões $3 \times g_{\max }$ sendo responsável por armazenar o número de manobras em automáticas, em manuais, e manobras totais por geração. Por exemplo, para uma configuração $G^{y}$, qualquer, na primeira linha dessa matriz na ipsilonésima coluna estará salva o número de manobras em automáticas alteradas em relação à configuração $G^{i}$; na segunda linha dessa matriz na ipsilonésima coluna estará salva o número de manobras em manuais alteradas em relação à configuração $G^{i}$ e por final a terceira linha dessa matriz na ipsilonésima coluna estará salva o número de manobras totais alteradas em relação à configuração $G^{i}$, em que o cálculo para estes valores de manobras é realizado através do Algoritmo 8: 
Algoritmo 8: Contador de Manobras.

1: Para cada configuração $G^{y}$, gerada a partir de uma configuração $G^{x}$, comparam-se todos os estados das duas chaves alteradas em $G^{y}\left(G_{j}^{y}\right.$ e $\left.G_{k}^{y}\right)$, com os estados das mesma em $G^{i}\left(G_{j}^{i}\right.$ e $\left.G_{k}^{i}\right)$, em que além disso verifica-se o tipo dessa chave.

2: $y \leftarrow 1$;

3: para $y=1$ até $y=g_{\max }$ faça:

4: $\quad$ Man.de Chaves Manuais $G^{y} \leftarrow$ Man.de ChavesManuais $G^{x}$

5: $\quad$ Man.de Chaves Auto $G^{y} \leftarrow$ Man. de Chaves Auto $G^{x}$

6: **Primeira chave alterada**

7: $\boldsymbol{s e}\left(G_{j}^{y} \neq G_{j}^{y}\right)$ então // Se $G_{j}^{y}$ não retornou ao seu estado em $G^{i}$.

8: $\quad \boldsymbol{s e}\left(G_{j}^{y}\right.$ é Man. de Chave Manual $)$ então

9: $\quad$ Man. de Chaves Manuais $G^{y}=$ Man.de Chaves Manuais $G^{y}+1$

10: $\quad$ se não

11: $\quad$ Man. de Chaves Auto $G^{y}=$ Man. de Chaves Auto $G^{y}+1$

12: se não // Se $G_{j}^{y}$ retornou ao seu estado em $G^{i}$.

13: $\quad \boldsymbol{s e}\left(G_{j}^{y}\right.$ é Man. de Chave Manual) então

14: $\quad$ Man. $\quad$ de Chaves Manuais $G^{y}=$ Man.de Chaves Manuais $G^{y}-1$

15: $\quad$ se não

16: $\quad$ Man. de Chaves Auto $G^{y}=$ Man. de Chaves Auto $G^{y}-1$

$17: * *$ Segunda chave alterada**

18: $\boldsymbol{s} \boldsymbol{e}\left(G_{k}^{y} \neq G_{k}^{y}\right)$ então // Se $G_{k}^{y}$ não retornou ao seu estado em $G^{i}$.

19: $\quad \boldsymbol{s e}\left(G_{k}^{y}\right.$ é Man.de Chave Manual $)$ então

20: $\quad$ Man. $\quad$ de Chaves Manuais $G^{y}=$ Man.de Chaves Manuais $G^{y}+1$

21: $\quad$ se não

22: $\quad$ Man. de Chaves Auto $G^{y}=$ Man. de Chaves Auto $G^{y}+1$

23: se não // Se $G_{k}^{y}$ retornou ao seu estado em $G^{i}$.

24: $\quad \boldsymbol{s e}\left(G_{k}^{y}\right.$ é Man. de Chave Manual ) então

25: $\quad$ Man. $\quad$ de Chaves Manuais $G^{y}=$ Man.de Chaves Manuais $G^{y}-1$

26: $\quad$ se não

27: $\quad$ Man. de Chaves Auto $G^{y}=$ Man. de Chaves Auto $G^{y}-1$

Para ilustrar o procedimento proposto, considero o grafo da Figura 4.1, (Kagan 1999), que corresponde a uma configuração de um SD composto por 8 alimentadores, 23 setores e 28 chaves, sendo que as arestas pontilhadas representam chaves normalmente abertas (NA) e as contínuas representam chaves 
normalmente fechadas (NF); as arestas da cor azul chaves automáticas e as com a cor preta chaves manuais. Portanto, a partir da isolação do setor sob falta e da reconexão dos setores sãos que ficaram fora de serviço, as manobras em chaves ocorrem sempre em pares, assim temos três formas de computar as manobras, conforme descrito no Algoritmo 8, considerando uma configuração $G^{i}$ e uma configuração $G^{y}$ gerada a partir de $G^{x}$. Seguem abaixo exemplos dos três casos de cálculo de manobras proposto pelo Algoritmo 8,

Caso 1: quando o estado em $G^{y}$, das duas chaves alteradas em $G^{x}$, é diferente em $G^{i}$. Através do Algoritmo 8, sabe-se que o número total de chaves alteradas em $G^{y}$, em relação à $G^{i}$, será o número total de chaves alteradas em $G^{x}$ mais dois; e que antes de computar o número de chaves alteradas de $G^{y}$, deve-se verificar de que tipo elas são, para que assim seja incrementando o contador específico (Man.de Chaves Manuais $G^{y}$ e Man.de Chaves Auto $G^{y}$ ).

Por exemplo, utilizando a Figura 4.1 considere uma falta no setor 2, e a seleção da primeira configuração factível para gerar uma segunda configuração factível, em que para gerar essa configuração foi efetuada a manobra de abertura da chave 17 e o fechamento da chave 20. Para computar essas manobras em $G^{2}$, em relação à $G^{i}$, o Algoritmo proposto busca o número de manobras manuais e manobras automáticas da configuração que a gerou, onde para este exemplo foi $G^{1}$, e $\quad$ o salva em (Man.de Chaves Manuais $G^{2}$ e Man.de Chaves Auto $G^{2}$ ) respectivamente. $\mathrm{Na}$ Tabela 4.1, podemos observar que na primeira coluna da matriz, estão armazenados os valores de manobras necessárias para gerar esta configuração $G^{1}$, portanto os contadores assumiram inicialmente os seguintes valores Man.de Chaves Manuais $G^{2}=1$ e Man.de Chaves Auto $G^{2}=2$. Assim o Algoritmo 8 comparará separadamente, o estado em $G^{2}$ das chaves alteradas (17 e 20) como o estado em $G^{i}$, onde estão armazenados no vetor apresentado na Tabela 4.4, para a chave 17, que foi aberta e cujo estado passou pra 0. Observe que possui estado diferente em $G^{i}$, logo um dos contadores deverá ser incrementado, mas para saber em qual contador incrementar deverá fazer uma nova consulta na Tabela 4.4 na coluna 17 para verificar o tipo da chave. Logo após análise, obtém-se que a chave 17 é manual, portanto o contador que deverá ser incrementado em um será o contador Man.de Chaves Manuais $G^{2}$ que passará a armazenar Man. de Chaves Manuais $G^{2}=2$. O mesmo procedimento é feito com a chave 20, que através da Tabela 4.4 é definida com sendo automática, portanto o contador de 
automática passará armazenar o valor de Man.de Chaves Auto $G^{2}=3$. Portanto depois desta verificação a Tabela 4.1 é atualizada gerando como podemos observar na Tabela 4.2 .

Para geração da configuração 3 , vamos adotar o abertura da chave 22 e fechamento da chave 24 da configuração 2, para este caso uma das chaves alteradas é automática, portanto o número de manobras desta configuração será apresentado na Tabela 4.3

Tabela 4-1 Matriz responsável por armazenas manobras por configuração.

\begin{tabular}{|l|l|l|l|l|l|l|l|}
\hline Configuração & 1 & 2 & 3 & 4 & 5 & $\ldots$ & $g_{\max }$ \\
\hline Man. Chave Auto. & 2 & & & & & $\ldots$ & \\
\hline Man. De Chave Manual & 1 & & & & & $\ldots$ & \\
\hline Manobras Totais & $\mathbf{3}$ & & & & & $\ldots$ & \\
\hline
\end{tabular}

Tabela 4-2: Matriz atualizada para configuração 2.

\begin{tabular}{|l|l|l|l|l|l|l|l|}
\hline Configuração & 1 & 2 & 3 & 4 & 5 & $\ldots$ & $g_{\max }$ \\
\hline Man. Chave Auto. & 2 & 2 & & & & $\ldots$ & \\
\hline Man. De Chave Manual & 1 & 3 & & & & $\ldots$ & \\
\hline Manobras Totais & $\mathbf{3}$ & $\mathbf{5}$ & & & & $\ldots$ & \\
\hline
\end{tabular}

Tabela 4-3: Matriz atualizada para configuração 3.

\begin{tabular}{|l|l|l|l|l|l|l|l|}
\hline Configuração & 1 & 2 & 3 & 4 & 5 & $\ldots$ & $g_{\max }$ \\
\hline Man. Chave Auto. & 2 & 2 & 3 & & & $\ldots$ & \\
\hline Man. De Chave Manual & 1 & 3 & 4 & & & $\ldots$ & \\
\hline Manobras Totais & $\mathbf{3}$ & $\mathbf{5}$ & $\mathbf{7}$ & & & $\ldots$ & \\
\hline
\end{tabular}

Tabela 4-4: Vetor que armazena os estado e tipos das chaves presentes no sistema.

\begin{tabular}{|l|c|c|c|c|c|c|c|c|c|c|c|c|c|c|}
\hline $\mathbf{N}^{\circ}$ da Chave & $\mathbf{1}$ & $\mathbf{2}$ & $\mathbf{3}$ & $\mathbf{4}$ & $\mathbf{5}$ & $\mathbf{6}$ & $\mathbf{7}$ & $\mathbf{8}$ & $\mathbf{9}$ & $\mathbf{1 0}$ & $\mathbf{1 1}$ & $\mathbf{1 2}$ & $\mathbf{1 3}$ & $\mathbf{1 4}$ \\
\hline Estado & 0 & 0 & 1 & 0 & 1 & 1 & 1 & 0 & 1 & $\mathbf{0}$ & 0 & $\mathbf{1}$ & 1 & $\mathbf{0}$ \\
\hline Tipo & 0 & 0 & 0 & 0 & 0 & 0 & 0 & 0 & 0 & $\mathbf{1}$ & 0 & $\mathbf{1}$ & 0 & $\mathbf{1}$ \\
\hline $\mathbf{N}^{\circ}$ da Chave & $\mathbf{1 5}$ & $\mathbf{1 6}$ & $\mathbf{1 7}$ & $\mathbf{1 8}$ & $\mathbf{1 9}$ & $\mathbf{2 0}$ & $\mathbf{2 1}$ & $\mathbf{2 2}$ & $\mathbf{2 3}$ & $\mathbf{2 4}$ & $\mathbf{2 5}$ & $\mathbf{2 6}$ & $\mathbf{2 7}$ & $\mathbf{2 8}$ \\
\hline Estado & 0 & 0 & 1 & 0 & $\mathbf{1}$ & 0 & 1 & $\mathbf{1}$ & 1 & 0 & 1 & 1 & $\mathbf{0}$ & 1 \\
\hline Tipo & 0 & 0 & 0 & 0 & $\mathbf{1}$ & 0 & 0 & $\mathbf{1}$ & 0 & 0 & 0 & 0 & $\mathbf{1}$ & 0 \\
\hline
\end{tabular}




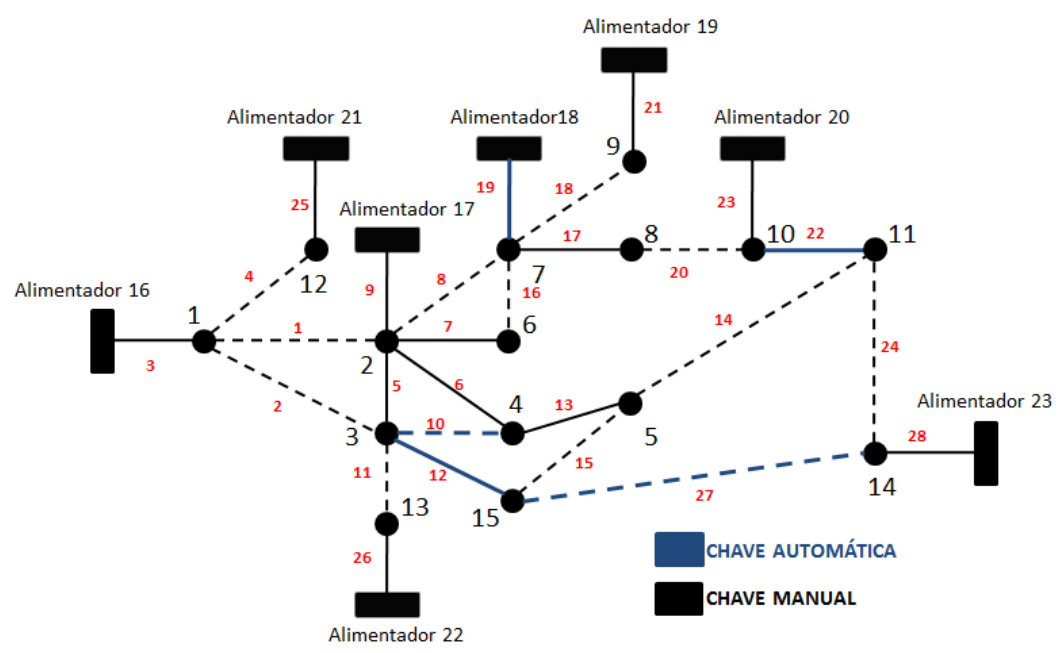

Figura 4-1: Configuração Inicial, SDR Kagan.

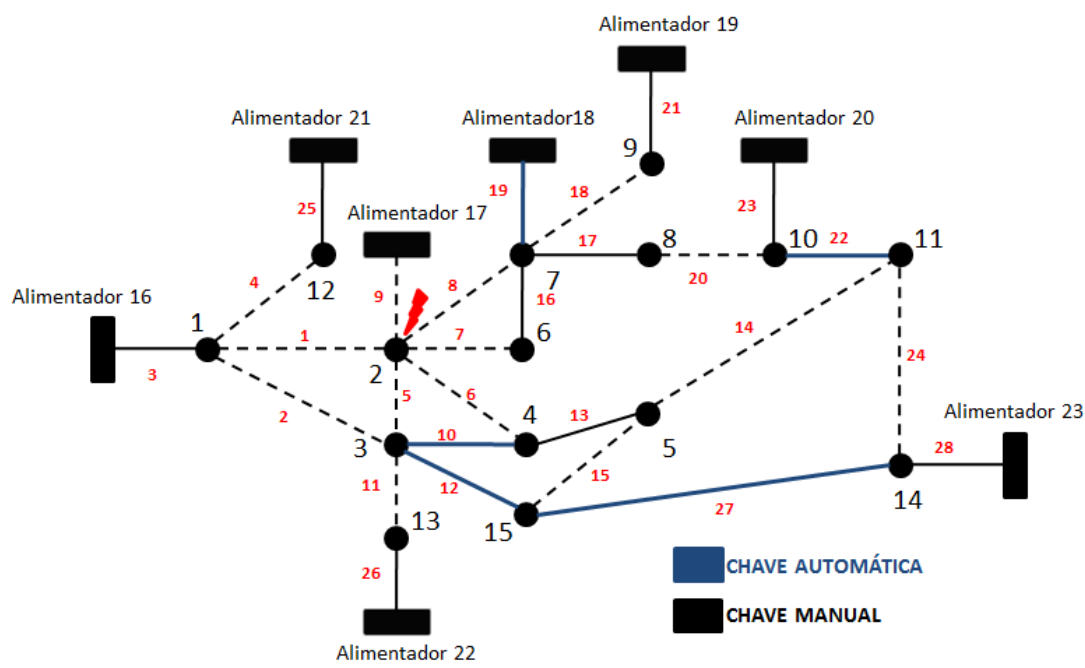

Figura 4-2: Primeira Configuração Factível, SDR Kagan.

Caso 2: o estado de $G^{y}$, das duas chaves aletradas em $G^{x}$, é igual ao estado de $G^{i}$. Através do Algoritmo 8 da mesma forma que foi feito no caso 1, será necessário determinar o tipo da chave alterada para decrementar em 2 os contadores específico. Por exemplo, vamos considerar uma geração 4 por meio de abertura da chave 20 e fechamento da chave 17 da configuração 3 determinada. Tendo em vista que a configuração foi obtida através de $G^{3}$, então os contadores assumirão valores iniciais respectivamente de Man. de Chaves Manuais $G^{4}=4$ e Man. de Chaves Auto $G^{4}=3$. Logo após, fazendo a comparação das chaves com a configuração inicial $G^{i}$, foi verificado que o estado não alterou, portanto os contadores deverão ser decrementados, e para determinação dos contadores é feita análise da Tabela 4.4 em que estão definidos: 
as chaves 17 e 20 são chaves do tipo manual, portanto os contadores terão os seguintes valores

respectivamente Man. de Chaves Manuais $G^{4}=2$ e Man. de Chaves Auto $G^{4}=3$, e os valores que serão salvos na quarta coluna da matriz estão ilustrados na Tabela 4.5.

Tabela 4-5: Matriz atualizada para configuração 4.

\begin{tabular}{|l|l|l|l|l|l|l|l|}
\hline Configuração & 1 & 2 & 3 & 4 & 5 & $\ldots$ & $g_{\max }$ \\
\hline Man. Chave Auto. & 2 & 2 & 3 & 3 & & $\ldots$ & \\
\hline Man. De Chave Manual & 1 & 3 & 4 & 2 & & $\ldots$ & \\
\hline Manobras Totais & $\mathbf{3}$ & $\mathbf{5}$ & $\mathbf{7}$ & $\mathbf{5}$ & & $\ldots$ & \\
\hline
\end{tabular}

Caso 3: o estado de $G^{y}$ e, de uma das chaves aletradas em $G^{x}$, é igual ao estado de $G^{i}$, enquanto que o estado da outra chave em $G^{y}$ é diferente do seu estado em $G^{i}$. Portanto, conforme os casos 1 e 2 devem verificar-se o estado e o tipo da chave e manter o mesmo valor dos contadores armazenados. Por exemplo, considera a configuração 5 , gerada a partir da configuração 3 por meio da abertura da chave 23 e fechamento da chave 17. Conforme Algoritmo 8, os contadores estão com os seguintes valores iniciais armazenados Man.de Chaves Manuais $G^{5}=$ 4 e Man. de Chaves Auto $G^{5}=3$ referente à configuração 3. Fazendo análise para a chave 23 verifica-se que alterou estado em relação $G^{i}$ e a chave é do tipo manual, portanto o contador de chave manual será incrementado assumindo valor de Man. de Chaves Manuais $G^{5}=5$. Já para a chave 17 verificou-se que não houve alteração do estado e que também é uma chave do tipo manual, portanto o contador de chave manual deverá ser decrementado, ou seja, assumirá o valor de Man. de Chaves Manuais $G^{5}=4$. Portanto no final do Algoritmo o número de manobras para configuração 5 será conforme ilustrado na Tabela 5.6.

Tabela 4-6: Matriz atualizada para configuração 5.

\begin{tabular}{|l|l|l|l|l|l|l|l|}
\hline Configuração & 1 & 2 & 3 & 4 & 5 & $\ldots$ & $g_{\max }$ \\
\hline Man. Chave Auto. & 2 & 2 & 3 & 3 & 3 & $\ldots$ & \\
\hline Man. De Chave Manual & 1 & 3 & 4 & 2 & 4 & $\ldots$ & \\
\hline Manobras Totais & $\mathbf{3}$ & $\mathbf{5}$ & $\mathbf{7}$ & $\mathbf{5}$ & $\mathbf{7}$ & $\ldots$ & \\
\hline
\end{tabular}




\subsection{Conclusões}

Durante a apresentação da metodologia proposta nesta dissertação, verificouse a capacidade de priorização de chaves automáticas durante o processo de restabelecimento de energia. Quando comparada com a metodologia tomada como base, a metodologia proposta torna-se um diferencial, pois através das alterações dos critérios das tabelas pares de manobras e a criação de um novo contador de manobras, tornou-se possível atender a todos os objetivos propostos. 


\section{Capítulo}

\section{Resultados Experimentais}

Neste capítulo serão apresentados os resultados de diversas simulações computacionais da aplicação da metodologia proposta para o tratamento do problema de restabelecimento de energia com priorização de chaves automáticas. As simulações computacionais foram realizadas considerando o sistema de distribuição de energia elétrica da cidade de São Carlos, configuração em operação no ano de 1994, e suas versões duplicada, quadruplicada e octuplicada.

Apresentar-se-ão simulações considerando a ocorrência de uma e múltiplas faltas. Em todas as simulações foram utilizados os seguintes parâmetros de entrada:

- Número máximo de indivíduos gerados $\left(g_{\max }\right)=100.000$;

- Tamanho das subpopulações armazenadas em tabelas $\left(S_{p 1, \ldots, p 11}\right)=5$.

Para efetuar as simulações, foi utilizando um computador com processador Core 2 Quad 2.4GHz, 8GB de memória RAM, Sistema Operacional Linux Ubuntu versão 12.04, e compilador de linguagem C gcc-4.4.

Diante do problema de não dispor da informação da localização das chaves automáticas, desenvolveu-se um programa auxiliar para distribuir as chaves automáticas ao longo dos sistemas simulados. Para cada sistema o programa auxiliar considerou que 7\% das chaves existentes são automáticas, distribuindo-as de forma aleatória ao longo dos sistemas testados. Esse percentual foi escolhido após o estudo das características de alguns SDs de concessionárias brasileiras.

As características dos sistemas utilizados nos testes são as seguintes:

- Sistema 1 (S1 = SD da cidade de São Carlos): 3.860 barras, 532 setores, 631 chaves (509 NF e $122 \mathrm{NA}$ ), sendo, 43 chaves automáticas e 588 chaves manuais, 23 alimentadores e 3 subestações; 
- Sistema 2 (S2 = SD de São Carlos Duplicado): 7.720 barras, 1.064 setores, 1.275 chaves (1.018 NF e 257 NA), sendo, 86 chaves automáticas e 1189 chaves manuais, 46 alimentadores e 6 subestações;

- Sistema 3 (S2 = SD de São Carlos Quadriplicado): 15.440 barras, 2.128 setores, 2.573 chaves (2.036 NF e $537 \mathrm{NA}$ ), sendo, 168 chaves automáticas e 2405 chaves manuais, 92 alimentadores e 12 subestações;

- $\quad$ Sistema 4 (S2 = SD de São Carlos Octuplicado): 30.880 barras, 4.256 setores, 5.158 chaves (4.072 NF e $1.086 \mathrm{NA})$, sendo, 337 chaves automáticas e 4821 chaves manuais, 184 alimentadores e 24 subestações.

Portanto, a fim de validar a metodologia proposta, foram efetuadas simulações nos sistemas 1, 2, 3 e 4 considerando a ocorrência de uma e múltiplas faltas. Na seção 5.2 são apresentadas as simulações com uma única falta e na seção 5.3 com múltiplas faltas.

\subsection{Simulações Para Uma Única Falta}

Com o intuito de validar a metodologia proposta para tratamento do problema de restabelecimento de energia em situações de uma única falta, foram realizados 50 testes em cada um dos quatros sistemas testes considerados no estudo, totalizando 200 execuções da metodologia. Em todos os quatro sistemas testados foi considerada a existência de uma falta no setor 22 , que fica bem na saída do alimentador 9, como podemos observar na Figura 5.1. Observe que para isolar o setor 22 em falta ocorrerá interrupção de fornecimento de energia para todos os consumidores desse alimentador. 


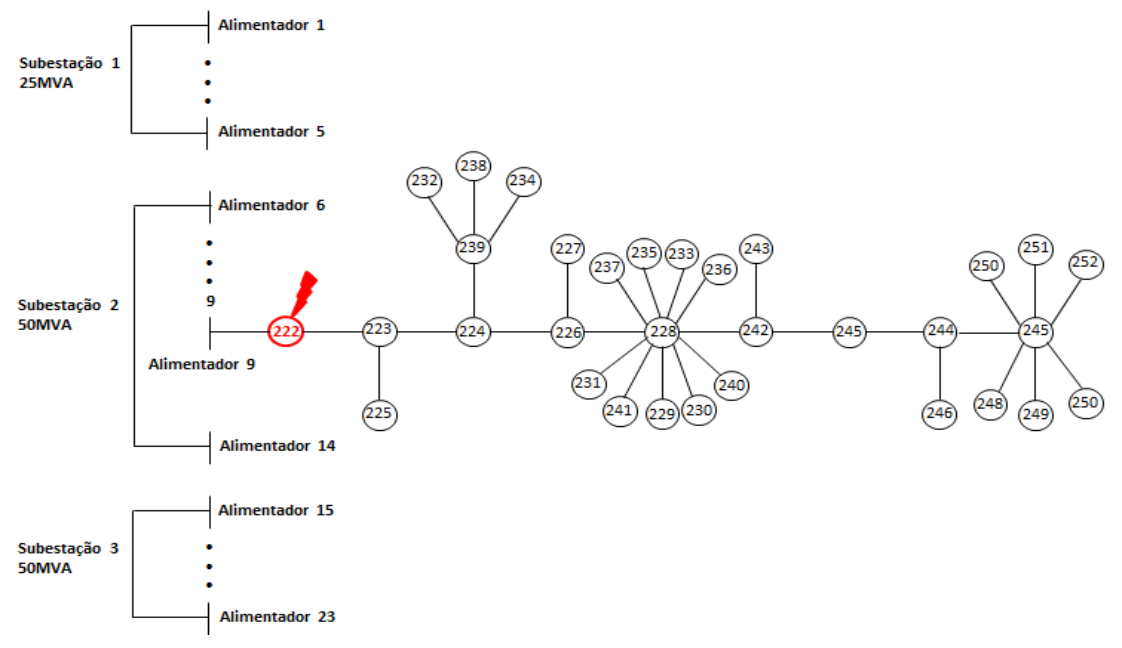

Figura 5-1: Falta no setor 222 do alimentador 9.

Conforme mencionado anteriormente, no capítulo 4 após o setor em falta ter sido identificado e isolado, a metodologia proposta começa a sua execução por meio da determinação da primeira configuração factível, isto é, a primeira configuração na qual os setores são sem fornecimento já estão re-conectados a rede mantendo a estrutura radial e o setor em falta encontra-se isolado. Na Tabela 5.1 são apresentadas as características das diversas primeiras configurações factíveis obtidas pela metodologia proposta quando aplicada aos Sistemas 1,2,3 e 4. Destacase que pelos valores médios e máximos obtidos, a primeira configuração factível encontrada é, para maioria das simulações realizadas, imprópria para operação, devido ao elevado carregamento da rede, ou seja, são configurações factíveis, mas soluções infactíveis.

Conforme descrito na Seção 4.2.2, logo após o término do processo evolutivo dar-se-á inicio à etapa de seleção da solução final, ou seja, da escolha do melhor indivíduo. O melhor indivíduo é selecionado de acordo com os critérios préestabelecidos na seção 4.2.2, lembrado que no final do processo evolutivo, devido aos filtros impostos nas tabelas, apenas soluções factíveis estarão presentes. Portanto, a fim de validar a capacidade de otimização da metodologia proposta, foi confeccionada a Tabela 5.2, que fornece as restrições operacionais e as perdas ôhmicas do melhor individuo no final do processo. Comparando as Tabelas 5.1 e 5.2 é possível observar, através dos valores de queda de tensão, carregamento da rede, carregamento da subestação e perdas ôhmicas, a capacidade da metodologia proposta em minimizar as soluções tornando-as factíveis para todos os sistemas. 
Tabela 5-1: Falta no setor 222 do alimentador 9. Valores das restrições operacionais e perdas para primeira configuração factível obtida. *Desvio Padrão

\begin{tabular}{|c|c|c|c|c|c|}
\hline \multicolumn{6}{|c|}{ APÓS RESTABELECIMENTO } \\
\hline & & MíNIMO & MÉDIO & MÁXIMO & DP* \\
\hline \multirow{4}{*}{ S1 } & Queda de tensão (\%) & 3,25 & 3,4 & 3,8 & 0,2 \\
\hline & Carreg da Rede (\%) & 116,33 & 132,6 & 156,9 & 2,39 \\
\hline & Carreg. De SE (\%) & 99,75 & 103,06 & 107,5 & 0,9 \\
\hline & Perdas (kW) & 228,17 & 358,08 & 415,64 & 48,19 \\
\hline \multirow{4}{*}{ S2 } & Queda de tensão (\%) & 4,12 & 4,5 & 4,8 & 0,9 \\
\hline & Carreg da Rede (\%) & 102 & 138,7 & 155,1 & 3,11 \\
\hline & Carreg. De SE (\%) & 102,7 & 106,3 & 111 & 0,7 \\
\hline & Perdas (kW) & 539,6 & 562,3 & 580,9 & 1,1 \\
\hline \multirow{4}{*}{ S3 } & Queda de tensão (\%) & 3,25 & 3,32 & 4,5 & 0,84 \\
\hline & Carreg da Rede (\%) & 67,12 & 102,45 & 109,6 & 12,65 \\
\hline & Carreg. De SE (\%) & 54,85 & 56,45 & 59,3 & 1,3 \\
\hline & Perdas (kW) & 1096,1 & 1224 & 1365,5 & 14,3 \\
\hline \multirow{4}{*}{ S4 } & Queda de tensão (\%) & 3,25 & 3,7 & 5 & 1,1 \\
\hline & Carreg da Rede (\%) & 65 & 104,96 & 109,6 & 9 \\
\hline & Carreg. De SE (\%) & 54,5 & 56 & 58,75 & 1,12 \\
\hline & Perdas (kW) & 2290,5 & 2452,4 & 2632,5 & 17 \\
\hline
\end{tabular}

Tabela 5-2: Falta no setor 222 do alimentador 9. Valores das restrições operacionais e perdas ao final do processo evolutivo. *Desvio Padrão

\begin{tabular}{|c|c|c|c|c|c|}
\hline \multicolumn{6}{|c|}{ SOLUÇÃO FINAL DO PROCESSO EVOLUTIVO } \\
\hline & & MíNIMO & MÉDIO & MÁXIMO & DP* \\
\hline \multirow{4}{*}{ S1 } & Queda de tensão (\%) & 2,3 & 2,89 & 3,29 & 1,39 \\
\hline & Carreg da Rede (\%) & 56,63 & 65,46 & 96,4 & 9,29 \\
\hline & Carreg. De SE (\%) & 67 & 85,56 & 99,47 & 8,37 \\
\hline & Perdas (kW) & 121,4 & 233,51 & 344,08 & 44,31 \\
\hline \multirow{4}{*}{ S2 } & Queda de tensão (\%) & 3,15 & 3,25 & 3,39 & 1,36 \\
\hline & Carreg da Rede (\%) & 56,63 & 71,36 & 97,38 & 10,82 \\
\hline & Carreg. De SE (\%) & 76,63 & 88,47 & 97,37 & 6,06 \\
\hline & Perdas (kW) & 426,13 & 501,4 & 697,9 & 35,12 \\
\hline \multirow{4}{*}{ S3 } & Queda de tensão (\%) & 3,2 & 3,72 & 4,1 & 0,67 \\
\hline & Carreg da Rede (\%) & 64,5 & 79,12 & 92,81 & 0,6 \\
\hline & Carreg. De SE (\%) & 82,1 & 92,7 & 93 & 1,6 \\
\hline & Perdas (kW) & 945,39 & 1124 & 1367,85 & 21 \\
\hline \multirow{4}{*}{ S4 } & Queda de tensão (\%) & 3,2 & 3,66 & 4,1 & 0,75 \\
\hline & Carreg da Rede (\%) & 63,12 & 78 & 95,1 & 1,4 \\
\hline & Carreg. De SE (\%) & 82 & 90,5 & 95 & 1,3 \\
\hline & Perdas (kW) & 1980,76 & 2358,6 & 2739,1 & 15,9 \\
\hline
\end{tabular}

restabelecimento de energia, além da re-conexão das cargas sãs fora de serviço e da minimização das restrições operacionais e das perdas ôhmicas, é necessária uma 
minimização do número de manobras de chaves utilizadas para gerar uma nova solução. Portanto, através da Tabela 5.3 podemos observar para os Sistemas 1, 2, 3 e 4, o número máximo, médio e mínimo de manobras de chaves manuais e automáticas obtidas pelo método proposto.

Tabela 5-3: Número de Manobras de Chaves para a solução final para os Sistemas 1,2,3 e 4, na ocorrência de uma única falta. *Desvio Padrão

\begin{tabular}{|c|c|c|c|c|c|}
\hline \multicolumn{6}{|c|}{ NÚMERO DE MANOBRAS SOLUÇÃO FINAL } \\
\hline & & MíNIMO & MÉDIO & MÁXIMO & DP* \\
\hline \multirow{3}{*}{ S1 } & Man. Ch Auto & 1 & 1,54 & 3 & 0,7 \\
\hline & Man. Ch Manuais & 3 & 3,78 & 6 & 0,5 \\
\hline & Man. Total & 5 & 5,32 & 7 & 0,7 \\
\hline \multirow{3}{*}{ S2 } & Man. Ch Auto & 1 & 2,12 & 4 & 0,5 \\
\hline & Man. Ch Manuais & 2 & 3 & 4 & 0,72 \\
\hline & Man. Total & 3 & 5,12 & 7 & 0,62 \\
\hline \multirow{3}{*}{ S3 } & Man. Ch Auto & 1 & 1,5 & 4 & 0,9 \\
\hline & Man. Ch Manuais & 3 & 4,1 & 6 & 2,3 \\
\hline & Man. Total & 5 & 5,6 & 7 & 2,4 \\
\hline \multirow{3}{*}{ S4 } & Man. Ch Auto & 1 & 2,1 & 3 & 0,3 \\
\hline & Man. Ch Manuais & 3 & 4,2 & 8 & 0,9 \\
\hline & Man. Total & 4 & 6,3 & 9 & 0,7 \\
\hline
\end{tabular}

Analisando a Tabela 5-3, conforme o sistema foi aumentando, o algoritmo não perdeu eficiência, pelo contrário, quando comparado ao número mínimo de manobras totais de $\mathrm{S} 1$ com $\mathrm{S} 4$, $\mathrm{S} 4$ obteve desempenho melhor do que $\mathrm{S} 1$, em que o mesmo solicitou no mínimo 4 manobras totais para solução final, ressaltando que em todas as soluções finais encontradas para todos os sistemas havia no mínimo uma manobra de chave automática.

\subsubsection{Capacidade de Priorização de Chaves Automáticas}

Com intuito de avaliar a capacidade da metodologia proposta para encontrar a melhor solução, ou seja, aquela com o menor número de manobras de chaves e que priorize a utilização de chaves automáticas; foi desenvolvida a Tabela 5-4 que fornece as características operacionais e as manobras (totais, automáticas e manuais) da melhor solução encontrada durante todo processo evolutivo, sendo assim possível analisar através da Tabela 5-5 o percentual de vezes que a melhor solução foi encontrada. 
De forma sequencial os critérios descritos abaixo são determinantes para definição da melhor solução:

- Número Total de Manobras de Chaves;

- Número de Manobras de Chaves Manuais;

- Carregamento da Rede;

- Queda de tensão;

- Carregamento da SE;

- Perdas ôhmicas.

Analisando a Tabela 5-4, que fornece o melhor indivíduo encontrado para cada sistema de teste. Portanto podemos concluir que a melhor solução encontrada na ocorrência de uma contingência foi no Sistema S1, em que utilizando o mesmo número de manobras das demais, obteve-se o maior número de operações de chaves automáticas.

Tabela 5-4: Características dos melhores indivíduos encontrados durante o algoritmo, para os Sistemas 1,2,3 e 4, na ocorrência de uma única falta.

\begin{tabular}{|c|c|c|c|c|c|}
\hline \multirow{8}{*}{ 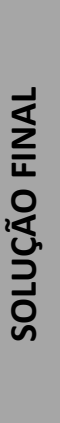 } & & SISTEMA 1 & SISTEMA 2 & SISTEMA 3 & SISTEMA 4 \\
\hline & Queda de tensão (\%) & 3,25 & 3,25 & 3,28 & 3,52 \\
\hline & Carreg da Rede (\%) & 87,03 & 59,31 & 93,88 & 64,06 \\
\hline & Carreg. da SE (\%) & 95,77 & 87,06 & 95,19 & 95,53 \\
\hline & Perdas (kW) & 270,17 & 426,13 & 1274,12 & 2241,24 \\
\hline & Man. Ch Auto & 2 & 1 & 1 & 1 \\
\hline & Man. Ch Manuais & 3 & 4 & 4 & 4 \\
\hline & Man. Totais & 5 & 5 & 5 & 5 \\
\hline
\end{tabular}

Para complementar esta avaliação foram efetuadas 50 simulações a fim de gerar um gráfico (Figura 5.2) mostrando o percentual de vezes que a melhor solução, para cada sistema de teste, esteve presente durante todo processo evolutivo. Sendo assim podemos concluir que o percentual de seleção do melhor indivíduo foi maior que 50\% para todos os sistemas, destacando-se para o sistema $\mathrm{S} 1$ em que o percentual de vezes que o melhor indivíduo foi encontrado foi de aproximadamente $65 \%$. 


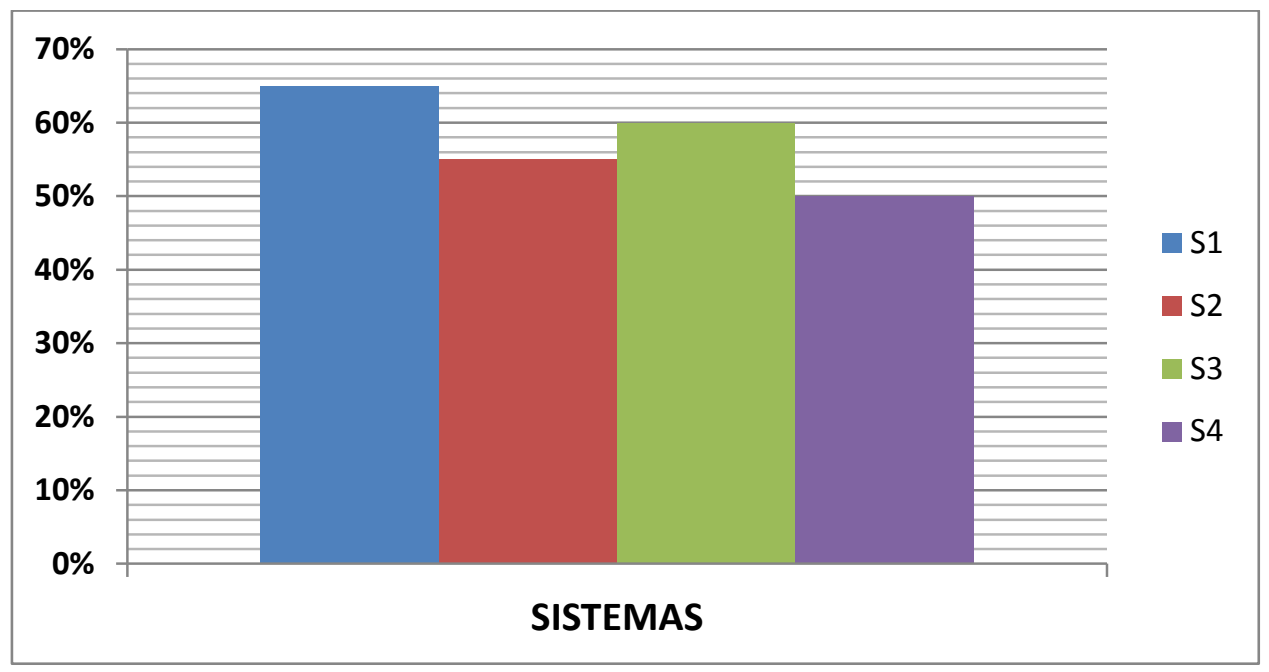

Figura 5-2: Porcentual de vezes que a melhor solução foi encontrada, para os Sistemas 1,2,3 e 4, na ocorrência de uma única falta.

\subsection{Simulações para Múltiplas Faltas}

Com intuito de validação da metodologia proposta para o tratamento do problema de restabelecimento de energia em situações de múltiplas contingências, foram realizados 50 testes, em cada um dos quatros sistemas de teste considerados nos estudos, totalizando 200 execuções da metodologia proposta. Em todos os quatro sistemas testados foram consideradas duas faltas: uma no setor 182, do alimentador 6 , e outra no setor 464 , do alimentador 22 , conforme ilustrado nas figuras 5.3 e 5.4 respectivamente. Observe que esses setores são adjacentes a chaves automáticas.

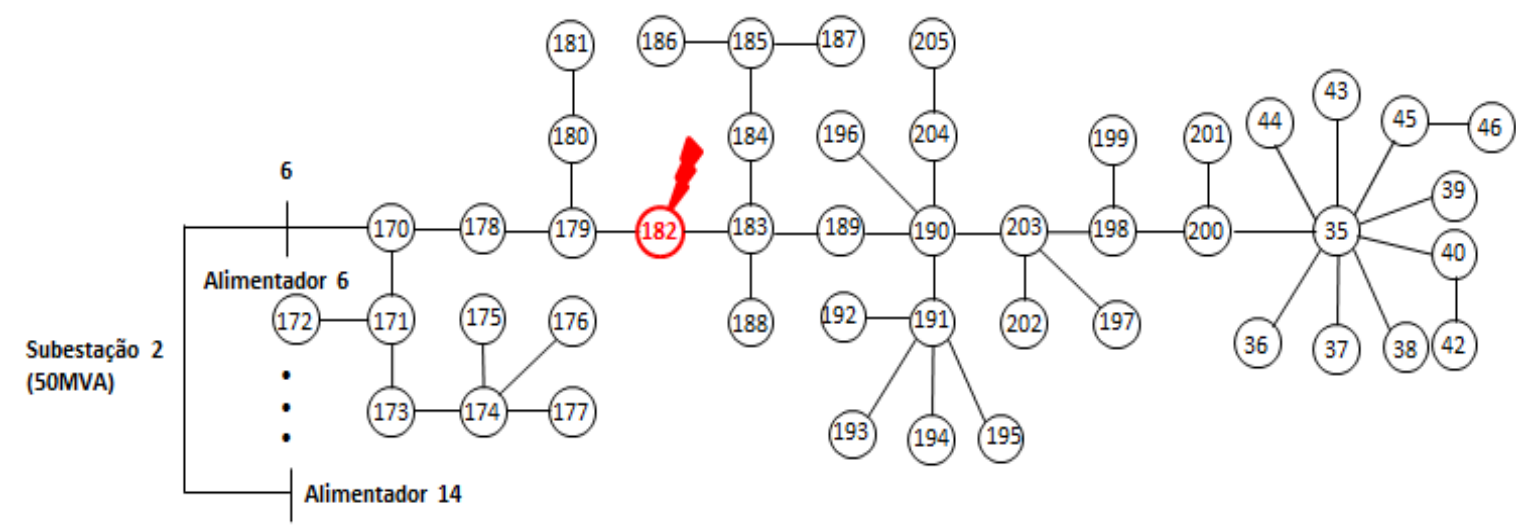

Figura 5-3: Falta no setor 182 do alimentador 6. 


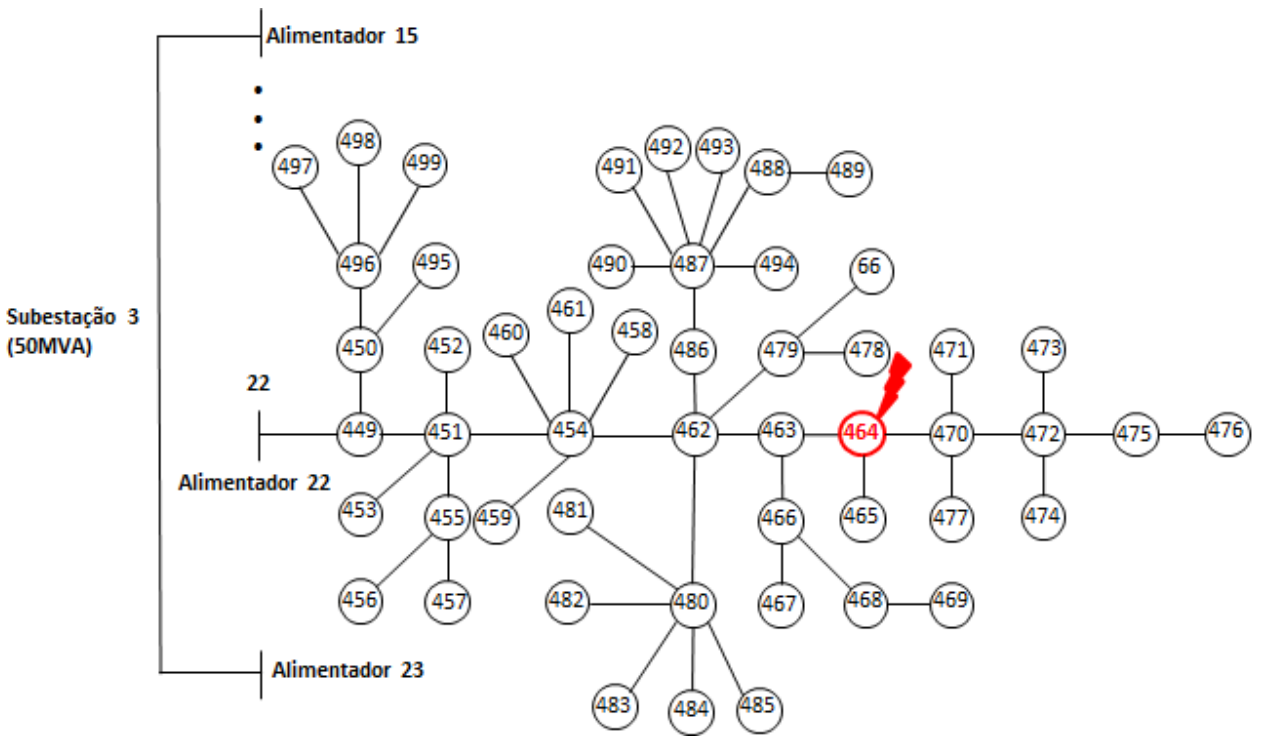

Figura 5-4: Falta no setor 464 do alimentador 6

Considerando os resultados apresentados na Tabela 5-1, que fornece as restrições operacionais e as perdas ôhmicas da primeira configuração factível obtida pelo algoritmo, podemos observar que os resultados encontrados em todos os sistemas serão inviáveis para aplicação, devido à sobrecarga da rede.

Tabela 5-5: Falta nos setores 182 e 464. Valores das restrições operacionais e perdas para primeira configuração factível obtida. *Desvio Padrão

\begin{tabular}{|c|c|c|c|c|c|}
\hline \multicolumn{6}{|c|}{ APÓS RESTABELECIMENTO } \\
\hline & & MÍNIMO & MÉDIO & MÁXIMO & DP \\
\hline \multirow{4}{*}{ S1 } & Queda de tensão (\%) & 3,25 & 3,45 & 4,45 & 0,45 \\
\hline & Carreg da Rede (\%) & 100,23 & 110,15 & 152,02 & 13,59 \\
\hline & Carreg. De SE (\%) & 95,6 & 98,6 & 100,3 & 1,54 \\
\hline & Perdas (kW) & 284,9 & 318,17 & 364,3 & 16,6 \\
\hline \multirow{4}{*}{ S2 } & Queda de tensão (\%) & 4,75 & 4,8 & 6,5 & 0,88 \\
\hline & Carreg da Rede (\%) & 100,5 & 121,1 & 144,5 & 9,6 \\
\hline & Carreg. De SE (\%) & 92,5 & 96 & 100,12 & 1,4 \\
\hline & Perdas (kW) & 592,2 & 725,12 & 755,4 & 18,26 \\
\hline \multirow{4}{*}{ S3 } & Queda de tensão (\%) & 3,2 & 3,75 & 4,5 & 0,5 \\
\hline & Carreg da Rede (\%) & 79,1 & 111,45 & 152,02 & 12,4 \\
\hline & Carreg. De SE (\%) & 92,5 & 96,45 & 100,3 & 1,75 \\
\hline & Perdas (kW) & 1145,25 & 1253,8 & 1350,1 & 19 \\
\hline \multirow{4}{*}{ S4 } & Queda de tensão (\%) & 3,2 & 3,7 & 4,5 & 0,75 \\
\hline & Carreg da Rede (\%) & 80,12 & 115,45 & 144,5 & 10,9 \\
\hline & Carreg. De SE (\%) & 90,5 & 95,74 & 98,6 & 1,8 \\
\hline & Perdas (kW) & 2096,4 & 2145,66 & 2485,9 & 18,98 \\
\hline
\end{tabular}


Conforme descrito anteriormente, logo após o término do processo evolutivo, dar-se-á inicio a etapa de seleção da solução final. Portanto, fazendo uma comparação entre as Tabelas 5.5 e 5.6, pode-se comprovar, também para simulações de múltiplas faltas, a capacidade da metodologia proposta em obter soluções factíveis para o problema.

Tabela 5-6: Falta nos setor 182 e 464. Valores das restrições operacionais e perdas ao final do processo evolutivo. *Desvio Padrão

\begin{tabular}{|c|c|c|c|c|c|}
\hline \multicolumn{6}{|c|}{ SOLUÇÃO FINAL DO PROCESSO EVOLUTIVO } \\
\hline & & MíNIMO & MÉDIO & MÁXIMO & DP* \\
\hline \multirow{4}{*}{ S1 } & Queda de tensão (\%) & 2,12 & 2,5 & 3,29 & 1,06 \\
\hline & Carreg da Rede (\%) & 46,3 & 55,6 & 79,11 & 10,42 \\
\hline & Carreg. De SE (\%) & 63,12 & 78,88 & 92,15 & 7,85 \\
\hline & Perdas (kW) & 127,8 & 203,2 & 301,7 & 49,3 \\
\hline \multirow{4}{*}{ S2 } & Queda de tensão (\%) & 2,25 & 2,5 & 3,4 & 0,58 \\
\hline & Carreg da Rede (\%) & 51,4 & 71,3 & 82,88 & 1,5 \\
\hline & Carreg. De SE (\%) & 60,7 & 69,12 & 75,4 & 0,89 \\
\hline & Perdas (kW) & 425,4 & 507,91 & 632 & 51,4 \\
\hline \multirow{4}{*}{ S3 } & Queda de tensão (\%) & 2,2 & 3,2 & 3,4 & 0,4 \\
\hline & Carreg da Rede (\%) & 52,8 & 76,6 & 89,5 & 5 \\
\hline & Carreg. De SE (\%) & 62,45 & 73,2 & 80,1 & 1,2 \\
\hline & Perdas (kW) & 1096,6 & 1255,2 & 1385,9 & 22,5 \\
\hline \multirow{4}{*}{ S4 } & Queda de tensão (\%) & 2,2 & 3,2 & 3,4 & 0,6 \\
\hline & Carreg da Rede (\%) & 53 & 75,5 & 89,45 & 6,12 \\
\hline & Carreg. De SE (\%) & 62 & 72,4 & 82,85 & 1,7 \\
\hline & Perdas (kW) & 2215,75 & 2508,2 & 2941,5 & 19,78 \\
\hline
\end{tabular}

Objetivo de minimização do número de manobras pode ser analisado na Tabela 5.7, que apresenta os valore máximo, médio e mínimo de manobras totais, manobras de chaves automáticas e manobras de chaves manuais para todos os sistemas. Deve ser destacado que em todas as simulações realizadas houve pelo menos duas manobras de chaves automáticas presente no plano de restabelecimento obtido. 
Tabela 5-7: Número de Manobras de Chaves para a solução final para os Sistemas 1,2,3 e 4, na ocorrência de múltiplas faltas. *Desvio Padrão

\begin{tabular}{|c|c|c|c|c|c|}
\hline \multicolumn{6}{|c|}{ NÚMERO DE MANOBRAS SOLUÇÃO FINAL } \\
\hline & & MÍNIMO & MÉDIO & MÁXIMO & DP* \\
\hline \multirow{3}{*}{ S1 } & Man. Ch Auto & 2 & 3,04 & 8 & 1,29 \\
\hline & Man. Ch Manuais & 7 & 7,88 & 13 & 0,84 \\
\hline & Man. Total & 10 & 10,92 & 16 & 1,5 \\
\hline \multirow{3}{*}{ S2 } & Man. Ch Auto & 2 & 3,4 & 7 & 0,4 \\
\hline & Man. Ch Manuais & 8 & 8,2 & 13 & 2,1 \\
\hline & Man. Total & 10 & 11,6 & 15 & 2,2 \\
\hline \multirow{3}{*}{ S3 } & Man. Ch Auto & 2 & 4,5 & 6 & 0,6 \\
\hline & Man. Ch Manuais & 7 & 9 & 16 & 0,4 \\
\hline & Man. Total & 12 & 13,5 & 18 & 2,2 \\
\hline \multirow{3}{*}{ S4 } & Man. Ch Auto & 2 & 3,5 & 8 & 0,5 \\
\hline & Man. Ch Manuais & 7 & 8 & 13 & 1,6 \\
\hline & Man. Total & 10 & 11,5 & 18 & 0,9 \\
\hline
\end{tabular}

\subsubsection{Capacidade de Priorização de Chaves Automáticas}

Com intuito de avaliar a capacidade da metodologia proposta de encontrar a melhor solução factível, ou seja, a solução radial conectando todas as cargas sãs com o menor número de manobras de chaves e que priorize a utilização de chaves automáticas foi desenvolvida a Tabela 5-8. Ela fornece as características operacionais e manobras (totais, automáticas e manuais) da melhor solução encontrada durante todo o processo evolutivo, ilustrando o percentual de vezes que a melhor solução foi encontrada.

Tabela 5-8: Características dos melhores indivíduos encontrados durante o algoritmo, para os Sistemas 1,2,3 e 4, na ocorrência de múltiplas faltas.

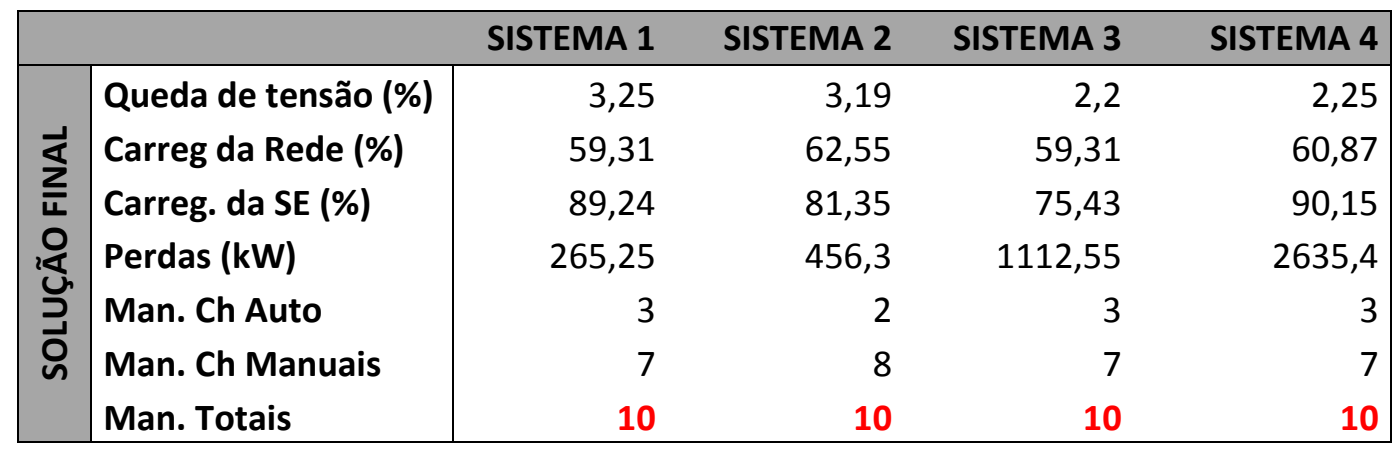


Para finalizar esta avaliação foi gerado um gráfico, da mesma forma que o realizado para Seção 5.1, em que também se obteve um percentual de seleção do melhor indivíduo maior que $50 \%$ para todos os sistemas. Vale destacar que para o sistema S1 o percentual de vezes que o melhor indivíduo foi encontrado foi de aproximadamente $75 \%$, ou seja, para múltiplas faltas a metodologia proposta também apresentou valores satisfatórios de capacidade da busca pela melhor solução.

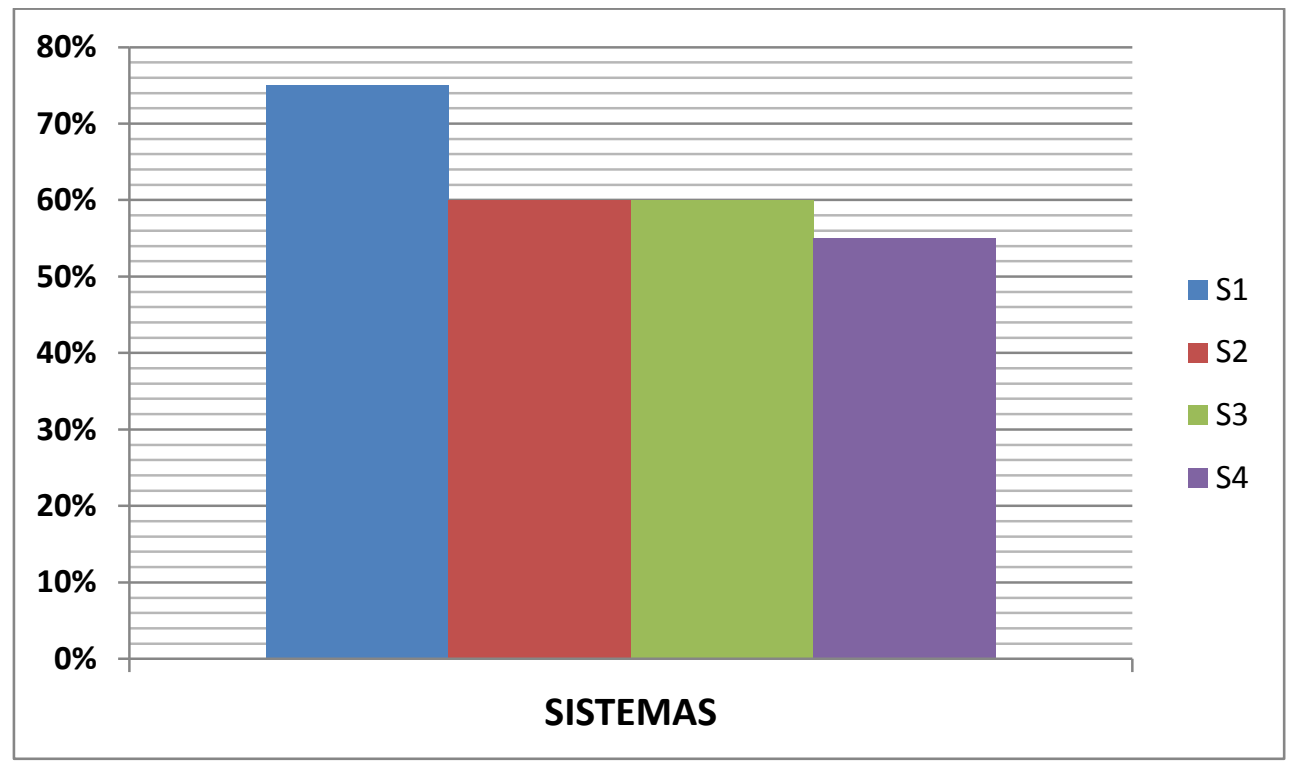

Figura 5-5: Porcentual de vezes que a melhor solução foi encontrada, para os Sistemas 1,2,3 e 4, na ocorrência de múltiplas faltas.

\subsubsection{Importância das Tabelas no Processo Evolutivo}

Conforme mencionado no capítulo 4, a metodologia proposta para restabelecimento de energia com priorização de chaves automáticas, denominada MEAN com Tabelas de Pares de Manobras Manuais, possui um total de onze tabelas. Porém, para selecionar a "melhor" solução factível para ser apresentada como resposta, a metodologia analisa apenas as soluções factíveis armazenadas nas quatro tabelas de pares de manobras manuais (tabelas $P_{i, i}=6, \ldots, 10$ ), justificando a importância dessas tabelas. Vale destacar que foram definidas 5 tabelas de pares de manobras em manuais para manter o mesmo padrão, ou mesmo número de tabelas de pares de manobras, da metodologia MEAN utilizada como base para desenvolvimento deste trabalho. 
As tabelas $P_{1}, P_{3}, P_{4}$ e $P_{5}$ relacionam-se com as restrições operacionais do problema de restabelecimento (respectivamente, tabelas relacionadas à função de agregação definida em relação às características operacionais equação 4.1, carregamento da rede, carregamento da subestação e queda de tesão). Dessa forma ajudam na varredura do espaço de busca, proporcionando maior diversidade. Já a tabela $P_{11}$ relaciona-se de forma direta com o objetivo de minimizar a utilização de chaves manuais. Porém, fica difícil entender a necessidade da tabela $P_{2}$, que armazena as soluções factíveis com menores valores de perdas resistivas.

Assim, com intuito de mensurar a importância da tabela $P_{2}$ (tabelas de perdas), foram realizadas 50 simulações em cada um dos quatro sistemas aplicando uma única falta no setor 222, eliminando a tabela $P_{2}$, com características idênticas às simulações apresentadas na seção 5.1 que foram realizadas considerando a tabela $P_{2}$.

Tabela 5-9 Características dos melhores indivíduos encontrados durante o algoritmo, para os Sistemas 1,2,3 e 4, na ocorrência de uma falta, sem a presença da tabela de perdas.

\begin{tabular}{|l|l|rrrr|}
\hline \multicolumn{5}{|c|}{ SOLUÇÃO FINAL DO PROCESSO EVOLUTIVO } \\
\hline \multirow{5}{*}{ S1 } & MíNIMO & MÉDIO & MÁXIMO & DP* \\
\hline & Queda de tensão (\%) & 3 & 3.65 & 4.88 & 1.6 \\
& Carreg da Rede (\%) & 59.31 & 70.29 & 98.33 & 15.21 \\
& Carreg. De SE (\%) & 70.82 & 90.01 & 99.57 & 27.19 \\
& Perdas (kW) & 232.84 & 416.33 & 532.55 & 52.03 \\
\hline \multirow{5}{*}{ S2 } & Queda de tensão (\%) & 3.58 & 4.01 & 4.91 & 1.71 \\
& Carreg da Rede (\%) & 65.46 & 76.19 & 99.42 & 17.2 \\
& Carreg. De SE (\%) & 80.45 & 92.81 & 99.89 & 19.55 \\
& Perdas (kW) & 539.91 & 648.22 & 886.39 & 40.9 \\
\hline \multirow{5}{*}{ S3 } & Queda de tensão (\%) & 3.63 & 4.28 & 5.62 & 2.7 \\
& Carreg da Rede (\%) & 75.7 & 84.05 & 94.85 & 1.5 \\
& Carreg. De SE (\%) & 85.92 & 97.04 & 98.06 & 2.3 \\
& Perdas (kW) & 1159.17 & 1370.82 & 1659.34 & 28.19 \\
\hline \multirow{5}{*}{ S4 } & Queda de tensão (\%) & 3.6 & 4.2 & 5.5 & 1.2 \\
& Carreg da Rede (\%) & 73.43 & 82.93 & 97.14 & 2.4 \\
& Carreg. De SE (\%) & 86.8 & 94.87 & 99.12 & 1.8 \\
& Perdas (kW) & 2293.7 & 2906.2 & 3435.6 & 20.2 \\
\hline
\end{tabular}


Tabela 5-10: Número de Manobras de Chaves para a solução final para os Sistemas 1,2,3 e 4, na ocorrência de uma falta, sem a presença da tabela de perdas. *Desvio Padrão

\begin{tabular}{|c|c|c|c|c|c|}
\hline \multicolumn{6}{|c|}{ NÚMERO DE MANOBRAS DA SOLUÇÃO FINAL } \\
\hline & & MÍNIMO & MÉDIO & MÁXIMO & DP \\
\hline \multirow{3}{*}{ S1 } & Man. Ch Auto & 1 & 2.06 & 3 & 1.2 \\
\hline & Man. Ch Manuais & 4 & 6.1 & 12 & 1.45 \\
\hline & Man. Total & 7 & 8.16 & 15 & 1.46 \\
\hline \multirow{3}{*}{ S2 } & Man. Ch Auto & 1 & 3.4 & 4 & 0.5 \\
\hline & Man. Ch Manuais & 4 & 8.6 & 12 & 0.72 \\
\hline & Man. Total & 7 & 9.24 & 15 & 0.62 \\
\hline \multirow{3}{*}{ S3 } & Man. Ch Auto & 1 & 3.45 & 4 & 0.9 \\
\hline & Man. Ch Manuais & 4 & 8.3 & 12 & 2.3 \\
\hline & Man. Total & 7 & 9.5 & 15 & 2.4 \\
\hline \multirow{3}{*}{ S4 } & Man. Ch Auto & 1 & 3.4 & 4 & 0.3 \\
\hline & Man. Ch Manuais & 4 & 8.5 & 12 & 0.9 \\
\hline & Man. Total & 7 & 8.92 & 15 & 0.7 \\
\hline
\end{tabular}

Comparando a Tabela 5-9 com a Tabela 5-2 podemos observar que as restrições operacionais e as perdas ôhmicas encontradas durante o processo evolutivo, para a simulação sem a presença da tabela de perdas, fornecem soluções factíveis mais com características piores quando comparadas com as soluções apresentadas na Tabelas 5.2. Por exemplo, fazendo uma comparação das soluções encontradas para o sistema $\mathrm{S} 1$, temos que para as simulações sem a presença da tabela de perdas (tabela 5.9) o valor médio de queda de tensão, por exemplo, foi de $3.65 \%$. Para as simulações com todas as tabelas presentes o valor máximo de queda de tensão encontrado foi de $3,29 \%$.

A tabela 5-10 foi elaborada para verificar a capacidade de minimização do número de manobras. Fazendo uma comparação entre as Tabelas 5-3 e 5-10, temos que o número de manobras das simulações sem a presença da tabela de perdas no processo evolutivo, Tabela 5-10, piorou quando comparada com os resultados das simulações com todas as tabelas presentes, Tabela 5-3.

Também foi confeccionada, conforme seção 5.1.1, a Tabela 5-11, que fornece o melhor indivíduo encontrado durante o processo evolutivo para cada sistema teste. Observe que sem a tabela de perdas o melhor indivíduo encontrado exige 7 (sete) manobras totais, sendo 4 (quatro) manobras de chaves manuais e 3 (três) manobras 
de chaves automáticas, ou seja, soluções piores quando comparadas com as soluções apresentadas na Tabela 5.4.

Tabela 5-11: Característica dos melhores indivíduos encontrados durante o algoritmo na ocorrência de um falta, sem a presença da tabela de perdas.

\begin{tabular}{|c|c|c|c|c|c|}
\hline \multirow{8}{*}{ 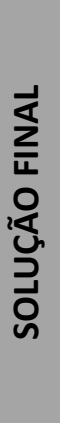 } & & SISTEMA 1 & SISTEMA 2 & SISTEMA 3 & SISTEMA 4 \\
\hline & Queda de tensão (\%) & 4.4 & 4.4 & 4.28 & 5.2 \\
\hline & Carreg da Rede (\%) & 90.59 & 89.11 & 73.43 & 80.5 \\
\hline & Carreg. da SE (\%) & 98.63 & 95.19 & 94.38 & 98.12 \\
\hline & Perdas (kW) & 440.1 & 712.5 & 1570.11 & 2439.7 \\
\hline & Man. Ch Auto & 3 & 3 & 3 & 3 \\
\hline & Man. Ch Manuais & 4 & 4 & 4 & 4 \\
\hline & Man. Totais & 7 & 7 & 7 & 7 \\
\hline
\end{tabular}

Após a análise de todas as simulações realizadas, verifica-se a importância da tabelas de perdas para o processo evolutivo. Observe que, apesar de minimização de perdas resistivas não ser um dos objetivos do problema de restabelecimento energia, a tabela de perdas melhora a diversidade entre os indivíduos gerados, ampliando a capacidade de a metodologia sair de ótimos locais. 


\section{Capítulo}

\section{Conclusões Finais e Perspectivas Futuras}

O propósito principal desta dissertação de mestrado é fornecer uma ferramenta computacional para elaborar planos de restabelecimento de energia em sistemas de distribuição de grande porte, para auxiliar operadores durante a ocorrência de contingências no sistema elétrico. Os diferenciais da metodologia proposta é que ela possibilita o tratamento de sistemas de SDs de grande porte, sem exigir redução alguma do sistema em análise, priorizando a utilização de chaves automáticas.

Conforme relatado no documento, para tratar o problema de restabelecimento, sendo que o mesmo exige uma resposta em um curto intervalo de tempo, a metodologia faz o uso de algoritmos evolutivos multi-objetivos, em que suas aplicações nos forneceram resultados satisfatórios. Neste trabalho, conforme mencionado, o algoritmo evolutivo utilizado como base para desenvolvimento da metodologia proposta foi o MEAN (Santos et al 2010). Assim, devida à sua importância para o desenvolvimento deste projeto, foi relatado com maiores detalhes seu funcionamento, enfatizando-se todas as modificações efetuadas para dar origem à metodologia proposta.

Para desenvolvimento da metodologia proposta, que foi denominada MEAN com Tabelas de Pares de Manobras Manuais, seis novas tabelas de subpopulações foram criadas. Sendo cinco para minimização de manobras de chaves manuais (que substituíram as cinco tabelas $P_{i}$ do MEAN, relacionadas com os menores valores de perdas e com $i$ pares de manobras, $i=1, \ldots, 5$ ); e uma para manobras ponderadas. Além disso, foi proposto um novo algoritmo para cálculo de manobras para determinação do número de manobras em chaves manuais e automáticas necessárias para implantação dos planos de restabelecimento obtidos pela metodologia. 
Com intuito de validar a metodologia proposta, foram efetuadas simulações computacionais no sistema de distribuição da cidade de São Carlos e suas versões duplicada, quadriplicada e octuplicada, considerando a ocorrência de uma e múltiplas faltas.

Durante as simulações realizadas foi possível concluir que a metodologia proposta possibilita a obtenção de planos adequados de restabelecimento de energia priorizando a utilização de chaves automáticas.

\subsection{Perspectivas Futuras}

Por fim, listam-se a seguir algumas perspectivas de trabalhos futuros:

1. Considerar outros aspectos práticos para o tratamento do problema de restabelecimento de energia, como a presença de reguladores de tensão, geração distribuída, etc.;

2. Melhorar o processo de geração de novos indivíduos no processo evolutivo, fazendo alterações nos operadores da RNP, para que durante sua aplicação consiga distinguir e priorizar a utilização de chaves automáticas;

3. Fazer uma análise mais detalhada da necessidade de 5 tabelas de pares de manobras em manuais para obtenção de soluções factíveis com mínimo número de operações em chaves manuais. De uma forma mais específica, verificar-se-á a possibilidade de utilizar apenas duas tabelas de manobras em manuais. Uma para armazenar soluções factíveis com zero manobras em chaves manuais e outra para armazenar soluções factíveis que contenham de 1 a 16 manobras em chaves manuais, utilizando os mesmos critérios de desempate, propostos neste trabalho, para inserção de indivíduos nessas tabelas. 


\subsection{Publicações}

\subsubsection{Artigos Publicados}

1. Fantin, C. A. ; Sanches, D. S. ; Marquez, R. A. C. ; Santos, A. C. ; Delbem, A. C. B.; London, J. B. A. . "Metodologia para Redução de Perdas de Energia Elétrica e Melhoria do Perfil de tensão em Sistemas de Distribuição de Energia”. In: 9th Latin-American Congress: Electricity Generation and Transmission, 2011, Mar Del Plata. Anais, 2011.

2. Sanches, D. S. ; Marquez, R. A. C. ; London, J. B. A. ; Delbem, A. C. B. ; Prado, R. S. ; Neto, O. M. . "Algoritmo de Evolução Diferencial Discreta Aplicado ao Problema de Restabelecimento de Energia em Sistemas de

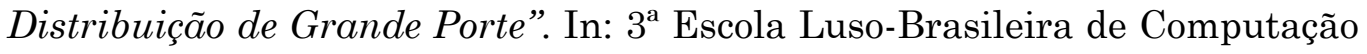
Evolutiva (ELBCE 2012).

3. Sanches, D. S. ; Marquez, R. A. C. ; Silva, M. ; Delbem, A. C. B.; London, J. B. A. "Integrando Relevantes Aspectos de Algoritmos Evolutivos MultiObjetivo Para Tratamento do Problema de Restabelecimento de Energia em Sistemas de Distribuição de Grande Porte" In: XIX edição do Congresso Brasileiro de Automática - CBA 2012.

\subsection{Participação em eventos científicos}

1. III Escola Luso-Brasileira de Computação Evolutiva, Abril de 2012, ICMC/USP, São Carlos - SP;

2. IV Workshop da Pós-Graduação do Departamento de Engenharia Elétrica e de Computação da EESC/USP, São Carlos - SP.

3. "Smart Distribution Systems". Curso ministrado pelo Prof. Dr $^{\circ}$ Koichi Nara, Presidente do Fukushima National College of Technology, Japão. EESC/USP, São Carlos - SP. 


\section{Referências Bibliográficas}

Amabis, J.M. \& Martho, G.R., 1985. Curso básico de biologia 3rd ed. E. M. Ltda, ed., São Paulo.

Aoki, K. et al., 1989. A New Algorithm for Service Restoration in Distribution Systems. Power Engineering Review, IEEE, 9(7), p.69.

Arciszewski, T. \& De Jong, K.A., 2001. Civil and structural engineering computing: 2001. In B. H. V. Topping, ed. Saxe-Coburg Publications, pp. 161-184..

Augugliaro, A., Dusonchet, L. \& Sanseverino, E.R., 2000. Multiobjective service restoration in distribution networks using an evolutionary approach and fuzzy sets. International Journal of Electrical Power \&amp; Energy Systems, 22(2), pp.103-110.

Ballard, D.H., 1999. An introduction to natural computing, MIT Press.

Baran, M. \& Wu, F.F., 1989. Optimal sizing of capacitors placed on a radial distribution system. Power Delivery, IEEE Transactions on, 4(1), pp.735-743.

Benayoun, R. et al., 1971. Linear programming with multiple objective functions: Step method (stem). Mathematical Programming, 1(1), pp.366-375.

Brandini, A.C., 2000. Análise crítica de algoritmos de fluxo de carga usados em sistemas de distribuição radial. FEIS-UNESP.

Carreno, E.M., Romero, R. \& Padilha-Feltrin, A., 2008. An Efficient Codification to Solve Distribution Network Reconfiguration for Loss Reduction Problem. Power Systems, IEEE Transactions on, 23(4), pp.1542-1551.

Carvalho, M.R., 2006. Estudo Comparativo de Fluxo de Potência para Sistemas de Distribuição Radial. Dissertação de Mestrado EESC-USP.

Castro, R.E., 2001. Otimização de Estruturas com Multi-objetivos via Algoritmos Genéticos de Pareto. Tese de Doutorado UFRJ. 
Cespedes, R.G., 1990. New method for the analysis of distribution networks. Power Delivery, IEEE Transactions on, 5(1), pp.391-396.

Chen, C.S. et al., 2000. Application of binary integer programming for load transfer of distribution systems. In Power System Technology, 2000. Proceedings. PowerCon 2000. International Conference on. pp. 305-310 vol.1.

Coello Coello, C.A., Van Veldhuizen, D.A. \& Lamont, G.B., 2002. Evolutionary algorithms for solving multi-objective problems. Academic, ed., New York, NY: Genetic Algorithms and Evolutionary Computation.

Cormen, T.H., 2002. Algoritmos: teoria e prática, Campus.

Das, D., Nagi, H.S. \& Kothari, D.P., 1994. Novel method for solving radial distribution networks. Generation, Transmission and Distribution, IEE Proceedings-, 141(4), pp.291-298.

Deb, K., 2001. Multi-objective optimization using evolutionary algorithms.

Deb, K. et al., 2002. A fast and elitist multiobjective genetic algorithm: NSGAII. Evolutionary Computation, IEEE Transactions on, 6(2), pp.182-197.

Delbem, A. et al., 2004. Node-Depth Encoding for Evolutionary Algorithms Applied to Network Design. In Kalyanmoy Deb, ed. Springer Berlin / Heidelberg, pp. 678-687.

Delbem, A.C.B., de Carvalho, A.C.P.L.F. \& Bretas, N.G., 2005. Main chain representation for evolutionary algorithms applied to distribution system reconfiguration. Power Systems, IEEE Transactions on, 20(1), pp.425-436.

Eiben, A.E. \& Smith, J.E., 2003. Introduction to evolutionary computing, Berlin: Springer: Natural Computinf Series.

Fantin, C.A., 2012. Análise de Observabilidade e de Redundância de Medidas no contexto de Estimação de Estado Trifásica. Dissertação de Mestrado USP.

Fogel, L., 1962. Autonomus automata 4th ed., Industrial Research.

Fukuyama, Y. \& Chiang, Hsaio-Dong, 1995. A parallel genetic algorithm for service restoration in electric power distribution systems. In Fuzzy Systems, 1995. International Joint Conference of the Fourth IEEE International Conference on Fuzzy Systems and The Second International Fuzzy Engineering Symposium., Proceedings of 1995 IEEE International Conference on. pp. 275-282 vol.1. 
Gabriel, P.H. \& Delbem, A.C.B., 2008. Fundamentos de Algoritmos Evolutivos. USP.

Garcia, V.J. \& França, P.M., 2008. Multiobjective service restoration in electric distribution networks using a local search based heuristic. European Journal of Operational Research, 189(3), pp.694-705.

Goldberg, D.., 1989. Genetic Algorithms in Search, Optimization, and Machine Learning 1st ed., Boston, MA.

Gomes, F.V. et al., 2006. A New Distribution System Reconfiguration Approach Using Optimum Power Flow and Sensitivity Analysis for Loss Reduction. Power Systems, IEEE Transactions on, 21(4), pp.1616-1623.

Gradshteyn, I.S. \& Ryzhik, I.M., 2000. Table of Integrals, Series, and Products 6th ed., San Diego, CA.

Haimes, Y., Lasdon, L. \& Wismer, D., 1971. On a Bicriterion Formulation of the Problems of Integrated System Identification and System Optimization. Systems, Man and Cybernetics, IEEE Transactions on, 1(3), pp.296-297.

Haque, M.H., 1996. Efficient load flow method for distribution systems with radial or mesh configuration. Generation, Transmission and Distribution, IEE Proceedings-, 143(1), pp.33-38.

Inagaki, J., Nakajima, J. \& Haseyama, M., 2006. A multiobjective service restoration method for power distribution systems. In Circuits and Systems, 2006. ISCAS 2006. Proceedings. 2006 IEEE International Symposium on. p. 4 pp.

Jensen, M.T., 2003. Reducing the run-time complexity of multiobjective EAs: The NSGA-II and other algorithms. Evolutionary Computation, IEEE Transactions on, 7(5), pp.503-515.

De Jong, K.A., 2006. Evolutionary computation: A unified approach, Cambride, MA: MIT Press.

Kagan, N., 1999. Configuração de Redes de Distribuição através de Algoritmos Genéticos e Tomada de Decisão Fuzzy. Tese de Livre Docência EP-USP.

Kagan, N., de Oliveira, C.C.C.B. \& Robba, E.J., 2005. Introdução aos sistemas de distribuição de energia elétrica, EDGARD BLUCHER. 
Kleinberg, M., Miu, K. \& Chiang, Hsiao-Dong, 2009. Service restoration of power distribution systems incorporating load curtailment. In Circuits and Systems, 2009. ISCAS 2009. IEEE International Symposium on. pp. 1709-1712.

Koza, J.R., 1992. Genetic programming: On the programming of computers by means of natural selection, Cambridge, MA: MIT Press.

Krishnakumar, K., 1989. Micro-genetice algorithms for stationary and nonstationary function optimization 1196th ed., SPIE: Inteligent Control and Adaptative Systems.

Kumar, Y., Das, B. \& Sharma, J., 2008. Multiobjective, Multiconstraint Service Restoration of Electric Power Distribution System With Priority Customers. Power Delivery, IEEE Transactions on, 23(1), pp.261-270.

Larraeñaga, P. \& Lozano, J., 2001. Estimation of distribuition algorithms: A new tool for evolutionary computation, Kluwer Academic Publishers.

Lima, T.W., 2009. Estrutua de Dados Eficientes para Algoritmos Evolutivos Aplicados a Projeto de Rede. Tese de Doutorado ICMC-USP.

Mansour, M.R. et al., 2009. Energy restoration in distribution systems using multi-objective evolutionary algorithm and an efficient data structure. In PowerTech, 2009 IEEE Bucharest. pp. 1-7.

Mantovani, J.R.S., Casari, F. \& Romero, R.A., 2000. Reconfiguração de sistemas de distribuição radiais utilizando o critério de queda de tensão. SBA Controle e Automação, 11(03), pp.150-159.

Mendoza, F., Garcia, A \& Bernal-Agustin, J.L., 2006. Application of the NPGA to the Design of Power Distribution Systems. In Transmission \& Distribution Conference and Exposition: Latin America, 2006. TDC '06. IEEE/PES. pp. 1-5.

Monticelli, A.J. \& Garcia, A.V., 2003. Introdução a Sistemas de Energia Elétrica, Campinas, SP: Editora Unicamp.

Morelato, A.L. \& Monticelli, A., 1989. Heuristic Search Approach to Distribution System Restoration. Power Engineering Review, IEEE, 9(10), pp.6566. 
Pigatin, V.N. \& London, J.B. A., 2009. Análise da Eficiência Computacional de Métodos para Cálculo de Fluxo de Carga. In Seminário Internacional de Iniciação Científica da USP. São Carlos.

Prasad, P.V., Sivanagaraju, S. \& Sreenivasulu, N., 2007. Network Reconfiguration for Load Balancing in Radial Distribution Systems Using Genetic Algorithm. Electric Power Components and Systems, 36(1), pp.63-72.

Sait, S.M. \& Youssef, H., 1999. Interative computer algorithms with applications in engineering: Solving combinatorial optimization problems, Los Alamitos, CA: IEEE Computer Society.

Sanches, D.S. et al., 2011. Integrating relevant aspects of moeas to solve loss reduction problem in large-scale Distribution Systems. In PowerTech, 2011 IEEE Trondheim. pp. 1-6.

Santos, A.C., 2009. Algoritmo Evolutivo Computacionalmente Eficente para Reconfiguração de Sistemas de Distribuição. Tese Doutorado-USP.

Santos, A.C., Delbem, A. \& Bretas, N.G., 2008. Energy restoration for largescale distribution system using EA and a new data structure. In Power and Energy Society General Meeting - Conversion and Delivery of Electrical Energy in the 21st Century, 2008 IEEE. pp. 1-8.

Santos, A.C. et al., 2010. Node-Depth Encoding and Multiobjective Evolutionary Algorithm Applied to Large-Scale Distribution System Reconfiguration. Power Systems, IEEE Transactions on, 25(3), pp.1254-1265.

Sarfi, R.J., Salama, M.M.A. \& Chikhani, A.Y., 1996. Distribution system reconfiguration for loss reduction: an algorithm based on network partitioning theory. Power Systems, IEEE Transactions on, 11(1), pp.504-510.

Sarfi, R.J., Salama, M.M.A. \& Chikhani, A.Y., 1995. Distribution system reconfiguration for loss reduction: an algorithm based on network partitioning theory. In Power Industry Computer Application Conference, 1995. Conference Proceedings., 1995 IEEE. pp. 503-509.

Schmidt, H.P. et al., 2005. Fast Reconfiguration of Distribution Systems Considering Loss Minimization. Power Systems, IEEE Transactions on, 20(3), pp.1311-1319. 
Shin, D.-J. et al., 2004. Optimal service restoration and reconfiguration of network using Genetic-Tabu algorithm. Electric Power Systems Research, 71(2), pp.145-152.

Shirmohammadi, D., 1992. Service restoration in distribution networks via network reconfiguration. Power Delivery, IEEE Transactions on, 7(2), pp.952-958.

Shirmohammadi, D. et al., 1988. A compensation-based power flow method for weakly meshed distribution and transmission networks. Power Systems, IEEE Transactions on, 3(2), pp.753-762.

Siti, M.W. et al., 2007. Reconfiguration and Load Balancing in the LV and MV Distribution Networks for Optimal Performance. Power Delivery, IEEE Transactions on, 22(4), pp.2534-2540.

Souza, B.A., 1995. Fluxo de potência em sistemas de distribuição. Dissertação de Mestrado UFPB.

Srinivas, M.S., 2000. Distribution load flows: a brief review. In Power Engineering Society Winter Meeting, 2000. IEEE. pp. 942-945 vol.2.

Teuscher, C. et al., 2003. Bio-inspired computing tissues: towards machines that evolve, grow, and learn. Biosystems, 68(2-3), pp.235-244.

Ticona, W.G.C. \& Delbem, A.C.B., 2008. Algoritmos evolutivos para otimização multi-objetivo. Relatório Técnico ICMC-USP.

Toune, S. et al., 2002. Comparative study of modern heuristic algorithms to service restoration in distribution systems. Power Delivery, IEEE Transactions on, 17(1), pp.173-181.

Van Veldhuizen, D.A., 1999. Multiobjective Evolutionary Algorithms: Classifications, Analyses, and New Innovations. Tese de Doutorado WrightPatterson AFB, OH.

Zhu, J.Z., 2002. Optimal reconfiguration of electrical distribution network using the refined genetic algorithm. Electric Power Systems Research, 62(1), pp.3742.

Zitzler, E. \& Thiele, L., 1999. Multiobjective evolutionary algorithms: a comparative case study and the strength Pareto approach. Evolutionary Computation, IEEE Transactions on, 3(4), pp.257-271. 